UNIVERSIDAdE DE SÃo PAULO

INSTITUTO DE FÍSICA

\title{
Efeitos de dimensão nas propriedades físicas e processos de adsorção em nanopartículas de prata
}

Ferenc Diniz Kiss

Orientador: Prof. Dr. Armando Corbani Ferraz

Co-Orientador Prof. Dr. Ronei Miotto

Tese de doutorado apresentada ao Instituto de

Física para a obtenção do título de Doutor em Ciências

Banca Examinadora

Prof. Dr. Armando Corbani Ferraz (IFUSP)

Profa. Dra. Lucy V.C. Assali (IFUSP)

Profa. Dra. Márcia Carvalho de Abreu Fantini (IFUSP)

Prof. Dr. Antônio Ferreira da Silva (UFBA)

Prof. Dr. Ivan da Cunha Lima (UERJ)

São Paulo 


\section{FICHA CATALOGRÁFICA}

Preparada pelo Serviço de Biblioteca e Informação do Instituto de Física da Universidade de São Paulo

Kiss, Ferenc Diniz

Efeitos de dimensão nas propriedades físicas e processos de adsorção em nanopartículas de prata. - São Paulo, 2010.

Tese (Doutorado) - Universidade de São Paulo. Instituto de Física - Depto. de Física dos Materiais e Mecânica

Orientador: Prof. Dr. Armando Corbani Ferraz

Área de Concentração: Física

Unitermos: 1. Propriedades dos sólidos;

2. Nanopartículas; 3. Superfície física; 4. Física computacional. 


\section{Agradecimentos}

Meus profundos agradecimentos ao Prof. Dr. Armando Corbani Ferraz e ao Prof. Dr Ronei Miotto pelo voto de confiança ao aceitarem me orientar, pela paciência com rigor e dedicação com seriedade na minha formação como pesquisador e pelos inúmeros conselhos e discussões fundamentais no desenvolvimento deste trabalho.

Agradeço a minha família, especialmente, a minha mãe e minha irmã e a Joana Gabriela, minha companheira, por todo amor, carinho, cuidado, atenção e compreensão oferecidos durante todos estes anos nos momentos de calmaria e de turbulência, além dos incentivos constantes que possibilitaram desenvolver e concretizar este trabalho de maneira saudável e segura.

Ao grande amigo Rodrigo Ramos, pela atenção mais que especial dada em diversos momentos, contribuindo direta e indiretamente no desenvolvimento deste trabalho, com discussões, ideias e sugestões, além do extremo cuidado na leitura da tese.

Aos companheiros cultivados na física, Joelson Cott, Rodrigo Amorim e Regina Lelis, pelas constantes dicas e orientações no uso do pacote de simulação VASP e dos computadores de alto desempenho do LCCA, pelas importantes discussões e agradável companhia todos estes anos.

Aos demais amigos e colegas do departamento de Física dos Materiais e Mecânica da USP, Cedric Rocha, Edwin Hobi, Jeverson Teodoro, José Padilha, Leonardo 
Matheus, Luana Pedroza, Marcos Brown, Matheus Lima, Pablo Damasceno, Gustavo Troiano, Rafael Nacimento, Renato Borges, Renato Pontes, Rolando Mamani e Thiago Martins da velha guarda; e Glaura Oliveira, Jarlersson Amazonas, Jeconias Ghimarães, Leandro Silva, Ney Sodré e Ricardo Igarashi da média guarda; e Amaury Souza, Filipe Camargo, Francisco Nogueira, José Max, Michel dos Santos, Pedro Brandimarte, Philipe, Rafael Rodrigues e Rodrigo Caro da nova guarda, que fazem do ambiente de trabalho um lugar particularmente agradável.

Aos amigos presentes na vida que acompanharam esta trajetória e, conscientes ou não de suas ações, ajudaram nas mais diversas formas, em especial, à Ana LuiZa, Guilherme Parra, Angela Penna, Beth Parra, Mariana Vieira, Carolina Paes e Carolina Ribeiro.

À Rosana Gimenes, Sandra Regina, Marisa Fernandes, Cláudia Conde, Éber Pato, Francisleine Mendes, Tais Cristina e Marina Sundfeld, pelo trato atencioso e cuidadoso das questões administrativas realizados durante todos estes anos no desenvolvimento do doutorado.

À equipe do Laboratório de Computação Científica Avançada da USP (LCCA) pela manutenção dos computadores de alto desempenho que possibilitaram a execução de parte substancial deste trabalho, em especial, ao Francisco Ribacionka, pela atenção cuidadosa e paciente.

Ao Conselho Nacional de Desenvolvimento Científico e Tecnológico Coordenação (CNPq) pelo suporte financeiro, dando fôlego para o sustento durante estes anos, possibilitando maior dedicação aos estudos. 


\section{Resumo}

Neste trabalho as propriedades físicas e químicas das nanopartículas (NPs) de prata de diferentes tamanhos e formatos são investigadas teoricamente utilizando cálculos de primeiros princípios dentro da Teoria do Funcional da Densidade (DFT), descrita em termos da Aproximação do Gradiente Generalizado (GGA), com o uso de Pseudopotenciais Ultrassuaves (USPP). Uma investigação sistemática das propriedades estruturais, energéticas, eletrônicas e vibracionais (faixa do infravermelho - IR) é realizada para as nanopartículas passivadas e não passivadas. Seguindo as observações experimentais construímos as nanopartículas livres utilizando o empacotamento cristalino FCC nas simetrias octaédrica, cubo-octaédrica, octaédrica truncada e esférica, e, também, na simetria icosaédrica não cristalina. Para avaliar a influência da dimensão das nanopoartículas em suas propriedades, são investigadas diferentes NPs com diâmetros variando entre 0,3 e 2,9 nm (entre 6 e 561 átomos). No presente estudo, são identificados três regimes característicos associados às dimensões das nanopartículas: (i) inferior a 1,5 nm (até 100 átomos), apresentando forte característica molecular; (ii) entre 1,5 e 2,0 nm (100 e 300 átomos), onde o comportamento molecular é influenciado pelo caroço cristalino; e (iii) acima de 2,0 nm (mais de 300 átomos), onde as propriedades do cristal são preponderantes, mas com modulação de superfície. Os efeitos da passivação são investigados considerando a adsorção dos radicais metil $\left(\mathrm{CH}_{3}\right)$ e vinil $\left(\mathrm{C}_{2} \mathrm{H}_{3}\right)$ em NPs menores que 2,0 nm. Nossos resultados sugerem que as propriedades físicas consideradas (ener- 
gia de formação, comprimentos de ligação e espectros IR) estão fortemente correlacionadas com a coordenação do sítio adsorvido. Os nossos cálculos da energia total sugerem que as adsorções realizadas sobre os sítios de menor coordenação são mais propensas a passivação pelas moléculas dos surfactantes considerados. Outros modelos de simplificação possíveis para a simulação das nanopartículas, como um único átomo ou secções transversais em hemisférios, também são investigados. Os nossos cálculos sugerem que os modelos simplificados devem ser usados com certo cuidado, por não descreverem adequadamente todas as propriedades físicas analisadas. 


\section{Abstract}

In this work, physical and chemical properties of silver nanoparticles (NPs) of different sizes and shapes are investigated theoretically using first principles calculations in the Density Functional Theory (DFT) framework, described in terms of the Generalized Gradient Approximation (GGA), and by using Ultra-Soft Pseudopotentials (USPP). A systematic investigation of energetics, structural, electronic and vibrational (infra-red range, IR) properties of both the passivated and nonpassivated nanoparticles are performed. Following experimental observations, free NPs are constructed using the crystalline FCC packing in octahedral, cube-octahedral, truncated octahedral and spherical symmetries, and also in non-crystalline icosahedral symmetry. In order to evaluate the influence of the nanoparticles's size in its properties, different NPs with diameters ranging between 0.3 and $2.9 \mathrm{~nm}$ (corresponding to 6 to 561 atoms) are investigated. In this study we identified three characteristics regimes associated with the nanoparticle's dimensions: (i) below $1.5 \mathrm{~nm}$ (100 atoms) where remarkably molecular aspects are observed; (ii) between 1.5 and $2.0 \mathrm{~nm}$ (100 and 300 atoms) where the molecular behavior is influenced by the core crystallinity; and (iii) above $2.0 \mathrm{~nm}$ (more than 300 atoms) where the crystal properties are preponderant, but with surface modulation. Passivation effects are investigated considering the adsorption of the methyl $\left(\mathrm{CH}_{3}\right)$ and vinyl $\left(\mathrm{C}_{2} \mathrm{H}_{3}\right)$ radicals on NPs smaller than $2.0 \mathrm{~nm}$. Our results suggests that the considered physical properties (formation energy, bond lengths, IR spectra) are strongly correlated 
to the adsorbed site coordination. Our total energy calculations suggest that lower coordinated adsorption sites are more likely to be passivated by the surfactant molecules considered. Other possible simplified models for simulating NPs, such as a single atom or polar cross sections are also investigated. Our calculations suggest that simplified models might be used with some care, as not all considered physical properties are well described by them. 


\section{Sumário}

Resumo i

$\begin{array}{ll}\text { Abstract } & \text { iii }\end{array}$

Introdução vii

1 Descrição teórica 1

1.1 Tratamento das interações eletrônicas . . . . . . . . . . . 2

1.1.1 Teoria do Funcional da Densidade - DFT . . . . . . . 3

1.1.2 A Energia de Troca e Correlação . . . . . . . . . . . . . 7

1.2 Tratamento das interaçõos entre elétrons e núcleos . . . . . . . . 10

1.2.1 Teoria do Pseudopotencial . . . . . . . . . . . . 11

1.2.2 Pseudopotencial separável . . . . . . . . . . . 17

1.2.3 Pseudopotencial Ultrassuave - USPP . . . . . . . . . . . 18

1.3 Energia total e relaxação estrutural . . . . . . . . . . . 22

1.3.1 Forças sobre os íons . . . . . . . . . . . . . . . . 24

1.3.2 Esquema de supercélula . . . . . . . . . . 25

1.4 Estudo vibracional . . . . . . . . . . . . . . . . 27

1.5 Pacote de simulação Vienna Ab-Initio - VASP . . . . . . . . . . . . 29

2 Construção das nanopartículas $\quad 31$

2.1 Nanopartículas poliédricas . . . . . . . . . . . . . 35

2.1.1 Nanopartículas octaédricas . . . . . . . . . . . 38

2.1.2 Nanopartículas octaédricas truncadas . . . . . . . . . . 41

2.1.3 Nanopartículas cubo-octaédricas . . . . . . . . . . 43 
2.1.4 Nanopartícula icosaédrica . . . . . . . . . . . 45

2.1.5 Comparação entre as nanopartículas poliédricas . . . . . . . 46

2.2 Nanopartículas esféricas . . . . . . . . . . . . . . . 48

3 Nanopartículas de prata livres $\quad 51$

3.1 Propriedades estruturais . . . . . . . . . . . . . . 53

3.2 Propriedades energéticas . . . . . . . . . . . . 55

3.3 Propriedades eletrônicas . . . . . . . . . . . . . . . 5 59

3.4 Propriedades vibracionais . . . . . . . . . . . . . . 66

4 Adsorção nas nanopartículas de prata $\quad 73$

4.1 Propriedades estruturais . . . . . . . . . . . . . . 74

4.2 Propriedades energéticas . . . . . . . . . . . . 78

4.3 Propriedades eletrônicas . . . . . . . . . . . . . 80

4.4 Propriedades vibracionais . . . . . . . . . . . . . . . . 82

5 Simplificações para os cálculos das nanopartículas 89

5.1 Propriedades vibracionais utilizando sítios representativos . . . . . 89

5.1.1 Propriedades vibracionais das nanopartículas livres . . . . . 90

5.1.2 Propriedades vibracionais das adsorções . . . . . . . . . 96

5.2 Recorte da nanopartícula em hemisfério . . . . . . . . . . . . . 98

5.3 Átomo de prata . . . . . . . . . . . . . . . . 100

6 Conclusões 103

A Demonstração do primeiro teorema de Kohn-Sham 109

B Termo $F_{x}(s)$ e $H\left(r_{s}, \xi, t\right)$ da energia de troca e correlação PW91 111

$\begin{array}{ll}\text { C Resultados preliminares para a prata } & 113\end{array}$

D Resultados preliminares para as moléculas e radicais livres $\quad 117$

$\begin{array}{lll}\text { E Aproximação esférica } & 121\end{array}$

Referências Bibliográficas $\quad 125$ 


\section{Introdução}

As propriedades dos materiais dependem dos elementos químicos presentes em sua composição, da disposição dos átomos no interior das estruturas e das interações eletrônicas resultantes. O tamanho das estruturas, por sua vez, influencia significativamente em suas propriedades, sendo especialmente relevante na ciência das nanoestruturas e na nanotecnologia[1], e estando atualmente, colocado ao escrutínio experimental e teórico no comportamento de sistemas condensados, com dimensões características de até $100 \mathrm{~nm}$.

Assim nos últimos tempos, a nova ciência de materiais tem recebido muita atenção da comunidade científica pela grande variedade de propriedades de grande potencial tecnológico, com aplicações emergentes de ciência básica, não apenas em física, mas em áreas da ciência como a química e a biomedicina, por exemplo.

Consequência direta desses esforços é o crescente aperfeiçoamento da manipulação de nanoestruturas tais como: nanotubos, nanofios, nanopartículas, fulerenos, "buckyballs", pontos quânticos, entre outros [2, 3, 4]. Em face disso, técnicas experimentais recentemente desenvolvidas puderam ser modificadas à luz da utilização de efeitos peculiares associados às nanoestruturas.

Exemplo deste aperfeiçoamento, relacionado aos sistemas que são foco de estudo neste trabalho, foi o desenvolvimento das técnicas da Espectroscopia Raman Amplificada por Superfície (SERS - "Surface Enhanced Raman Spectroscopy" - ou "Scattering"). Foi descoberto, na década de 70, que os sinais de espectroscopia 
Raman (espalhamento inelástico da luz, descoberto na década de 20 em trabalho laureado com prêmio Nobel de 1930) de moléculas orgânicas podem ser amplificados por fatores de até $10^{6}[5,6,7]$ quando as moléculas estão adsorvidas sobre superfícies metálicas rugosas. Notadamente a prata desempenhou um papel fundamental nestas descobertas, presente nos trabalhos originais a esse respeito, sendo ainda corrente o seu emprego com esta técnica.

Como se observa na literatura [5, 6, 7], a amplificação dos sinais espectroscópicos, além de pronunciada, não é acompanhada de novos sinais que perturbem significativamente a identificação das assinaturas vibracionais das moléculas em estudo, fazendo o emprego da técnica progressivamente popular desde então.

Um estudo com a molécula rhodamina-6G (R6G) adsorvida sobre nanopartículas de prata apresentou a amplificação do sinal Raman em um fator de $10^{14} \mathrm{em}$ relação às medidas convencionais [8]. Desta maneira, a espectroscopia SERS tem sido empregada em nanopartículas de prata, em suspensões coloidais ou em ilhas crescidas em diferentes substratos. Particularmente, o emprego de nanopartículas tem viabilizado a detecção de uma única molécula $[8,9,10]$. A chave por traz do efeito que possibilitou o SERS está intrinsecamente ligado a efeitos quânticos surgidos em nanoestruturas, como a ressonância de plasmons $[11,12]$.

Além disso, é corrente a proposição do emprego das nanopartícula metálicas no desenvolvimento de biossensores, ou como transportadores de drogas e agentes antimicrobianos $[13,14]$, sugerindo o seu potencial emprego na biomedicina. A exemplo destas aplicações, em um trabalho de Shrivastava e colaboradores [15] demonstrou-se que nanopartículas de prata com dimensões entre 10 e $15 \mathrm{~nm}$ são excelentes agentes antibactericidas; e Elechiguerra e colaboradores [16], ao combinarem uma proteína com nanopartículas de prata de diversos tamanhos, conseguiram inibir a ação do vírus HIV-I, entretanto esse efeito ocorreu, exclusivamente, com nanopartículas entre 1 e $10 \mathrm{~nm}$. Verifica-se ainda na literatura que é sugerido o 
seu emprego em tratamentos experimentais contra o câncer $[17,18,19,20]$, e como marcadores para detecção de oligonucleotídeos no DNA e RNA [21]

Os tamanhos reduzidos das nanopartículas, por sua vez, também definem dificuldades como a sua passagem pelas membranas celulares, afetando a fisiologia de células animais, de modo que as aplicações estão dependentes da contínua avaliação a respeito de sua toxidade [22], apesar das amostras macroscópicas de sais de prata serem bastante conhecidas e seguras com respeito à seu uso como desinfetante.

A grande diferença entre as propriedades eletrônicas e estruturais de cristais e aquelas observadas em suas respectivas nanoestruturas deriva, em geral, de efeitos introduzidos pelo confinamento de elétrons e pela presença significativa de superfícies. Nas nanopartículas, por exemplo, o número de átomos da superfície é comparável com o número de átomos que compõe o volume total, influenciando decisivamente as suas propriedades físicas e químicas. Também a forma e o tamanho das nanopartículas atuam significativamente na definição de suas propriedades catalisadoras, ópticas e eletromagnéticas [23, 24, 25, 26].

Entre os objetivos deste trabalho estão (i) a investigação da influência do tamanho e forma das nanopartículas de prata em sua reatividade; bem como (ii) a comparação de previsões realizadas por meio da Teoria do Funcional da Densidade (DFT) com respeito ao tratamento de nanopartículas inteiras e o uso de estruturas simplificadas, tais como átomos, aglomerados ou partes da nanopartícula.

O uso das simplificações na modelagem de nanopartículas é bastante corrente, pois, enquanto a maior parte dos estudos experimentais atuais utiliza nanopartículas com dimensões maiores que $3 \mathrm{~nm}$, a capacidade computacional atualmente disponível não permite uma descrição mais rigorosa, por meio de metodologias de primeiros princípios, mesmo para sistemas em seu limite de tamanho inferior. Apesar de nanopartículas menores (em torno de $3 \mathrm{~nm}$ ) estarem dentro da capacidade das máquinas disponíveis, o tempo necessário para o cálculo sistemático de um conjunto 
de possíveis estruturas de uma dada nanopartícula e propriedades derivadas, torna a investigação completa proibitiva.

Desta forma, a fim de superar tais limitações técnicas nos modelos computacionais, é usual empregar aproximações para o tratamento das superfícies de nanopartículas em sistemas híbridos (como moléculas adsorvidas em superfícies), em termos de modelos como: de superfície plana [18], casca monoatômica com poucos átomos [27], ou mesmo de um único átomo [19].

Por vezes, as simplificações conseguem reter os aspectos fundamentais da interação ocorrida entre as moléculas e as nanopartículas, levando a resultados comparáveis com os dados experimentais disponíveis [18, 19], e oferecendo suporte teórico suficiente para a interpretação dos fenômenos observados. Todavia, não é claro que estes resultados fortuitos possam ser generalizados inequivocamente, ou se estão restritos aos casos em que foram relatados por meio de seu sucesso. De maneira geral a representação simplificada de nanopartículas, por meio da DFT em particular, e de outras teorias ab-initio, é uma questão em aberto [20, 28].

O presente trabalho está dividido em 5 capítulos, cujo conteúdo está organizado como segue.

No capítulo 1 apresentamos o formalismo teórico utilizado, onde sumarizamos os principais elementos e resultados da Teoria do Funcional da Densidade (DFT), bem como os aspectos técnicos empregados na aplicação desse modelo teórico como a teoria de pseudopotenciais ultrassuaves que empregamos.

No capítulo 2 apresentamos as diferentes nanopartículas estudadas neste trabalho, sob os aspectos gerais de sua geometria não relaxada, e os modelos envolvidos em sua construção.

No capítulo 3 apresentamos os resultados obtidos no tratamento DFT para as nanopartículas livres de prata, por meio da relaxação estrutural e eletrônica, bem como uma análise sistemática dos observáveis físicos de interesse. 
No capítulo 4 apresentamos os resultados obtidos em sistemas híbridos, onde tratamos as adsorções de compostos orgânicos sobre as nanopartículas de prata, no que diz respeito às propriedades físicas abordadas no capítulo anterior. Os estudos de adsorção são realizados com pequenos compostos, pois tem o objetivo de focar a análise em propriedades básicas envolvendo as ligações químicas nas superfícies das nanopartículas.

No capítulo 5 tratamos das simplificações para a descrição das propriedades das nanopartículas livres e adsorvidas comparativamente aos resultados obtidos ao longo das seções anteriores.

De modo a simplificar a discussão e análise, os resultados foram divididos entre três grandes áreas:

- Estrutural e geométrica: número de átomos, forma, tipos de sítios, razão de sítios superfície/interior, distância de ligação e número de vizinhos;

- Energético e eletrônico: energia por átomo de cada estrutura, densidades de estados, densidades de carga, níveis de energia, distribuição espacial dos níveis próximo ao nível de Fermi e transferência de carga;

- Vibracional: espectros Raman e infravermelho (IR), modos vibracionais. 


\section{Capítulo 1}

\section{Descrição teórica}

Neste capítulo apresentamos o formalismo teórico utilizado no estudo das nanopartículas de prata. A determinação da estrutura é obtida através da minimização da energia total e das forças com relação às coordenadas nucleares e eletrônicas.

Um sólido é um sistema de muitos corpos composto por núcleos e elétrons, cujas propriedades são decorrentes das interações entre todas estas partículas. A energia total de um sistema com elétrons e núcleos pode ser obtida resolvendo a equação de Schrödinger independente do tempo para a função de onda total eletrônica e nuclear $\Psi_{\text {tot }}$

$$
E_{T o t}=\left\langle\Psi_{t o t}\left|\hat{T}_{N}+\hat{V}_{N N}+\hat{T}_{e}+\hat{V}_{e e}+\hat{V}_{N e}\right| \Psi_{t o t}\right\rangle
$$

onde os termos $\hat{V}_{N N}, \hat{V}_{e e}$ e $\hat{V}_{N e}$ representam, respectivamente, as interações de Coulomb entre os núcleos, entre os elétrons e entre os elétrons e os núcleos, e os termos $\hat{T}_{N}$ e $\hat{T}_{e}$ representam, respectivamente, as energias cinéticas dos núcleos e elétrons.

Como as forças coulombianas nas interações entre núcleos e elétrons são de mesma intensidade mas a massa do elétron é muito menor, podemos supor que os elétrons respondem quase instantaneamente aos movimentos dos núcleos, ou seja, os núcleos podem ser tratados adiabaticamente. Isso permite separar as coordenadas eletrônicas e nucleares na função de onda total $\Psi_{\text {tot }}(\mathbf{R}, \mathbf{r})$, que passa a ser escrita 
como o produto da função de onda nuclear $\Psi_{N}(\mathbf{R})$ e eletrônica $\Psi_{e}(\mathbf{R}, \mathbf{r})$,

$$
\Psi_{t o t}(\mathbf{R}, \mathbf{r}) \equiv \Psi_{N}(\mathbf{R}) \Psi_{e}(\mathbf{R}, \mathbf{r})
$$

É interessante observar que a função de onda nuclear depende apenas das coordenadas nucleares $(\mathbf{R})$ enquanto a eletrônica depende de ambas as coordenadas $(\mathbf{R}, \mathbf{r})$.

A aproximação adiabática ou aproximação de Born-Oppenheimer, reduz o problema à solução da dinâmica dos elétrons em uma configuração congelada dos núcleos. Na equação 1.1 as energias nuclear $\left(E_{N}\right)$ e eletrônica $\left(E_{e}\right)$ podem ser escritas separadamente e, como a configuração nuclear é estática, o termo da energia cinética nuclear é nulo. Assim, a energia total passa a ser escrita como,

$$
E_{T o t}=\underbrace{\left\langle\Psi_{N}\left|\hat{V}_{N N}\right| \Psi_{N}\right\rangle}_{E_{N}}+\underbrace{\left\langle\Psi_{e}\left|\hat{T}_{e}+\hat{V}_{e e}+\hat{V}_{N e}\right| \Psi_{e}\right\rangle}_{E_{e}}
$$

A equação 1.3 envolve muitos corpos e sua solução analítica é desconhecida. Entretanto, pode-se introduzir algumas simplificações, que serão tratadas nas seções seguintes, que possibilitam a obtenção da energia total com precisão e eficiência.

\subsection{Tratamento das interações eletrônicas}

Neste trabalho o tratamento das interações eletrônicas é realizado dentro da Teoria do Funcional da Densidade formulada em 1964 por Pierre C. Hohenberg e Walter Kohn. Esta teoria demonstrou ser uma poderosa ferramenta para o cálculo de sistemas interagentes, permitindo o tratamento de estruturas com um grande número de átomos a partir de uma formulação de primeiros princípios, que valeu a Walter Kohn o prêmio Nobel de Química de 1998. Os trabalhos originais da Teoria do Funcional da Densidade foram publicados em 1964 por Hohenberg e Kohn [29] e no ano seguinte por Kohn e Sham [30]. 


\subsubsection{Teoria do Funcional da Densidade - DFT}

A ideia central da Teoria do Funcional da Densidade consiste na demonstração rigorosa de que um sistema de elétrons interagentes no estado fundamental pode ser descrito pela sua densidade $\rho(\mathbf{r})$ e que qualquer propriedade pode ser escrita como um funcional desta densidade. Os dois teoremas que a fundamentam são:

- Teorema I: O potencial externo $V_{e x t}(\mathbf{r})$ de um sistema de partículas interagentes é, a menos de uma constante, univocamente determinado pela densidade de carga dessas partículas no estado fundamental $\rho(\mathbf{r})$ (apêndice A);

- Teorema II: Conhecido o potencial externo que age sobre o sistema é possível definir sua energia total como um funcional da densidade $n(\mathbf{r})$. A energia e a densidade associadas ao mínimo global deste funcional são, respectivamente, a energia $E^{0}$ e a densidade $\rho(\mathbf{r})$ exatas do estado fundamental do sistema.

Dentro da aproximação adiabática, o potencial $V_{N e}$ da equação 1.3 representa um conjunto de núcleos fixos que age sobre os elétrons do sistema como um potencial externo $V_{\text {ext }}$ fixo e independente da configuração eletrônica. Sendo assim, a energia eletrônica $E_{e}$ pode ser adequadamente tratada dentro da teoria do funcional da densidade. A energia eletrônica é convenientemente escrita com um funcional da densidade da seguinte forma,

$$
E_{e}[n]=F[n]+\int V_{e x t}(\mathbf{r}) n(\mathbf{r}) d \mathbf{r} .
$$

O funcional $F[n]$ representa as interações puramente eletrônicas,

$$
F[n]=\left\langle\Psi_{e}\left|\hat{T}_{e}+\hat{V}_{e e}\right| \Psi_{e}\right\rangle,
$$

onde $\Psi_{e}$, é um estado do sistema com densidade $n(\mathbf{r})$. 
Conforme o segundo teorema de Hohenberg e Kohn [29], o funcional $E_{e}[n]$ obedece o princípio variacional com relação à $n(\mathbf{r})$ e é o mínimo global quando $n(\mathbf{r})$ é igual à densidade de carga do estado fundamental $\rho(\mathbf{r})$,

$$
E_{e}^{0}=E_{e}[\rho]=F[\rho]+\int V_{e x t}(\mathbf{r}) \rho(\mathbf{r}) d \mathbf{r}
$$

$\operatorname{com} F[\rho]=\operatorname{mínimo}\left\langle\Psi_{e}\left|\hat{T}_{e}+\hat{V}_{e e}\right| \Psi_{e}\right\rangle$ e $E_{e}^{0}$ a energia do estado fundamental.

As propriedades magnéticas dos sistemas estão relacionadas a distinção e interação entre as componentes de spin dos elétrons. A inclusão do spin na Teoria do Funcional da Densidade é realizada escrevendo separadamente as densidades de cada componente de spin, $n_{\uparrow}(\mathbf{r})$ e $n_{\downarrow}(\mathbf{r})$, e a densidade total dada pela soma dessas duas contribuições,

$$
n(\mathbf{r})=\sum_{\sigma} n_{\sigma}(\mathbf{r})=n_{\uparrow}(\mathbf{r})+n_{\downarrow}(\mathbf{r}) .
$$

Dessa forma, o funcional da energia passa a ser dependente das duas componentes de spin,

$$
E_{e}\left[n_{\uparrow}, n_{\downarrow}\right]=F\left[n_{\uparrow}, n_{\downarrow}\right]+\int V_{e x t}(\mathbf{r})\left(n_{\uparrow}(\mathbf{r})+n_{\downarrow}(\mathbf{r})\right) d \mathbf{r} .
$$

\section{O Funcional da energia e a equação de Kohn-Sham}

A Teoria do Funcional da Densidade é formulada sem aproximações, sendo, portanto, uma teoria exata para tratar o problema de muitos elétrons interagentes no estado fundamental e sujeitos a um potencial externo $V_{\text {ext }}(\mathbf{r})$. Entretanto, existem duas dificuldades que não permitem o tratamento exato na prática:

i. o funcional eletrônico $F\left[n_{\uparrow}, n_{\downarrow}\right]=\left\langle\Psi_{e}\left|\hat{T}_{e}+\hat{V}_{e e}\right| \Psi_{e}\right\rangle$ é desconhecido; e

ii. é necessário um método para se obter a densidade que minimize o funcional da energia $E_{e}$ 
Para contornar estas dificuldades, Kohn e Sham [30], utilizando os formalismos de Hartree-Fock [31, 32] e de Thomas-Fermi [33], descreveram a função de onda total eletrônica $\Psi_{e}$ como um produto de funções orbitais $\psi_{s}(\mathbf{r})$,

$$
\Psi_{e}=\prod_{s=i, \sigma} \psi_{s}=\psi_{1 \uparrow} \cdot \psi_{1 \downarrow} \ldots \psi_{i \uparrow} \cdot \psi_{i \downarrow}
$$

e a densidade escrita como,

$$
n(\mathbf{r})=\sum_{s} n_{s}(\mathbf{r})=\sum_{s} f_{s}\left|\psi_{s}(\mathbf{r})\right|^{2}
$$

sendo $n_{s}(\mathbf{r})$ a densidade eletrônica de cada estado $s$. O índice $s$ representa, por simplicidade, os estados eletrônicos $(i=1,2,3 \ldots)$ e de $\operatorname{spin}(\sigma=\uparrow$ e $\downarrow), s=i, \sigma$. Os fatores $f_{s}$ indicam a ocupação eletrônica de cada estado $s$ obedecendo a estatística de Fermi.

Para resolver a primeira dificuldade, Kohn e Sham propuseram a seguinte expressão para o funcional $F\left[n_{\uparrow}, n_{\downarrow}\right]$,

$$
F\left[n_{\uparrow}, n_{\downarrow},\left\{\psi_{s}\right\}\right]=T_{N I}\left[\left\{\psi_{s}\right\}\right]+\frac{1}{2} \iint \frac{n(\mathbf{r}) n\left(\mathbf{r}^{\prime}\right)}{\left|\mathbf{r}-\mathbf{r}^{\prime}\right|} d \mathbf{r}^{\prime} d \mathbf{r}+E_{x c}\left[n_{\uparrow}, n_{\downarrow}\right] .
$$

O primeiro termo do lado direito representa a energia cinética de um sistema de elétrons não interagentes (NI) com densidade $n(\mathbf{r})$, o segundo termo é a energia coulombiana e o último termo é conhecido como energia de troca e correlação (xc - "exchange and correlation"). A energia de troca e correlação é um funcional universal da densidade que inclui as correções para a obtenção da energia exata do sistema de muitos corpos interagentes.

O termo de troca e correlação $E_{x c}$ é conhecido apenas para sistemas simplificados e necessita ser aproximado. O termo da energia cinética dos elétrons não interagentes $T_{N I}$ é obtido aplicando-se o operador energia cinética sobre os orbitais $\psi_{s}(\mathbf{r})$,

$$
T_{N I}\left[\left\{\psi_{s}\right\}\right]=\sum_{s} f_{s}\left\langle\psi_{s}\left|-\frac{1}{2} \nabla^{2}\right| \psi_{s}\right\rangle .
$$


Dentro desta proposta, o funcional da energia total eletrônica tem a seguinte forma,

$$
\begin{aligned}
E_{e}\left[\left\{\psi_{s}\right\}, n_{\uparrow}, n_{\downarrow}, V_{e x t}\right] & =T_{N I}\left[\left\{\psi_{s}\right\}\right]+\int V_{e x t}(\mathbf{r}) n(\mathbf{r}) d \mathbf{r}+ \\
& +\frac{1}{2} \iint \frac{n(\mathbf{r}) n\left(\mathbf{r}^{\prime}\right)}{\left|\mathbf{r}-\mathbf{r}^{\prime}\right|} d \mathbf{r}^{\prime} d \mathbf{r}+E_{x c}\left[n_{\uparrow}, n_{\downarrow}\right],
\end{aligned}
$$

e o estado fundamental é obtido quando $n(\mathbf{r})=\rho(\mathbf{r})$.

A segunda dificuldade é resolvida levando em consideração a propriedade estacionária da equação 1.13 que, sujeita a condição

$$
\int \delta n(\mathbf{r}) d \mathbf{r}=0
$$

fornece a equação

$$
\int \delta n(\mathbf{r})\left\{\frac{\hat{T}_{N I}}{\delta n}+V_{K S}\right\} d \mathbf{r}=0
$$

onde

$$
V_{K S}=V_{e x t}(\mathbf{r})+\int \frac{n\left(\mathbf{r}^{\prime}\right)}{\left|\mathbf{r}-\mathbf{r}^{\prime}\right|} d \mathbf{r}^{\prime}+\frac{\delta E_{x c}\left[n_{\uparrow}, n_{\downarrow}\right]}{\delta n}
$$

é conhecido como potencial de Kohn-Sham.

As equações 1.14 e 1.15 são equivalentes às de um sistema de elétrons não interagentes sujeitos ao potencial efetivo $V_{K S}(\mathbf{r})$. Portanto, para um dado potencial $V_{K S}$, é possível se obter a densidade resolvendo a equação do tipo Schrödinger de uma partícula,

$$
\left\{-\frac{1}{2} \nabla^{2}+V_{K S}(\mathbf{r})\right\} \psi_{S}(\mathbf{r})=\varepsilon \psi_{S}(\mathbf{r}),
$$

que é conhecida como equação de Kohn e Sham.

A solução da equação 1.17 fornece um conjunto de funções de onda do estado fundamental $\left[\psi_{1}^{0}(\mathbf{r}), \ldots, \psi_{s}^{0}(\mathbf{r})\right]$, que permite a obtenção da densidade de carga do estado fundamental $\rho(\mathbf{r})$ através da equação 1.10 e da energia total eletrônica através da equação 1.13 . 
A equação 1.17 só pode ser resolvida de forma auto-consistente. Isto acontece porque o potencial $V_{K S}(\mathbf{r})$ depende da densidade $n(\mathbf{r})$ que, por sua vez, depende das funções de onda $\psi_{s}$, que só podem ser obtidas se conhecido o $V_{K S}(\mathbf{r})$. O ciclo de auto-consistência, é composto das seguintes etapas:

- a partir de um conjunto inicial de funções de onda constrói-se uma densidade de carga $n(\mathbf{r})$ e calcula-se o potencial $V_{K S}$ pela equação 1.16 ;

- com este potencial resolve-se a equação de Kohn-Sham para obter um conjunto de funções $\psi_{s}$;

- a partir deste conjunto de funções uma nova densidade é calculada pela equação 1.10 ;

- compara-se o potencial de Hartree obtido para esta nova densidade e para a densidade do início do ciclo. O potencial é calculado pela equação de Poisson,

$$
\nabla^{2} V_{H}=n(\mathbf{r})
$$

- se a diferença entre os potenciais for maior que a precisão desejada, recomeçase o ciclo com a nova densidade obtida, que é repetido até que a diferença no potencial esteja dentro de determinada precisão.

Quando a autoconsistência é alcançada, a densidade obtida é a densidade do estado fundamental $\rho(\mathbf{r})$ para aquele potencial externo.

\subsubsection{A Energia de Troca e Correlação}

O maior problema existente na aplicação da teoria do funcional da densidade está na descrição do funcional da energia de troca e correlação $E_{x c}$ que permanece desconhecido e deve ser aproximado. As duas aproximações mais utilizadas 
são: a Aproximação da Densidade Local (LDA) e a Aproximação do Gradiente Generalizado (GGA).

\section{Aproximações da Densidade Local (LDA) e do Gradiente Generalizado (GGA)}

A LDA foi proposta por Kohn e Sham [30] e é uma das aproximações mais simples e muito utilizada desde a formulação da Teoria do Funcional da Densidade. Nesta aproximação é considerado que a densidade varia lentamente e a energia de troca e correlação $E_{x c}$ pode, então, ser escrita como,

$$
E_{x c}^{L D A}\left[n_{\uparrow}, n_{\downarrow}\right]=\int \varepsilon_{x c}\left[n_{\uparrow}, n_{\downarrow}\right] n(\mathbf{r}), d \mathbf{r}
$$

onde $\varepsilon_{x c}[n]$ é a energia de troca e correlação por elétron. Sendo assim, o potencial de troca e correlação $v_{x c}$ é dado por,

$$
v_{x c}\left[n_{\uparrow}, n_{\downarrow}\right]=\frac{\partial\left(\varepsilon_{x c}\left[n_{\uparrow}, n_{\downarrow}\right] n(\mathbf{r})\right)}{\partial n}=\varepsilon_{x c}\left[n_{\uparrow}, n_{\downarrow}\right]+n(\mathbf{r}) \frac{\partial \varepsilon_{x c}\left[n_{\uparrow}, n_{\downarrow}\right]}{\partial n} .
$$

$\mathrm{Na}$ aproximação LDA a energia $\varepsilon_{x c}$ em um ponto $\mathbf{r}$ é considerada igual à energia de um gás de elétrons uniforme com a densidade daquele ponto,

$$
\varepsilon_{x c}^{L D A}=\varepsilon_{x c}^{u n i f}
$$

e os termos de troca $\varepsilon_{x}$ e correlação $\varepsilon_{c}$ são tratados separadamente,

$$
\varepsilon_{x c}=\varepsilon_{x}+\varepsilon_{c}
$$

A energia de troca $\varepsilon_{x}$ para o gás de elétrons uniforme pode ser calculada analiticamente como na formulação de Hartree-Fock,

$$
\varepsilon_{x}=-\frac{3}{4}\left(\frac{3}{\pi}\right)^{\frac{1}{3}}[n(\mathbf{r})]^{\frac{1}{3}}=\frac{-0.4582}{r_{s}(\mathbf{r})}
$$

onde a densidade $n(\mathbf{r})$ está escrita em função do raio de Wigner-Seitz, $r_{s}(\mathbf{r})$,

$$
n(\mathbf{r})=\left[\frac{4 \pi}{3} r_{s}^{3}(\mathbf{r})\right]^{-1}
$$


Por outro lado, a correlação $\varepsilon_{c}$ do gás de elétrons uniforme só possui uma expressão analítica para as regiões com $r_{s}<1$ ou $r_{s}>2$. Mas, como o intervalo da descontinuidade é pequeno $\left(1<r_{s}<2\right)$, é possível realizar uma interpolação numérica tornando a energia $\varepsilon_{c}$ contínua para toda a extensão de $r_{s}$. A expressão da energia $\varepsilon_{c}$ proposta por Cerperley e Alder [34] e parametrizada por Perdew e Zunger [35] é uma das mais utilizadas. Nela, os pontos para interpolação são obtidos através de cálculos de Monte Carlo quântico para o gás de elétrons uniforme e interagente.

Apesar dos bons resultados obtidos, a aproximação LDA está limitada aos sistemas em que a densidade seja quase uniforme, não descrevendo de forma adequada sistemas com densidades altamente localizadas ou pouco homogêneas. $\mathrm{Na}$ tentativa de descrever melhor estes sistemas, foram incorporados os efeitos da não homogeneidade no funcional da energia de troca e correlação $E_{x c}$, que é a base da aproximação do gradiente generalizado (GGA).

As diversas formas da aproximação GGA são variantes de uma mesma expressão dependente das densidades de spin, e de seus gradientes,

$$
E_{x c}^{G G A}\left[n_{\uparrow}, n_{\downarrow}\right]=\int f\left(n_{\uparrow}, n_{\downarrow}, \nabla n_{\uparrow}, \nabla n_{\downarrow}\right) d \mathbf{r} .
$$

onde $f$ é uma função analítica e parametrizada. As diferenças entre as aproximações existentes estão na forma da parametrização. Dentre as propostas existentes utilizamos aquela elaborada por Perdew e Wang (PW91) [36, 37], na representação proposta por Perdew e colaboradores. [38] por ser mais concisa.

Na aproximação PW91 a energia de troca e correlação $E_{x c}$ é obtida pela combinação de gradientes na expansão do termo de troca e correlação de um gás de elétrons uniforme, com as energias de troca e correlação escritas separadamente.

$$
E_{x c}=E_{x}+E_{c}
$$

O termo de troca é independente da polarização de spin $\xi$ e definido por,

$$
E_{x}^{P W 91}[n]=\int \varepsilon_{x}^{\mathrm{unif}}(n) F_{x}(s) n(\mathbf{r}) d \mathbf{r}
$$


onde $s=\frac{|\nabla n(\mathbf{r})|}{2 \phi k_{F} n(\mathbf{r})} \operatorname{com} k_{F}=\frac{1}{r_{s}}\left(\frac{9 \pi}{4}\right)^{\frac{1}{3}}$. Já o termo de correlação é dependente da polarização de spin e tem a seguinte forma,

$$
E_{c}^{P W 91}\left[n_{\uparrow}, n_{\downarrow}\right]=\int\left[\varepsilon_{c}^{\text {unif }}\left(r_{s}, \xi\right)+H\left(r_{s}, \xi, t\right)\right] n(\mathbf{r}) d \mathbf{r}
$$

onde $t=\frac{|\nabla n(\mathbf{r})|}{2 \phi k_{s} n(\mathbf{r})}, k_{s}=\sqrt{\frac{4 k_{F}}{\pi a_{0}}}$ e $\xi=\frac{n_{\uparrow}(\mathbf{r})-n_{\downarrow}(\mathbf{r})}{n(\mathbf{r})}$. As funções $F_{x}(s)$ e $H\left(r_{s}, \xi, t\right)$ são descritas com mais detalhes no apêndice B.

\subsection{Tratamento das interações entre elétrons e nú- cleos}

A interação entre os elétrons e os núcleos é definida pelo potencial de Coulomb e depende do arranjo nuclear. Como citado na seção anterior, a configuração dos núcleos é mantida fixa, definindo o ambiente no qual os elétrons se rearranjam conforme seus estados eletrônicos.

Para melhor entender esta interação vamos partir do ambiente atômico (átomo isolado). Nesse ambiente o potencial sentido pelos elétrons se deve a um único núcleo de carga $Z$ cuja solução fornece os estados eletrônicos atômicos. Quando o átomo é transferido para outros ambientes, como moléculas, superfícies ou cristais, estes estados são perturbados na formação das ligações químicas.

Os elétrons cujos estados atômicos sofrem muita influência quando transferidos do ambiente atômico para outro, por participarem efetivamente das ligações, são denominados elétrons da valência. Por outro lado, os elétrons mais fortemente ligados ao núcleo, que praticamente não participam das ligações químicas e, portanto, praticamente não tem seus estados atômicos perturbados, são denominados elétrons do caroço.

Pelo fato dos estados do caroço não serem significativamente perturbados pelo rearranjo eletrônico da valência nos diferentes ambientes, podem, de maneira apro- 
ximada, ser mantidos congelados. Nesta aproximação, o átomo, composto por todos os elétrons e o núcleo, pode ser substituído por um pseudoátomo, composto pelos elétrons da valência e um caroço iônico. O caroço iônico inclui o núcleo e os elétrons do caroço mantidos nos seus estados atômicos. Como as propriedades dos materiais estão fortemente relacionadas com as ligações químicas é esperado que o congelamento dos estados do caroço pouco ou nada interfira nas propriedades obtidas usando essa aproximação [39].

Para a valência, o caroço iônico equivale a um núcleo com uma carga efetiva reduzida $Z_{v}=Z-Z_{e f}$, sendo $Z_{e f}$ a carga efetiva dos elétrons do caroço. Sendo assim, os elétrons da valência ficam sujeitos a um potencial efetivo que resulta do potencial atrativo do núcleo parcialmente cancelado pelo potencial repulsivo dos elétrons do caroço. Este potencial resultante é denominado pseudopotencial.

O pseudopotencial simplifica o cálculo de estrutura eletrônica, reduzindo significativamente o número de elétrons que são tratados explicitamente pela eliminação dos estados do caroço, substituindo um problema que envolve todos os elétrons por outro que envolve apenas os elétrons de valência, como representado na figura 1.1.

O átomo de prata, por exemplo, possui 47 elétrons distribuídos nos estados $1 s^{2} 2 s^{2} 2 p^{6} 3 s^{2} 3 p^{6} 3 d^{10} 4 s^{2} 4 p^{6} 4 d^{10} 5 s^{1}$, onde os estados $4 d^{10} 5 s^{1}$ são os mais perturbados e correspondem efetivamente à valência. Dessa forma, um sistema composto de $N$ átomos de prata e, portanto, $M=47 N$ elétrons, é substituído por um problema que envolve apenas $M=11 N$ elétrons, reduzindo cerca de 4 vezes o número de elétrons a serem tratados explicitamente.

\subsubsection{Teoria do Pseudopotencial}

A origem da Teoria do Pseudopotencial está fortemente relacionada com a escolha da descrição da função de onda eletrônica $\psi(r)$ em uma base de ondas pla- 


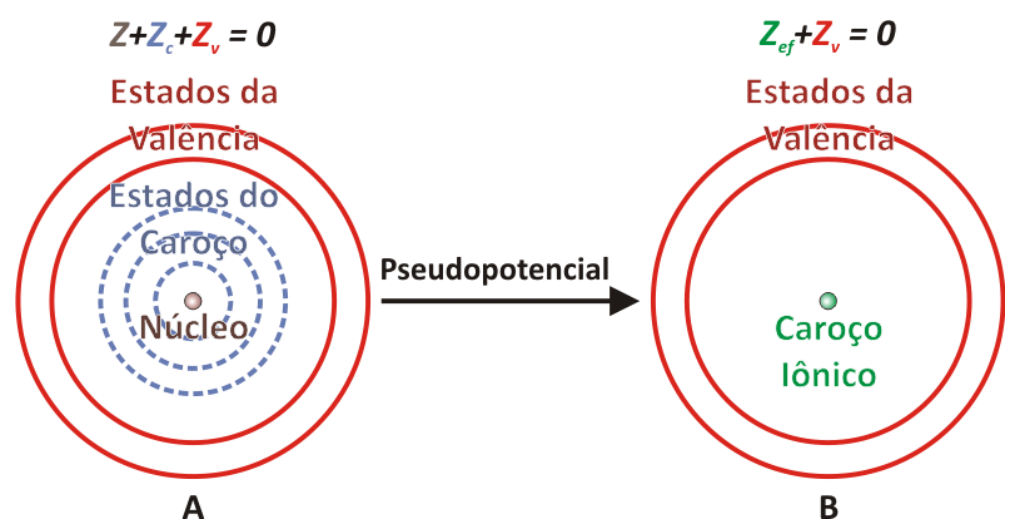

Fig. 1.1: Representação das subdivisões do átomo em núcleo (marrom), estados do caroço (azul) e estados da valência (vermelho) e a correspondente simplificação realizada pelo método de pseudopotencial. A região do núcleo mais os elétrons do caroço é substituída por um caroço iônico com uma carga efetiva equivalente $Z_{e f}$ (verde). As cargas do núcleo, do caroço e da valência são representadas respectivamente por $Z, Z_{c}$ e $Z_{v}$

nas (PW - "plane waves")

$$
\psi(r)=\sum_{k} c_{k} \cdot e^{i k r} .
$$

A adoção da expansão em ondas planas se deve ao fato de que, a princípio, pode-se descrever qualquer função através de uma expansão de Fourier e por simplificar o tratamento de sistemas periódicos.

Entretanto, devido a forte interação com o núcleo e a ortogonalidade entre os estados, as funções de ondas dos elétrons são localizadas e apresentam oscilações na região próxima ao núcleo, sendo necessário um número muito grande de ondas planas para serem bem descritas. Para contornar este problema, Herring [40] propôs que as funções de ondas da valência $\psi_{v}$ fossem escritas como uma combinação linear de uma função suave e sem nós $\varphi_{v}$, expandida em ondas planas, com estados ligados do caroço $\psi_{c}$,

$$
\left|\psi_{v}\right\rangle=\left|\varphi_{v}\right\rangle+\sum_{c} b_{c v}\left|\psi_{c}\right\rangle
$$

Os estados ligados do caroço são ortogonais entre si, $\left\langle\psi_{c} \mid \psi_{c^{\prime}}\right\rangle=\delta_{c, c^{\prime}}$ e os coeficientes $b_{c v}$ são determinados por construção, forçando a ortogonalidade entre $\psi_{v} \mathrm{e}$ 
$\psi_{c},\left\langle\psi_{v} \mid \psi_{c}\right\rangle=0$ e $b_{c v}=-\left\langle\varphi_{v} \mid \psi_{c}\right\rangle$. Dessa forma a região sinuosa e com muitas oscilações é tratada com funções de caroço enquanto a parte que é representada por ondas planas é suave, necessitando de um número reduzido de ondas planas para ser descrito. Esta sugestão, conhecida como ondas planas ortogonalizadas (OPW “Orthogonalized Plane Wave”), foi a origem do método de pseudopotencial.

Inspirado no método OPW, Phillips e Kleinman [41] estudaram as propriedades de cancelamento entre o potencial do núcleo e o potencial dos elétrons do caroço e demonstraram que a parte suave da função da valência $\varphi_{v}$ satisfaz a equação de Schrödinger modificada,

$$
\left(\hat{H}+\sum_{c}\left(\varepsilon_{v}-\varepsilon_{c}\right)\left|\psi_{c}\right\rangle\left\langle\psi_{c}\right|\right)\left|\varphi_{v}\right\rangle=\varepsilon_{v}\left|\varphi_{v}\right\rangle
$$

onde $\varepsilon_{v}$ e $\varepsilon_{c}$ são, respectivamente, os autovalores dos estados da valência e do caroço para o Hamiltoniano atômico $\hat{H}=\hat{T}+\hat{V}$,

$$
\hat{H}\left|\psi_{v}\right\rangle=\varepsilon_{v}\left|\psi_{v}\right\rangle \text { e } \hat{H}\left|\psi_{c}\right\rangle=\varepsilon_{c}\left|\psi_{c}\right\rangle
$$

Isso demonstra que podemos escrever uma pseudo-Hamiltoniana que fornece os mesmos autovalores para a valência da hamiltoniana original, entretanto, utilizando a pseudofunção de valência $\varphi_{v}$ que é suave e sem nós,

$$
\hat{H}^{p s}=\hat{H}+\sum_{c}\left(\varepsilon_{v}-\varepsilon_{c}\right)\left|\psi_{c}\right\rangle\left\langle\psi_{c}\right|
$$

Como os autovalores $\varepsilon_{c}$ são sempre menores que os autovalores $\varepsilon_{v}$, o segundo termo do lado direito é equivalente a um potencial repulsivo $\hat{V}_{R}$,

$$
\hat{V}_{R}=\sum_{c}\left(\varepsilon_{v}-\varepsilon_{c}\right)\left|\psi_{c}\right\rangle\left\langle\psi_{c}\right|
$$

Desta forma a pseudo-Hamiltoniana pode ser escrita como,

$$
\hat{H}^{p s}=\hat{T}+\hat{V}+\hat{V}_{R}
$$


onde o potencial resultante,

$$
\hat{V}^{p s}=\hat{V}+\hat{V}_{R}
$$

representa um potencial atrativo mais suave, consequência do cancelamento entre o termo atrativo $\hat{V}$ e o termo repulsivo $\hat{V}_{R}$. Este potencial resultante $\hat{V}^{p s}$ é denominado pseudopotencial. Cohen e Heine [42] mostraram que dentro da região do caroço o cancelamento entre $\hat{V}$ e $\hat{V}_{R}$ é quase completo, o que levou a total exclusão dos estados do caroço no tratamento de sistema, sendo realizado de forma explícita apenas com os estados da valência.

\section{Pseudopotenciais de primeiros princípios}

Os pseudopotenciais de primeiros princípios são gerados a partir de cálculos atômicos envolvendo todos os elétrons. Estes cálculos utilizam a teoria do funcional da densidade, resolvendo a equação radial de Kohn-Sham,

$$
\left\{-\frac{1}{2} \frac{\partial^{2}}{\partial r^{2}}+\frac{l(l+1)}{2 r^{2}}+\hat{V}_{K S}[n]\right\} r R_{l}^{t e}(r)=\varepsilon_{l} r R_{l}^{t e}(r)
$$

onde a função de onda atômica de todos os elétrons $\Phi_{l m}^{t e}(r, \theta, \varphi)$ está separada nas componentes radial $R_{l}^{t e}(r)$ e esférica $Y_{l m}(\theta ; \varphi)$,

$$
\Phi_{l m}^{t e}(r, \theta, \varphi)=R_{l}^{t e}(r) Y_{l m}(\theta, \varphi)
$$

O potencial $V_{K S}(n)$ é dado pela equação 1.16 , sendo que o potencial externo é devido ao núcleo de número atômico $\mathrm{Z}$, portanto,

$$
\hat{V}_{K S}=-\frac{Z}{r} \hat{I}+\hat{V}_{H}+\hat{V}_{x c}
$$

onde $\hat{I}$ é operador identidade. A partir dos resultados dos autovalores e autofunções obtidos para todos os elétrons são construídas as pseudofunções $R_{l}^{p s}(r)$. O pseudopotencial atômico é obtido a partir da inversão da equação radial de Kohn-Sham, 
equação 1.37 ,

$$
v_{l}^{p s-a t o m}(r)=\varepsilon_{l}-\frac{l(l+1)}{2 r^{2}}+\frac{1}{2 r R_{l}^{p s}(r)} \frac{\partial^{2}}{\partial r^{2}}\left[r R_{l}^{p s}(r)\right],
$$

impondo, para evitar a singularidade do pseudopotencial, que as pseudofunções não apresentem nós e se comportem com $r^{l}$ quando se aproximam da origem e, para garantir a continuidade do pseudopotencial, que possuam derivadas contínuas até segunda ordem.

Na figura 1.2 temos a comparação entre a função de onda de todos os elétrons sujeita ao potencial coulombiano e a correspondente pseudofunção sujeita ao pseudopotencial. A partir do raio de corte $r_{c}$ a função de onda e o potencial de todos os elétrons coincidem, respectivamente, com a pseudofunção e o pseudopotencial.

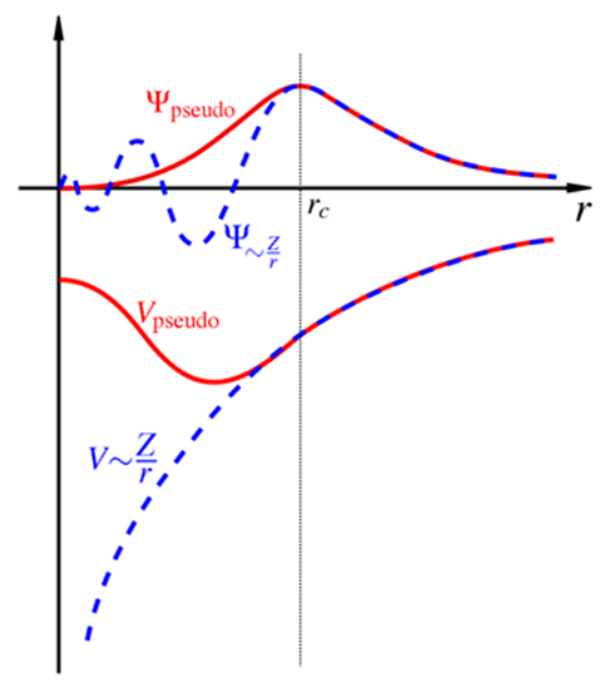

Fig. 1.2: Comparação entre a função de onda de todos os elétrons sujeita ao potencial coulombiano (tracejado azul) e a pseudofunção sujeita ao correspondente pseudopotencial (linha vermelha).

Finalmente, para se produzir o pseudopotencial que represente apenas a região do caroço, possibilitando a sua transferência para ambientes diferentes do atômico, é necessário retirar do pseudopotencial atômico as interações de Hartree e de troca 
e correlação dos elétrons da valência

$$
v_{l}^{p s}(r)=v_{l}^{p s-a t o m}(r)-\int \frac{\rho_{v}\left(r^{\prime}\right)}{r-r^{\prime}} d \mathbf{r}^{\prime}-v_{x c}\left[\rho_{v}\right]
$$

onde $\rho_{v}$ corresponde a densidade apenas dos elétrons da valência.

\section{Pseudopotencial de norma conservada}

O pseudopotencial deve ser construído de forma que reproduza adequadamente os efeitos do potencial de todos os elétrons na região fora do caroço. Neste sentido, Hamman, Schlüter e Chiang[43] (HSC) propuseram quatro propriedades básicas:

i. os autovalores da valência do cálculo com todos os elétrons devem coincidir com os pseudoautovalores,

$$
\varepsilon_{v}^{t e}=\varepsilon_{v}^{p s}
$$

ii. a pseudofunção de onda $\varphi_{v}$ deve ser idêntica a função de onda de todos os elétrons $\psi_{v}$ a partir de um raio de corte $r_{c}$, escolhido após a região de grandes oscilações, e deve ser suave e sem nós para a região dentro do raio de corte,

$$
R^{p s}(r)= \begin{cases}\text { suave e sem nós, } & \text { para } r \leq r_{c} \\ R^{t e}(r), & \text { para } r \geq r_{c}\end{cases}
$$

iii. a integral da densidade de carga do cálculo de todos os elétrons e a da pseudodensidade devem ser iguais dentro da esfera de raio $r_{c}$

$$
\int_{0}^{r_{c}}\left|r R^{p s}(r)\right|^{2} d r=\int_{0}^{r_{c}}\left|r R^{t e}(r)\right|^{2} d r
$$

iv. a derivada logarítmica e a primeira derivada com relação a energia da função de onda do cálculo de todos os elétrons e da pseudofunção devem ser iguais para $r \geq r_{c}$. 
Os dois últimos itens estão relacionados pela identidade da regra de soma de Friedel,

$$
\left.\frac{1}{2}\left[\left(r R_{l}\right)^{2} \frac{\partial}{\partial \varepsilon} \frac{\partial}{\partial r} \ln R_{l}\right]\right|_{\substack{r=r_{c} \\ \varepsilon=\varepsilon_{l}}}=\int_{0}^{r_{c}} r^{2} R_{l}^{2} d r .
$$

Os pseudopotenciais que seguem estas propriedades são denominados pseudopotenciais de primeiros princípios de norma conservada. Existem várias formas destes pseudopotenciais na literatura que se diferenciam principalmente pela forma da pseudofunção.

\subsubsection{Pseudopotencial separável}

O pseudopotencial não é local por construção, agindo de forma diferente para cada momento angular, e pode ser escrito como,

$$
\hat{V}^{p s}=\sum_{l}^{\infty} \sum_{m=-l}^{l}|l m\rangle v_{l}^{p s}(r)\langle l m|,
$$

onde $\langle\mathbf{r} \mid l m\rangle=Y_{l m}(\theta, \phi)$ são os harmônicos esféricos e $v_{l}^{p s}(r)$ são os pseudopotenciais para cada componente $l$, obtidos pela equação 1.41. Entretanto, como os termos $v_{l}^{p s}(r)$ convergem rapidamente com o crescimento de $l$, o caroço é percebido da mesma maneira por todas as componentes $l>l_{\max }$, e o pseudopotencial pode ser reescrito separando a parte local da parte não local.

$$
\begin{aligned}
\hat{V}^{p s} & =\sum_{l}^{\infty} \sum_{m=-l}^{l}|\operatorname{lm}\rangle v_{l o c}^{p s}(r)\left\langle l m\left|+\sum_{l}^{l_{\max }} \sum_{m=-l}^{l}\right| \operatorname{lm}\right\rangle v_{l}^{p s}(r)-v_{l o c}^{p s}(r)\langle\operatorname{lm}| \\
& =v_{l o c}^{p s}(r) \hat{I}+\sum_{l}^{l_{\max }} \sum_{m=-l}^{l}|\operatorname{lm}\rangle \Delta v_{l}^{p s}(r)\langle\operatorname{lm}|,
\end{aligned}
$$

onde $\hat{I}$ é a matriz identidade e o último termo representa a parte não local do pseudopotencial,

$$
\Delta \hat{V}_{l}^{p s}=\sum_{m=-l}^{l}|l m\rangle \Delta v_{l}^{p s}(r)\langle\operatorname{lm}| .
$$


Conforme proposto por Kleynman e Bylander [44], a parte não local do pseudopotencial pode ser escrita de maneira geral como,

$$
\Delta \hat{V}_{l}^{p s}=\sum_{m=-l}^{l} \frac{\left|\chi^{l m}\right\rangle\left\langle\chi^{l m}\right|}{\left\langle\chi^{l m} \mid \Phi_{l m}^{p s}\right\rangle},
$$

que pode ser entendido como um operador de projeção, onde as funções projetoras, que são dependentes da escolha do potencial local, são dadas por,

$$
\left|\chi^{l m}\right\rangle=\Delta \hat{V}_{l}^{p s}\left|\Phi_{l m}^{p s}\right\rangle=\left(\varepsilon_{l}-\hat{T}-v_{l o c}^{p s} \hat{I}\right)\left|\Phi_{l m}^{p s}\right\rangle
$$

onde a pseudofunção de onda é autoestado da pseudo-Hamiltoniana com autovalores $\varepsilon_{l}$,

$$
\left(\hat{T}+\hat{V}^{p s}\right)\left|\Phi_{l m}^{p s}\right\rangle=\left(\hat{T}+\hat{V}_{l o c}^{p s}+\Delta \hat{V}_{l}^{p s}\right)\left|\Phi_{l m}^{p s}\right\rangle=\varepsilon_{l}\left|\Phi_{l m}^{p s}\right\rangle
$$

$\operatorname{com} \hat{V}_{l o c}^{p s}=v_{l o c}^{p s} \hat{I}$.

A separação entre as componentes local e não local do pseudopotencial tem como objetivo reduzir o custo computacional, visto que a obtenção da parte não local é a operação mais custosa entre os diferentes termos da Hamiltoniana.

\subsubsection{Pseudopotencial Ultrassuave - USPP}

Nos pseudopotenciais de norma conservada a função de onda de todos os elétrons é substituída, dentro de um raio de corte, por uma pseudofunção suave, sem nós e com a mesma norma, ou seja, que contém a mesma carga nessa região. Após o raio de corte, ambas as funções são idênticas. Para garantir essas condições e uma boa transferibilidade, que reproduza a distribuição de carga e do momento, é necessário que o raio de corte fique próximo ao máximo mais extremo da função de onda de todos os elétrons. Entretanto, os elementos com orbitais muito localizados produzem pseudopotenciais profundos que ainda necessitam de um conjunto grande de ondas planas para serem bem descritos. São exemplos desses elementos 
com orbitais localizados aqueles da primeira coluna da tabela periódica, as terras raras e aqueles que incluem orbital tipo $d$. O aumento do raio de corte permite suavizar ainda mais o pseudopotencial, entretanto compromete a transferibilidade, exigindo testes adicionais para assegurar a qualidade do pseudopotencial nos novos ambientes.

Na regra da soma de Friedel, equação 1.44, relacionada com a transferibilidade, a troca de fase depende da norma da função de onda e, por isso, a conservação da norma foi imposta na construção dos pseudopotenciais. Entretanto, com exceção a essa condição, a norma não é estritamente necessária para a solução da equação de autoconsistência. Vanderbilt [45, 46, 47] demonstrou que removendo a condição de conservação da norma é possível escolher um raio de corte maior, independente do máximo da função de onda, e construir pseudofunções muito mais suaves que nos métodos tradicionais. Isso possibilitou a criação de pseudopotenciais igualmente transferíveis, entretanto muito mais suaves conhecidos como Pseudopotenciais Ultrassuaves - (USPP - "Ultra-Soft Pseudopotential”).

A figura 1.3 ilustra como a pseudofunção para o orbital $2 p$ do oxigênio construída dentro do método HSC, que conserva a norma, é tão localizada quanto a função de todos os elétrons e, por outro lado, como a pseudofunção construída com o método USPP é bem mais suave. Em geral, o raio de corte para o método USPP é maior num fator de 1,5, em relação ao necessário para o método com conservação da norma, permitindo construção de pseudofunções muito mais suaves.

A conservação da norma exige que a diferença entre a densidade de carga da função de onda atômica de todos os elétrons $\Phi_{i l m}^{t e}$ e a pseudofunção de onda atômica $\Phi_{i l m}^{p s}$ seja nula, $Q_{i j}^{l}=0$ onde,

$$
Q_{i j}^{l}=\left\langle\Phi_{i l m}^{t e} \mid \Phi_{j l m}^{t e}\right\rangle_{r_{c}}-\left\langle\Phi_{i l m}^{p s} \mid \Phi_{j l m}^{p s}\right\rangle_{r_{c}}
$$

Vanderbilt demonstrou que a condição $Q_{i j}^{l}=0$ não é necessária se for adotado o 


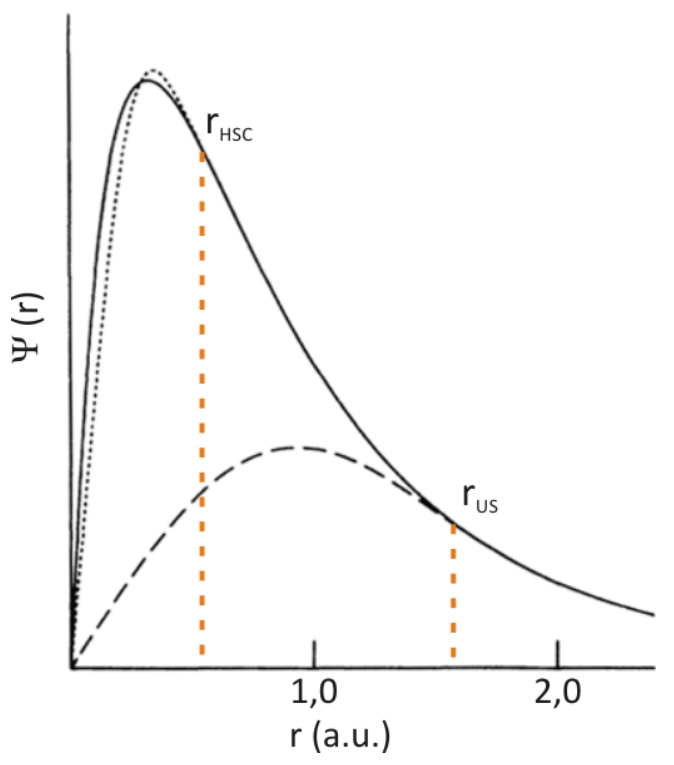

Fig. 1.3: Função de onda radial do orbital $2 p$ do oxigênio (linha sólida) e as correspondentes pseudofunções geradas com os pseudopotenciais de norma conservada HSC (linhas pontilhada) e Ultrassuave (linha tracejada) e seus respectivos raios de corte $r_{H S C}$ e $r_{U S}$. Figura adaptada do trabalho de Vanderbilt (1990) [46]

seguinte operador de sobreposição não local,

$$
\hat{S}=\hat{I}+\sum_{i, j} \sum_{l} \sum_{m=-l}^{l} Q_{i j}^{l}\left|\beta_{i}^{l m}\right\rangle\left\langle\beta_{j}^{l m}\right|
$$

e redefinindo o operador potencial não local como

$$
\Delta \hat{V}_{l}^{U S}=\sum_{i j} D_{i j}^{l-i o n} \sum_{m=-l}^{l}\left|\beta_{i}^{l m}\right\rangle\left\langle\beta_{j}^{l m}\right|,
$$

onde $\left|\beta_{j}^{l m}\right\rangle$ são funções locais definidas por,

$$
\left|\beta_{i}^{l m}\right\rangle=\sum_{j}\left(B^{-1}\right)_{i j}^{l}\left|\chi_{j}^{l m}\right\rangle
$$

$\operatorname{com} B_{i j}^{l}=\left\langle\Phi_{i l m}^{p s} \mid \chi_{j}^{l m}\right\rangle$. Os termos $D_{i j}^{l-i o n}$ são dados por,

$$
D_{i j}^{l-i o n}=B_{i j}^{l}+\varepsilon_{i l} Q_{i j}^{l}
$$

onde $\varepsilon_{i l}$ são os autovalores das pseudofunções atômicas,

$$
\left(\hat{T}+\hat{V}^{p s}\right)\left|\Phi_{i l m}^{p s}\right\rangle=\left(\hat{T}+\hat{V}_{l o c}^{p s}+\Delta \hat{V}_{l}^{p s}\right)\left|\Phi_{i l m}^{p s}\right\rangle=\varepsilon_{i l}\left|\Phi_{i l m}^{p s}\right\rangle .
$$


Com esta definição é possível restabelecer a conservação da norma,

$$
\left\langle\Phi_{i l m}^{t e} \mid \Phi_{j l m}^{t e}\right\rangle_{r_{c}}=\left\langle\Phi_{i l m}^{p s}|\hat{S}| \Phi_{j l m}^{p s}\right\rangle_{r_{c}}
$$

onde o conjunto de pseudofunções atômicas $\left|\Phi_{i l m}^{p s}\right\rangle$ são soluções do problema generalizado de autovalores,

$$
\hat{H}\left|\Phi_{i l m}^{p s}\right\rangle=\varepsilon_{i l} \hat{S}\left|\Phi_{i l m}^{p s}\right\rangle .
$$

Para os cálculos de estrutura eletrônica que utilizam o método de pseudopotencial ultrassuave a densidade de carga, calculada apenas com as pseudofunções, é menor que a densidade de carga total do sistema. Isto ocorre devido a carga deficitária em cada caroço, consequência da não conservação da norma nessa região. Essa diferença na densidade de carga deve ser corrigida para que os termos da Hamiltoniana de Kohn-Sham, que dependem da densidade, sejam descritos corretamente. A correção é feita ao final de cada ciclo de autoconsistência e a densidade corrigida tem a seguinte forma,

$$
\rho_{v}(\mathbf{r})=\sum_{n}^{o c} f_{n}\left[\varphi_{n}(\mathbf{r}) \varphi_{n}^{*}(\mathbf{r})+\sum_{l} \sum_{m=-l}^{l} \sum_{i, j}\left\langle\varphi_{n} \mid \beta_{i}^{l m}\right\rangle Q_{i j}^{l}(\mathbf{r})\left\langle\beta_{j}^{l m} \mid \varphi_{n}\right\rangle\right] .
$$

onde o segundo termo dentro dos colchetes representa toda a correção na densidade de carga devido a não conservação da norma com

$$
Q_{i j}^{l}(\mathbf{r})=\Phi_{i l m}^{t e *}(\mathbf{r}) \Phi_{j l m}^{t e}(\mathbf{r})-\Phi_{i l m}^{p s *}(\mathbf{r}) \Phi_{j l m}^{p s}(\mathbf{r})
$$

Integrando densidade $\rho_{v}$ sobre a condição de normalização $\left\langle\varphi_{n}|\hat{S}| \varphi_{m}\right\rangle=\delta_{n m}$ obtemos o número de elétrons do sistema $N$,

$$
\begin{aligned}
N=\int \rho_{v}(\mathbf{r}) d \mathbf{r} & =\sum_{n}\left[\left\langle\varphi_{n} \mid \varphi_{n}\right\rangle+\sum_{l} \sum_{m=-l}^{l} \sum_{i, j}\left\langle\varphi_{n} \mid \beta_{i}^{l m}\right\rangle Q_{i j}^{l}\left\langle\beta_{j}^{l m} \mid \varphi_{n}\right\rangle\right] \\
& =\sum_{n}\left\langle\varphi_{n}\left|\left(\hat{I}+\sum_{l} \sum_{m=-l}^{l} \sum_{i, j}\left|\beta_{i}^{l m}\right\rangle Q_{i j}^{l}\left\langle\beta_{j}^{l m}\right|\right)\right| \varphi_{n}\right\rangle \\
& =\sum_{n}\left\langle\varphi_{n}|\hat{S}| \varphi_{n}\right\rangle
\end{aligned}
$$


A equação secular autoconsistente mantém a mesma forma da equação 1.58,

$$
\hat{H}\left|\varphi_{n}\right\rangle=\varepsilon_{n} \hat{S}\left|\varphi_{n}\right\rangle
$$

entretanto agora o potencial local inclui as contribuições de Hartree e de troca e correlação das interações entre os elétrons,

$$
v_{l o c}=v_{l o c}^{p s}+v_{H}\left[\rho_{v}\right]+v_{x c}\left[\boldsymbol{\rho}_{v}\right] .
$$

Devido a não localidade do operador de projeção $\hat{S}$, o potencial local $v_{l o c}$ passa a contribuir na parte não local do pseudopotencial, modificando os termos de matriz $D_{i j}^{l-i o n}$ para

$$
D_{i j}^{l}=D_{i j}^{l-i o n}+\int v_{l o c} Q_{i j}^{l}(\mathbf{r}) d \mathbf{r}
$$

$\mathrm{e}$

$$
\Delta \hat{V}^{p s-U S}=\sum_{l} \sum_{i j} D_{i j}^{l} \sum_{m=-l}^{l}\left|\beta_{i}^{l m}\right\rangle\left\langle\beta_{j}^{l m}\right| .
$$

A energia total eletrônica no esquema de pseudopotencial ultrassuave toma a seguinte forma,

$$
E_{e}^{U S}=\sum_{s}\left\langle\phi_{s}\left|-\nabla^{2}+\Delta \hat{V}^{p s-U S}\right| \phi_{s}\right\rangle+\int v_{l o c} n(\mathbf{r}) d \mathbf{r}
$$

Portanto, o pseudopotencial ultrassuave descreve adequadamente a energia total eletrônica, mantendo as condições de transferibilidade, entretanto, necessitando de um conjunto bem menor de ondas planas.

\subsection{Energia total e relaxação estrutural}

A energia total do sistema é obtida somando a energia eletrônica $E_{e}^{U S}$, equação 1.66, à energia de interação entre os núcleos do sistema $E_{n}$,

$$
E_{\text {Tot }}^{U S}=E_{e}^{U S}+E_{n}
$$


onde a energia nuclear se deve apenas às interações coulombianas,

$$
E_{N}=\frac{1}{2} \sum_{\mu} \sum_{v \neq \mu} \frac{Z_{\mu} Z_{v}}{\left|\mathbf{R}_{\mu}-\mathbf{R}_{v}\right|}
$$

sendo $Z$ e $R$, respectivamente, o número atômico e a posição dos íons do sistema. Portanto,

$$
\begin{aligned}
E_{T o t}^{U S}=\sum_{S}\left\langle\phi_{S}\left|-\nabla^{2}+\Delta \hat{V}^{p s-U S}\right| \phi_{s}\right\rangle & +\int v_{l o c} n(\mathbf{r}) d \mathbf{r} \\
& +\frac{1}{2} \sum_{\mu} \sum_{v \neq \mu} \frac{Z_{\mu} Z_{v}}{\left|\mathbf{R}_{\mu}-\mathbf{R}_{v}\right|} .
\end{aligned}
$$

onde $v_{l o c}$ e $\Delta \hat{V}^{p s-U S}$ estão definidos nas equações 1.63 e 1.65 da seção anterior.

Assim, com o formalismo teórico apresentado até o momento é possível obter a energia total do sistema para uma configuração congelada de núcleos. Agora, é necessário um método para relaxar os núcleos na busca do mínimo global desta energia total.

Uma alternativa para obtenção deste mínimo é buscar a configuração que cancele as forças que agem sobre os núcleos. Para tal, resolve-se autoconsistentemente a equação de Kohn-Sham para a configuração fixa de núcleos e calculam-se as forças que agem sobre cada núcleo. De posse dessas forças podemos movimentar os núcleos no sentido de reduzi-las. Repete-se o procedimento para cada nova configuração de núcleos até que as forças sejam menores que a precisão desejada. Ao final do ciclo é obtida a configuração de equilíbrio que leva ao mínimo de energia. Entretanto, este procedimento garante apenas a obtenção do mínimo de energia local e não global da configuração inicial dos núcleos. Na prática, nenhum mecanismo garante que o mínimo global do sistema será atingido, e o que se faz é testar diferentes configurações iniciais e adota-se aquela que tiver o menor mínimo local. 


\subsubsection{Forças sobre os íons}

As forças sobre os íons são determinantes na obtenção da estrutura de equilíbrio e podem ser calculadas derivando a energia com respeito as coordenadas nucleares,

$$
\mathbf{F}_{\mu}=-\frac{\partial E_{T o t}}{\partial \mathbf{R}_{\mu}}
$$

Entretanto, a derivada deve ser feita sobre um funcional mais geral, que inclui a ortonormalidade das funções de onda através da introdução dos multiplicadores de Lagrange $\Lambda_{i j}$,

$$
\Xi=E_{T o t}+\sum_{i j} \Lambda_{i j}\left(\left\langle\psi_{i} \mid \psi_{j}\right\rangle-\delta_{i j}\right)
$$

que toma a seguinte forma quando são utilizadas as pseudofunções ultrassuaves $\varphi$,

$$
\Xi^{U S}=E_{T o t}^{U S}+\sum_{i j} \Lambda_{i j}\left(\left\langle\varphi_{i}|\hat{S}| \varphi_{j}\right\rangle-\delta_{i j}\right)
$$

Dentro da formulação de Hellmann-Feynman [48] a força sobre os íons pode ser escrita como,

$$
\mathbf{F}_{\mu}^{U S}=-\frac{\partial E_{T o t}^{U S}}{\partial \mathbf{R}_{\mu}}+\sum_{i j} \Lambda_{i j}\left\langle\varphi_{i}\left|\frac{\partial \hat{S}}{\partial \mathbf{R}_{\mu}}\right| \varphi_{j}\right\rangle .
$$

O cálculo da força no método de pseudopotencial ultrassuave apresenta termos extras, quando comparado com os métodos de norma conservada, decorrentes da dependência da posição dos núcleos na carga de compensação $Q_{i j}^{l}$ e no operador de projeção $\hat{S}[49,50,51]$.

A partir das forças que agem sobre os núcleos, lança-se mão de um método para movimentar os núcleos na direção de tornar mínimas essas forças dentro do critério de precisão admitido para a convergência.

Diferentemente de algoritmos fundamentados no formalismo de Car e Parrinello (CP) [52], nos quais se estabelece uma pseudodinâmica baseada no formalismo lagrangeano para a movimentação dos graus de liberdade eletrônicos e nucleares 
na busca dos valores de mínimo estruturais e eletrônicos, utilizamos o método de Gradiente Conjugado (CG) [53] para a escolha da direção e intensidade das movimentação na busca do mínimo de energia e posições de equilíbrio.

Com a separação das etapas de cálculo da estrutura eletrônica (passos eletrônicos) e de movimentação dos íons (passos iônicos), a relaxação iterativa do sistema se torna dependente de custosos cálculos computacionais de diagonalizações de matrizes, fazendo-se necessário o emprego de algoritmos que tornem eficiente a convergência para configurações vantajosas sob o aspecto energético, o que é conseguido com a busca direcionada implementada pelo CG. Esta abordagem, enfim, evita elementos potencialmente prejudiciais à eficiência na convergência como as flutuações características do método CP [50, 54]. Além disso, com o aperfeiçoamento das técnicas de paralelização, as operações de diagonalização de matrizes tornam-se menos custosas e, desta forma, métodos com essa perspectiva tornam-se mais vantajosos com respeito ao seu desempenho.

Nas etapas do CG (i) avalia-se inicialmente os valores das forças e energias; sendo, então, (ii) as posições dos íons e dos parâmetros de rede variados na direção das forças calculadas e do tensor de "stress' (como realizado nos algoritmos de Steepest Descent [53]), recalculando-se as forças e energias; a partir destes dois valores de força e energia (iii) uma interpolação quadrática nesta superfície de energia potencial (PES - "Potential Energy Surface"), de 3N dimensões, possibilita efetuar a correção da direção de variação das posições atômicas e dos parâmetros de rede [53]. Passos adicionais para melhorar a eficiência do procedimento são incorporados como variações do algoritmo de Brent [55]

\subsubsection{Esquema de supercélula}

O formalismo discutido até o momento foi desenvolvido para descrever sistemas periódicos, entretanto estruturas como superfícies, nanofios, moléculas e nanopartí- 
culas, que não apresentam periodicidade em uma, duas ou três direções, podem ser tratadas dentro do esquema de supercélulas.

No esquema de supercélula, a célula convencional é substituída por uma caixa que contém a estrutura de interesse com uma região de vácuo na direção, ou direções, em que a periodicidade foi quebrada. A imagem da supercélula é, então, reproduzida periodicamente por todo o espaço.

O papel do vácuo é separar as imagens adjacentes para que não interajam e, por isso, devem ser suficientemente grandes. Com isso, a periodicidade da estrutura não é estabelecida na direção separada pelo vácuo, reproduzindo os efeitos dos sistemas não periódicos.

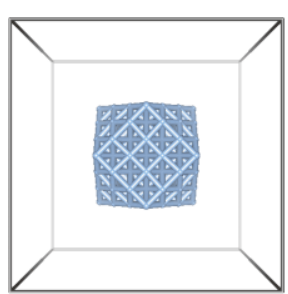

célula unitária

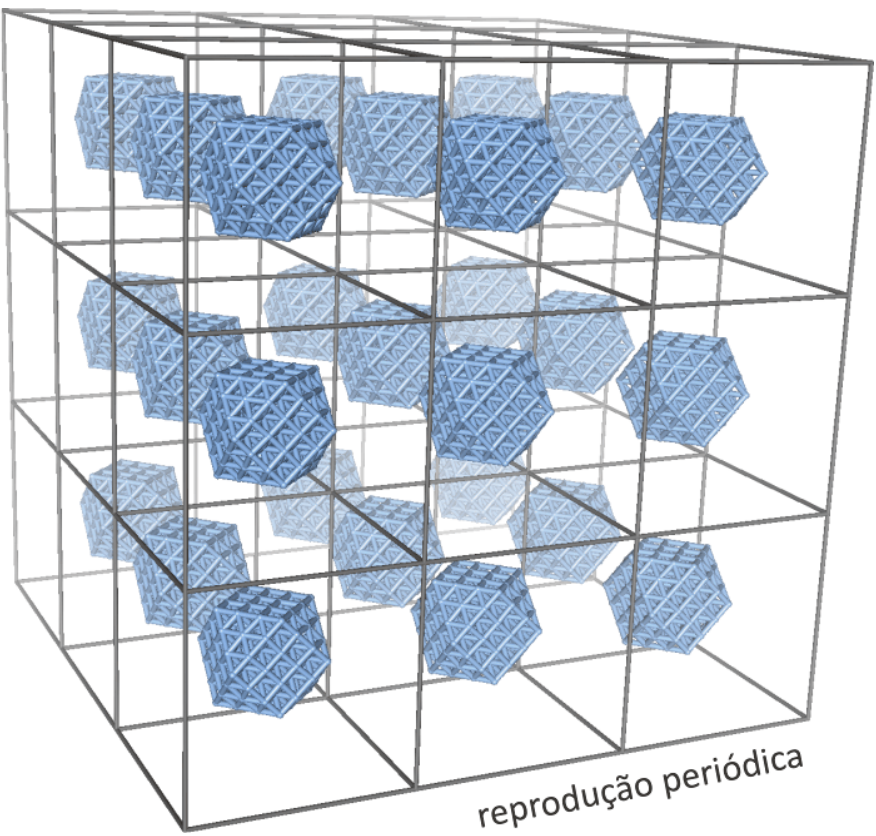

Fig. 1.4: Esquema da supercélula para uma nanopartícula com vácuo por todo o entorno. À esquerda a supercélula que é reproduzida periodicamente e a direita a reprodução de todas as imagens adjacentes à supercélula no centro.

Como uma nanopartícula não possui periodicidade em nenhuma direção, sua supercélula deve ser construída com vácuo em todas as direções, figura 1.4. Com uma região de vácuo suficientemente grande, podemos desprezar as interações da 
nanopartícula com suas imagens e considerar a nanopartícula isolada.

\subsection{Estudo vibracional}

O cálculo de autofrequências e dos modos de vibração correspondentes, associados aos sinais dos espectros vibracionais, pode ser realizado por meio do uso do cálculo de dipolos dinâmicos [56, 57], e através das forças de Helmann-Feynman, dentro do esquema da DFT.

Utilizamos em nossos cálculos a metodologia de construção da matriz Hessiana (ou matriz dinâmica), $H_{i j}$, e da aproximação semiclássica.

A partir da força, $F_{\alpha \beta}^{v \mu, \pm}$, que variações de $\pm d$ na direção $v$ (x, y ou z) do átomo $\alpha$ produzem na direção $\mu$ (x, y ou z) do átomo $\beta$, constrói-se a matriz $K_{\alpha \beta}^{\nu \mu}$ (simétrica),

$$
K_{\alpha \beta}^{v \mu}=\frac{1}{2} \frac{F_{\alpha \beta}^{v \mu,+}-F_{\alpha \beta}^{v \mu,-}+F_{\beta \alpha}^{\mu v,+}-F_{\beta \alpha}^{\mu \nu,+}}{2 d} .
$$

que representa a constante elástica do sistema.

Renumerando os termos da matriz $K_{\alpha \beta}^{\nu \mu}$, de maneira a mapeá-la em uma matriz com dois índices, $H_{i j}$, temos a matriz:

$$
H_{i j}=H_{3(\alpha-1)+v, 3(\beta-1)+\mu}=K_{\alpha \beta}^{v \mu}
$$

Assim, os índices da Hessiana, $H_{i j}$, variam de $1 \leq(i, j) \leq 3 N$, consistindo-se em uma matriz simétrica, cuja construção depende de $6 \mathrm{~N}$ cálculos de forças de Helmann-Feynman - obtidas para cada um dos deslocamentos $( \pm d)(2)$ em cada coordenada cartesiana (3) de cada um dos $\mathrm{N}$ átomos do sistema, realizados independentemente e acumulados nos termos da matriz.

Considerando-se a aproximação semiclássica no movimento oscilatório dos íons, a equação de Newton para osciladores pode ser escrita em termos da formulação Hessiana por,

$$
M \frac{d^{2}}{d t^{2}} \mathbf{u}=-H \mathbf{u}
$$


Onde $\mathrm{M}$ é uma matriz diagonal com $3 \mathrm{~N}$ coordenadas para cada um dos $\mathrm{N}$ átomos de um mesmo elemento inseridos no sistema (devidamente ordenados). O vetor $\mathbf{u}$ consiste no deslocamento dos átomos do sistema em relação à base cartesiana.

Impondo uma solução harmônica para a dinâmica resultante sobre cada um dos deslocamentos observados para os átomos, $\mathbf{u}=\mathbf{z} e^{i \omega t}$,

$$
H \mathbf{z}=\omega^{2} M \mathbf{z}
$$

A equação 1.76 pode ser colocada na forma de uma equação de autovalores ortogonais com a mudança de base: $q_{i}=M^{1 / 2} z_{i}$. Onde $q_{i}$ são conhecidas como coordenadas normais. A mudança entre as bases $\left\{q_{i}\right\}$ e $\left\{z_{i}\right\}$ é simplificada já que M é diagonal.

Com essa transformação as energias cinética e potencial passam a serem escritas como,

$$
T=\frac{1}{2} \sum_{i=1}^{3 N} \frac{d}{d t} q_{i}^{2} ; U=\frac{1}{2} \sum_{i=1}^{3 N} \omega^{2} q_{i}^{2}
$$

A intensidade emitida pelo $i$-ésimo modo normal de oscilação de um sistema é dada em termos do vetor momento de dipolo $\mu$ por $[56,57]$,

$$
I_{i}=\gamma\left|\frac{\partial \mu}{\partial q_{i}}\right|^{2} \text {. }
$$

Onde $\gamma$ consiste de fatores sensíveis a aspectos dos experimentos considerados, não sendo necessário o conhecimento à princípio, desde que se esteja interessado na análise da intensidade relativa entre os picos dos espectros calculados.

A avaliação de derivadas como essa em termos das coordenadas normais utilizando os deslocamentos cartesianos $x_{\tau}$ (na componente $\tau-\mathrm{x}$, y ou z) pode ser estendida por:

$$
\frac{\partial \mu_{v}}{\partial q_{i}}=\sum_{\alpha=1}^{N} \sum_{\tau=1}^{3} \frac{\partial \mu_{v}^{\alpha}}{\partial x_{\tau}} z_{i, 3(\alpha-1)+\tau}
$$

Onde temos a determinar a $\nu$-ésima componente de $\mu$ no átomo $\alpha$, sendo possível 
calcular usando-se o esquema de diferença finita,

$$
\frac{\partial \mu_{v}^{\alpha}}{\partial x_{\tau}}=\frac{\mu_{v}\left(x_{\tau}^{\alpha}+d\right)-\mu_{v}\left(x_{\tau}^{\alpha}-d\right)}{2 d}
$$

\subsection{Pacote de simulação Vienna Ab-Initio - VASP}

Todo o formalismo apresentado está implementado no pacote de simulação Vienna Ab-initio (VASP - "Vienna Ab-initio Simulation Package") [50, 58], desenvolvido para realizar simulações de dinâmica molecular quântica de primeiros princípios, utilizando a teoria do funcional da densidade. Neste trabalho utilizamos a versão 4.6 .28 


\section{Capítulo 2}

\section{Construção das nanopartículas}

Neste capítulo apresentaremos as nanopartículas (NPs) de prata estudadas, em suas formas estruturais não relaxadas estruturalmente e os processos de construção. $\mathrm{Na}$ literatura, as nanopartículas metálicas se apresentam em diferentes formatos e tamanhos. Podem ser tridimensionais, semelhantes a esferas, cubos, octaedros, dodecaedros entre outros poliedros [59, 60, 61, 62], ou bidimensionais, semelhantes a triângulos, quadrados e outros polígonos [22, 63].

Apesar de muitos estudos sugerirem qual seria a estrutura mais estável para determinado número de átomos $[64,65,66,67,68,69]$, outros trabalhos observam que tanto o formato como o empacotamento podem ser induzidos pelo método de crescimento utilizado em sua síntese $[24,59,70,71,72,73]$.

Em virtude da ligação metálica, os átomos têm liberdade para se arranjarem em um empilhamento compacto, apresentando um grande número de primeiros vizinhos e consequente alta densidade. Por isso, os metais geralmente se cristalizam na estrutura cúbica de face centrada (FCC - "Face Centered Cubic") ou hexagonal compacta (HCP - "Hexagonal Close-Packed "), conforme figura 2.1, que apresentam um fator de empacotamento de 0,74 com 12 primeiros vizinhos [74].

No cristal de prata os átomos se arranjam na configuração FCC, sendo esperado 

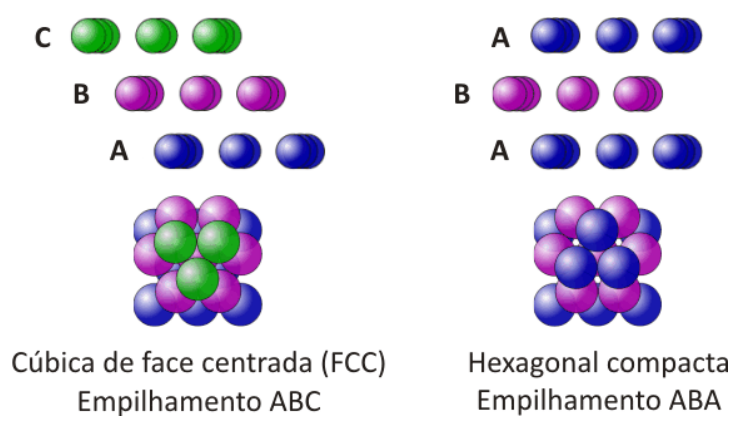

Fig. 2.1: Representação do empilhamento dos átomos das estruturas cristalinas FCC e HCP. Figura reproduzida de Christophe Dang Ngoc Chan (http://en.wikipedia.org/wiki/File:Empilement_compact.svg).

que os átomos nas nanopartículas maiores se aproximem desta configuração. Por outro lado, para os pequenos aglomerados não existe a restrição da periodicidade cristalina, possibilitando outras formas de agrupamentos. Estes agrupamentos podem ser simétricos como nas estruturas icosaédricas, que correspondem a sólidos regulares, ou não apresentar simetria bem definida $[69,75,76]$.

Os aglomerados sem simetria definida ocorrem pela agregação dos átomos em estruturas sem ordenamento claro, ou ainda, pela formação de estruturas com uma variedade de simetrias locais distintas na mesma nanopartícula.

Neste trabalho realizamos o estudo apenas das estruturas simétricas, que serão identificadas pelo número total de átomos e formato. O termo nanopartícula será utilizado de forma genérica para representar qualquer uma das estruturas estudadas, independentemente do tamanho.

As nanopartículas foram construídas tendo como base a geometria cúbica de face centrada (FCC) a partir de cortes do cristal perfeito e, também, na geometria icosaédrica (ico), que não é derivada de cortes sobre a estrutura cristalina. Nos casos baseados na estrutura FCC, construímos as nanopartículas a partir de cortes do cristal nos formatos octaedros (oct), octaedros-truncados (t-oct) e cubo-octaedros (c-oct). Os sólidos poliédricos regulares estão representados na figura 2.2. Também construímos as nanopartículas a partir de cortes esféricos centrados em um átomo 
da rede cristalina, que serão apresentados com mais detalhes na seção 2.2.

(a)

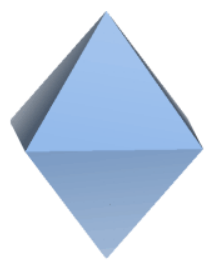

(b)

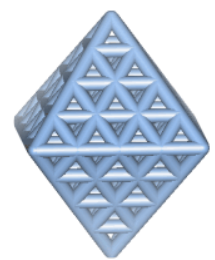

oct
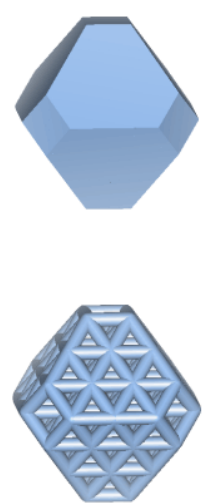

t-oct
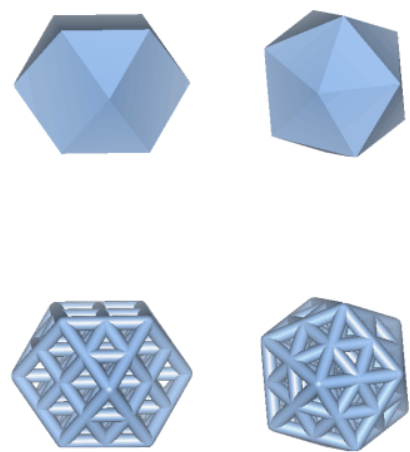

C-oct

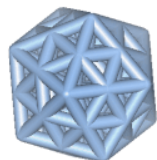

ico

Fig. 2.2: Representação dos sólidos regulares (a): octaedro (oct), octaedro truncado (t-oct), cubo-octaedro (c-oct) e icosaedro (ico); (b) Exemplos do arranjo dos átomos nas nanopartículas com as simetrias correspondentes.

Na figura 2.3 é possível identificar que a nanopartícula cubo-octaédrica de 309 átomos, estudada neste trabalho, é compatível com a imagem de uma nanopartícula de prata obtida por microscopia eletrônica de alta resolução (HREM - "High Resolution Electron Microscopy") [77], justificando, assim, a escolha do método de construção empregado. A nanopartícula apresenta claramente a família de planos [110] da rede cristalina FCC.

O átomo de prata na estrutura cristalina apresenta 12 primeiros vizinhos, ou seja, número de coordenação 12. Nas superfícies das nanopartículas os átomos podem apresentar sítios não equivalentes com coordenação entre 3 e 11, devido aos cortes que reduzem a primeira vizinhança dos átomos da superfície. Neste trabalho, consideramos como átomos de superfície aqueles que não apresentam a coordenação 12 do cristal. Por simplicidade, um sítio de coordenação 5, por exemplo, será identificado como "sítio c5" ou apenas c5. A figura 2.4 apresenta os sítios não equivalentes presentes nas superfícies das nanopartículas estudadas. 


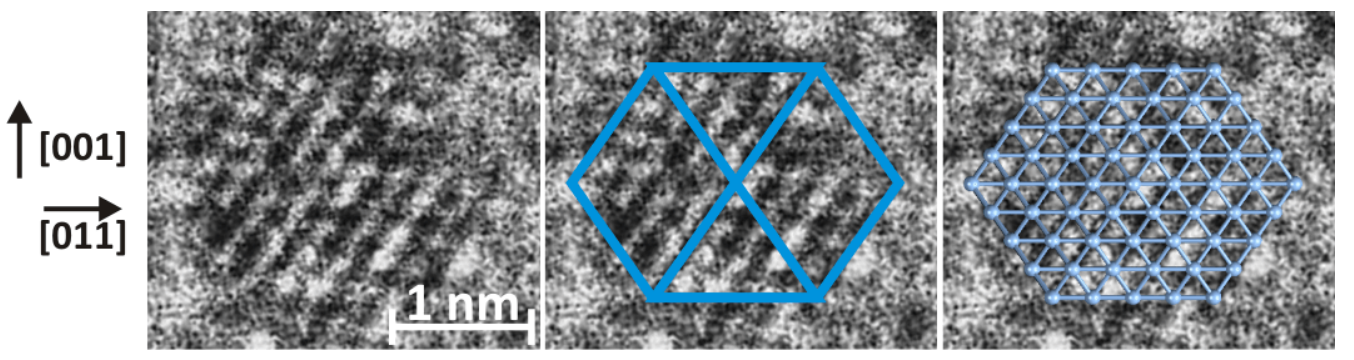

Fig. 2.3: Comparação entre a nanopartícula cubo-octaédrica de 309 átomos estudada neste trabalho com a imagem obtida por HREM [77]. As linhas azuis, sobrepostas à imagem na nanopartícula ao centro, representam as silhuetas da NP 309. As silhuetas correspondem às arestas que separam os planos [001] e [111] presentes na superfície desta nanopartícula. Na figura à direita, temos a representação dos átomos e ligações da NP 309 sobreposta à mesma imagem HREM.

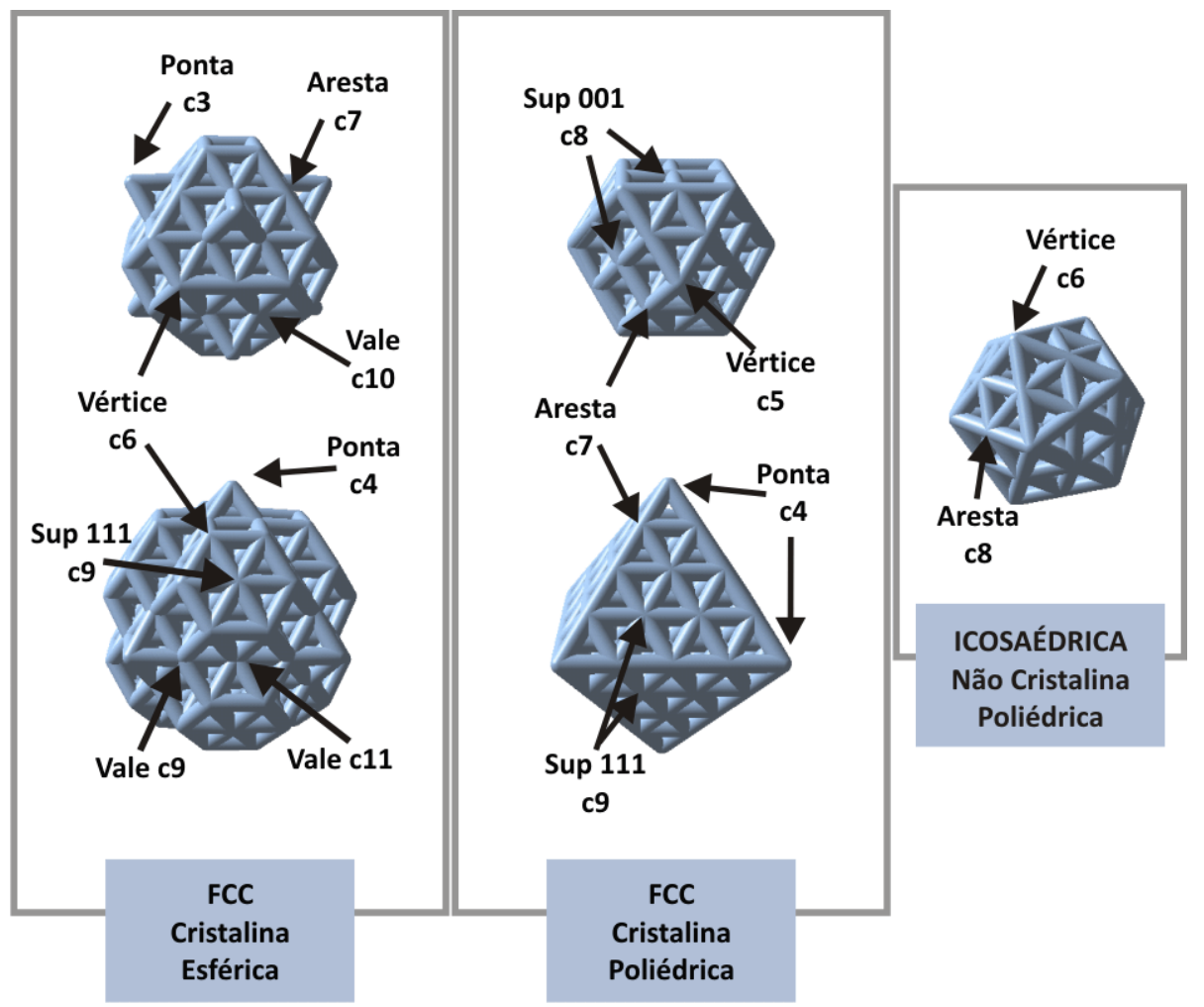

Fig. 2.4: Representação dos diferentes sítios presentes nas nanopartículas baseadas na estrutura FCC e icosaédrica. Os números nas indicação c3 à c11 correspondem às coordenações dos sítios, ou seja, ao número de primeiros vizinhos. 


\subsection{Nanopartículas poliédricas}

Uma propriedade das nanopartículas poliédricas é a baixa rugosidade de suas superfícies, compostas por planos de átomos semelhantes às superfícies [001] e [111]. As superfícies das nanopartículas poliédricas não apresentam degraus ou vales e são caracterizadas por 3 ou 4 sítios distintos decorrentes dos vértices, arestas e planos presentes nas superfícies.

Os átomos nos vértices das nanopartículas poliédricas apresentam coordenação c4 para as NPs oct, c5 para as c-oct ou c6 para as t-oct e ico. Os átomos das arestas apresentam coordenação c7 para as NPs oct, c-oct e t-oct, ou c8 para as ico. Os átomos das superfícies podem apresentar coordenação c8 para as NPs oct, c-oct e toct, que é semelhante à coordenação presente no corte da superfície [001] do cristal de prata, e c9 para todas as nanopartículas poliédricas estudadas, que, por sua vez, é semelhante ao sítio presente na superfície [111] da prata. Todos estes sítios estão representados na figura 2.4 .

Os sítios c6 e c7 da nanopartícula octaédrica truncada são equivalentes àqueles indicados nas NPs FCC esféricas da figura 2.4. Os sítios c8 e c9 são equivalentes àqueles indicados nas NPs FCC poliédricas na mesma figura.

Os sítios c4 possuem todos os seus primeiros vizinhos na superfície da nanopartícula, enquanto que os sítios c5 e c6 apresentam um vizinho no interior e os demais vizinhos na superfície.

Os sítios c7 estão presentes nas arestas do encontro de duas superfícies. Podem se formar do encontro de duas superfícies [111], apresentando um sítio vizinho no interior e os outros seis vizinhos na superfície, ou podem se formar do encontro da superfície [111] com a superfície [001], apresentando dois vizinhos no interior e os outros cinco na superfície.

Os sítios c8 presentes nas arestas das nanopartículas icosaédricas apresentam 
dois vizinhos no interior e seis na superfície. Já os sítios c8 presentes nas superfícies [001] das nanopartículas derivadas da estrutura FCC apresentam quatro vizinhos no interior da nanopartícula e os outros quatro na superfície.

Os sítios c9, por sua vez, possuem três vizinhos no interior da nanopartícula e os outros seis na superfície.

Como as nanopartículas poliédricas crescem por camadas, cobrindo por completo com uma camada de átomos a nanopartícula anterior de mesmo formato, também podem ser identificadas pelo número de camadas utilizadas na construção.

Nas tabelas 2.1, 2.2 e 2.3 apresentamos alguns parâmetros geométricos das nanopartículas poliédricas não relaxadas, derivados analiticamente em virtude de seu arranjo regular. São tabulados o diâmetro, área, volume (tab. 2.1); número total de átomos e número de átomos na superfície (tab. 2.2); quantidade de cada tipo de sítio na superfície, separados por suas coordenações (tab. 2.3).

Todas estes parâmetros apresentam regularidades e são dados em função do número de camadas $k$ e da distância de ligação entre os átomos $d$. Assumimos para o valor de $d$ a distância interatômica que obtivemos para o cristal de prata $(2,94 \AA$ apêndice C). Vale ressaltar que estes parâmetros são gerais para qualquer material com estrutura FCC ou icosaédrica, utilizando apenas o parâmetro $d$ do material escolhido.

Como as menores nanopartículas, com apenas uma ou duas camadas de átomos utilizadas na construção, não apresentam todos os átomos distintos característicos do seu formato nas nanopartículas maiores, podemos aferir que estas nanopartículas não representam estruturalmente as nanopartículas maiores. Entretanto com a inclusão de mais uma ou duas camadas, a superfície dessas nanopartículas já passam a apresentar todos os sítios distintos que são característicos do seu formato. Assim, com poucas camadas já se aproximam estruturalmente das nanopartículas maiores com o mesmo formato. 
Tab. 2.1: Diâmetro, área e volume das nanopartículas poliédricas não relaxadas, conforme o número de camadas $k$ e a distância de ligação $d$ entre os átomos utilizadas na construção da nanopartícula.

\begin{tabular}{|c|c|c|c|}
\hline Corte & diam $(\mathrm{nm})$ & área $\left(\mathrm{nm}^{2}\right)$ & volume $\left(\mathrm{nm}^{3}\right)$ \\
\hline oct-i & $\sqrt{2}(2 k) d$ & $2 \sqrt{3}(2 k)^{2} d^{2}$ & $\frac{1}{3} \sqrt{2}(2 k)^{3} d^{3}$ \\
oct-p & $\sqrt{2}(2 k-1) d$ & $2 \sqrt{3}(2 k-1)^{2} d^{2}$ & $\frac{1}{3} \sqrt{2}(2 k-1)^{3} d^{3}$ \\
t-oct & $2\left(k^{2}+2 k+2\right)^{\frac{1}{2}} d$ & $2 \sqrt{3}\left[(\sqrt{3}+1) k^{2}+8 k+4\right] d^{2}$ & $\frac{1}{3} \sqrt{2}\left(5 k^{3}+24 k^{2}+24 k+8\right) d^{3}$ \\
c-oct & $2 k d$ & $2 \sqrt{3}(\sqrt{3}+1) k^{2} d^{2}$ & $\frac{5}{3} \sqrt{2} k^{3} d^{3}$ \\
ico & $2 k d$ & $5 \sqrt{3} k^{2} d^{2}$ & $\frac{5}{12}(3+\sqrt{5}) k^{3} d^{3}$ \\
\hline
\end{tabular}

Tab. 2.2: Número total de átomos (at $\left.t_{t o t}\right)$ e número de átomos na superfície $\left(\mathrm{at}_{\text {sup }}\right)$ das nanopartículas poliédricas, conforme o número de camadas $k$ utilizadas na sua construção.

\begin{tabular}{|c|c|c|}
\hline Corte & at $_{\text {tot }}$ & at $_{\text {sup }}$ \\
\hline oct-i & $\frac{1}{3}\left[2(2 k)^{3}+6(2 k)^{2}+7(2 k)+3\right]$ & $4(2 k)^{2}+2$ \\
oct-p & $\frac{1}{3}\left[2(2 k-1)^{3}+6(2 k-1)^{2}+7(2 k-1)+3\right]$ & $4(2 k-1)^{2}+2$ \\
t-oct & $\frac{1}{3}\left(10 k^{3}+63 k^{2}+107 k+57\right)$ & $10 k^{2}+32 k+18$ \\
t-oct & $\frac{1}{3}\left(10 k^{3}+15 k^{2}+11 k+3\right)+6\left(8 k^{2}+16 k+9\right)$ & $10 k^{2}+2+16(2 k+1)$ \\
c-oct & $\frac{1}{3}\left(10 k^{3}+15 k^{2}+11 k+3\right)$ & $10 k^{2}+2$ \\
ico & $\frac{1}{3}\left(10 k^{3}+15 k^{2}+11 k+3\right)$ & $10 k^{2}+2$ \\
\hline
\end{tabular}

Tab. 2.3: Quantidade de cada espécie de sítio presente na superfície das nanopartículas poliédricas conforme o número de camadas $k$ utilizadas na sua construção. Os sítios são diferenciados pelo número de coordenação com a sua vizinhança.

\begin{tabular}{|c|c|c|c|c|c|c|}
\hline- & $\mathrm{c} 4$ & $\mathrm{c} 5$ & $\mathrm{c} 6$ & $\mathrm{c} 7$ & $\mathrm{c} 8$ & $\mathrm{c} 9$ \\
\hline oct-i & 6 & - & - & $12[(2 k)-1]$ & - & $\frac{8}{2}\left[(2 k)^{2}-3(2 k)+2\right]$ \\
oct-p & 6 & - & - & $12[(2 k-1)-1]$ & - & $\frac{8}{2}\left[(2 k-1)^{2}-3(2 k-1)+2\right]$ \\
t-oct & - & - & 24 & $\frac{24}{2}(2 k-1) / 3$ & $6(k-1)^{2}$ & $\frac{8}{2} k(k+5)$ \\
c-oct & - & 12 & - & $24(k-1)$ & $6(k-1)^{2}$ & $\frac{8}{2}\left(k^{2}-3 k+2\right)$ \\
ico & - & - & 12 & - & $30(k-1)$ & $\frac{20}{2}\left(k^{2}-3 k+2\right)$ \\
\hline
\end{tabular}




\subsubsection{Nanopartículas octaédricas}

As nanopartículas octaédricas (oct) podem ser construídas centradas em um átomo da rede cristalina ou centradas na região intersticial entre os átomos da rede. Quando apresentam o átomo no centro, possuem número total ímpar de átomos, sendo denominadas neste trabalho como octaédricas-i, ou oct-i. Se construídas com o interstício no centro possuem um número total par de átomos e serão denominadas como octaédricas-p, ou oct-p.

Os índices i e p serão convenientemente omitidos quando o número total de átomos for apresentado, já que no número total de átomos já está subentendido se a nanopartícula é do tipo p ou i. As propriedades geométricas das estruturas não relaxadas, em função do número de camadas $k$ utilizadas na construção, estão apresentadas nas tabelas 2.1, 2.2, 2.3.

Apesar das nanopartículas oct-i e oct-p terem os seus centros distintos, suas superfícies são muito parecidas. Em ambos os casos, possuem 8 faces triangulares com terminação c9 em sua superfície, equivalente à superfície [111] da rede cristalina FCC, 12 arestas composta por sítios c7 e 6 vértices com coordenação c4. A evolução do número total destes sítios na superfície com o aumento da nanopartícula, representada nos gráficos da figura 2.5 , também demonstra que ambas as estruturas, oct-i ou oct-p, são geometricamente equivalentes.

O número de sítios c4 na superfície das nanopartículas não muda com o tamanho, pois correspondem aos seis vértices da estrutura octaédrica. A quantidade dos sítios c7, por comporem as arestas, cresce linearmente com o diâmetro da nanopartícula. Já a quantidade de sítios c9, por constituírem os planos na superfície, cresce com o quadrado do diâmetro e, consequentemente, se tornam predominantes na superfície com o aumento da nanopartícula.

Para as nanopartículas octaédricas com cerca de 2,5 nm, os sítios c9 já estão em maior número que os demais. Nas nanopartículas com diâmetros da ordem 

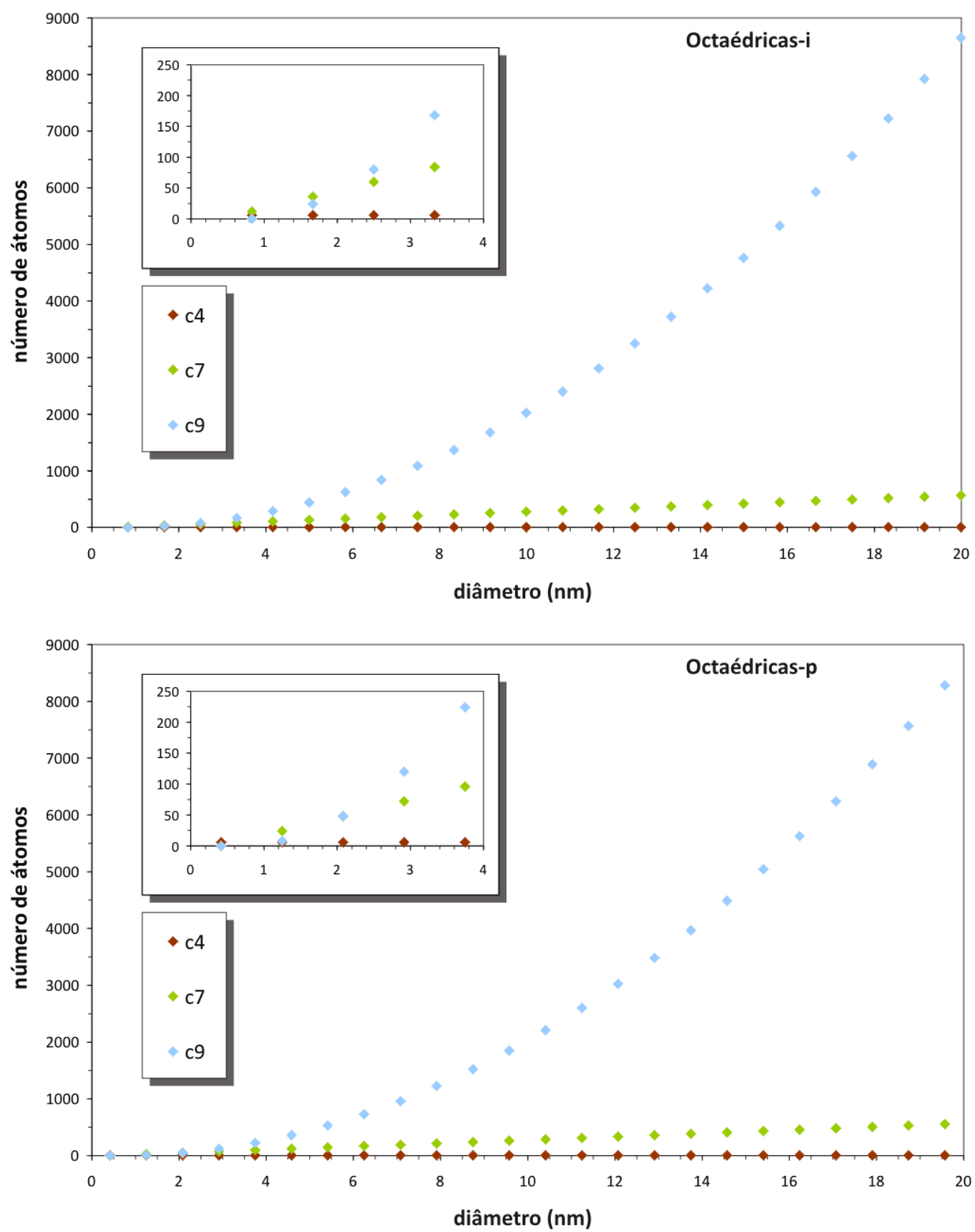

Fig. 2.5: Evolução da quantidade de cada sítio distinto presente na superfícies das NPs oct i e oct p com o aumento do diâmetro. O gráfico superior corresponde às NPs oct-i e o gráfico inferior às NPs oct-p. Em destaque a região até $4 \mathrm{~nm}$ que compreende a faixa de diâmetros das nanopartículas estudadas neste trabalho. Os pontos em marrom correspondem aos sítios c4, em verde aos sítios c7 e em azul aos sítios c9. 
de $5 \mathrm{~nm}$, os sítios c9 correspondem a cerca de $75 \%$ dos átomos da superfície, e chegam a representar mais que $90 \%$ para diâmetros da ordem de $15 \mathrm{~nm}$.

Na figura 2.6 estão representadas as nanopartículas oct-p e oct-i com até 03 camadas utilizadas na construção. Podemos observar que a NP 006 é composta apenas de sítios c4, ainda não apresentando os sítios c7 e c9 característicos deste formato em nanopartículas maiores.

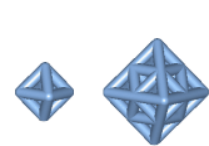

006

(1p)

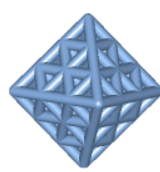

044

(2p)

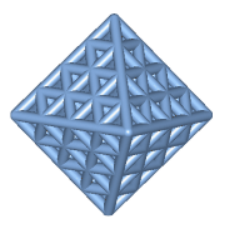

085

(2i)

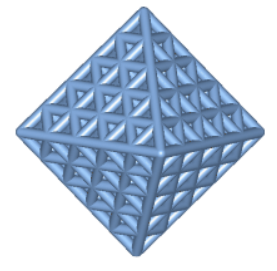

146

(3p)

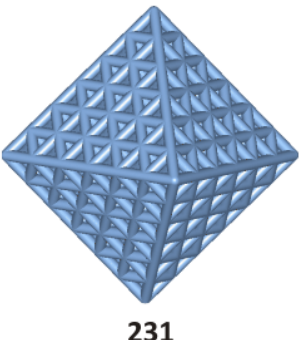

(3i)

Fig. 2.6: Nanopartículas octaédricas estudadas, com o número total de átomos e, entre parênteses, o número de camadas utilizadas na construção. O índice $p$ representa o conjunto de nanopartículas que estão centradas no interstício (apresentam número par de átomos oct-p) e o índice $i$ indica o conjunto das nanopartículas que são centradas em um átomo (apresentam número ímpar de átomos - oct-i).

Na NP 019, além dos sítios c4 nos vértices, já estão presentes o sítios c7 das arestas. Os sítios c9 passam a estar presentes à partir da NP 044. Apesar das coordenações destes sítios se manterem com o aumento da nanopartícula, suas vizinhanças mudam. Por exemplo, a vizinhança dos sítios c4 na NP 006 são sítios c4, enquanto que na NP 019 a vizinhança dos sítios c4 são sítios c7. Análise semelhante a esta pode ser estendida para os sítios c7 e c9.

Em geral, as nanopartículas maiores apresentam em sua superfície sítios com a mesma coordenação, entretanto, com vizinhanças bem distintas. A NP 231, por exemplo, apresenta três sítios c9 diferentes em cada uma das faces triangulares [111]. Um dos tipos de sítio c9 está localizado bem no centro da face com seis vizinhos na superfície também de coordenação c9. Estes seis vizinhos, por sua vez, 
são distintos do primeiro pois apresentam quatro vizinhos c9 e dois vizinhos c7. Por último, os sítios c9 que estão mais próximos aos vértices, apresentam dois vizinhos c9 e quatro vizinhos c7.

\subsubsection{Nanopartículas octaédricas truncadas}

As nanopartículas octaédricas truncadas ( $\mathrm{t}$-oct), como o próprio nome sugere, podem ser construídas a partir de truncamentos da nanopartícula octaédrica. A figura 2.7 representa os truncamentos possíveis realizados na NP 231 oct-i.

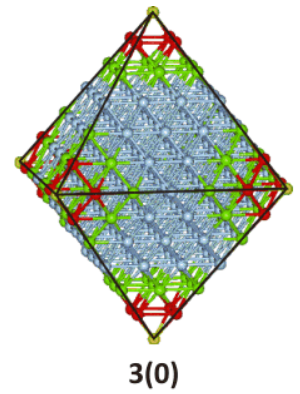

oct

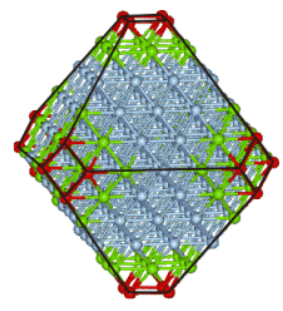

$3(1)$

t-oct

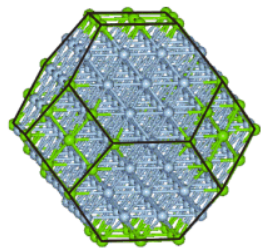

$3(2)$

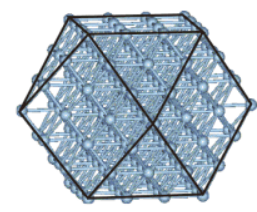

3(3)

c-oct

Fig. 2.7: Truncamentos da nanopartícula octaédrica. No índice $k(t)$ utilizado abaixo de cada figura o valor de $k$ indica o número de camadas utilizada na construção da nanopartícula octaédrica de referência e o valor de $(t)$ indica o número de camadas retirada das pontas para se obter a estrutura truncada. Em amarelo os átomos retirados da nanopartícula octaédrica no primeiro truncamento, em vermelho os átomos retirados no segundo truncamento e em verde os átomos retirados no terceiro truncamento. As linhas pretas representam as arestas dos encontros entre os planos presentes nas superfícies destas nanopartículas.

No primeiro truncamento $(t=1)$ são excluídos os átomos dos seis vértices, formando seis novos planos de átomos nas direções [001]. Apesar dos planos estarem nas direções [001], ainda não apresentam os sítios c8 característicos das superfícies [001]. Cada um dos seis planos obtidos pelo primeiro truncamento corresponde a quatro vértices com sítios c6.

O segundo truncamento $(t=2)$ é obtido pela exclusão destes seis planos formados pelo primeiro truncamento. Isso corresponde à exclusão de 24 átomos (6 
planos x 4 átomos por plano) e a formação de seis novos planos compostos por nove átomos. Cada plano de nove átomos já apresenta um sítio c8 característico da superfície [001].

O terceiro truncamento $(t=3)$ é obtido pela exclusão dos seis planos de nove átomos, formando seis novos planos com 16 átomos cada.

Para a NP 231 oct-i, que é construída com três camadas $(k=3)$, são possíveis apenas estes três truncamentos. Os dois primeiros truncamentos formam as nanopartículas t-oct, enquanto o terceiro forma a nanopartícula c-oct.

De maneira geral, uma nanopartícula octaédrica-i com $k$ camadas pode realizar os truncamentos até $t=k$, os truncamentos $t=k-1$ formam nanopartícula octaédricas truncadas e o truncamento $t=k$ forma a nanopartícula cubo-octaédrica. Já para as nanopartículas octaédricas-p são possíveis apenas até $t=k-1$ truncamentos e, consequentemente, não podem ser utilizadas para formar nanopartículas cubo-octaédricas.

Como decorrência dos truncamentos das NPs oct, a superfície das nanopartículas t-oct é composta por 06 faces quadradas e 08 faces hexagonais, correspondendo, respectivamente, às superfícies [001] e [111] da geometria FCC. Como podem ser construídas a partir dos cortes das nanopartículas oct-p ou oct-i, também serão, respectivamente, centradas no interstício entre os átomos da rede FCC e com número total par de átomos (t-oct-p), ou centradas em um átomo da rede FCC e com número total ímpar de átomos (t-oct-i).

As propriedades geométricas referentes às estruturas não relaxadas, em função do número de camadas $k$ utilizadas nas construções, foram apresentadas nas tabelas 2.1, 2.2, 2.3 para o truncamento do tipo $t=k-1$ e a evolução dos sítios distintos da superfície está representada na figura 2.8. Para este truncamento podemos observar que os sítios c8 e c9 são predominantes para as nanopartículas, se apresentando em quantidades praticamente equivalentes até cerca de $15 \mathrm{~nm}$. Acima deste diâ- 


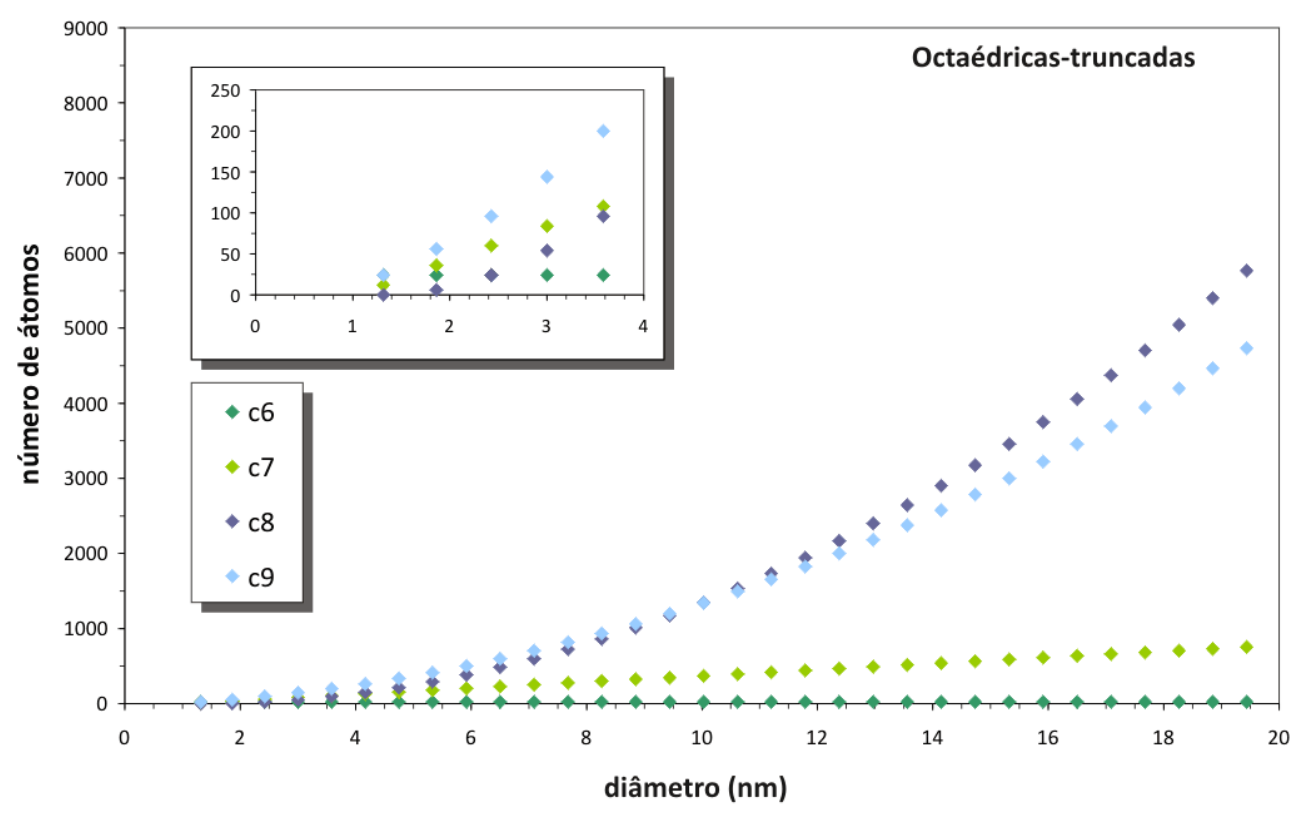

Fig. 2.8: Evolução dos sítios distintos presentes na superfície das nanopartículas octaédricas truncadas

metro a diferença entre a quantidades destes sítios na superfície passa a ser mais significativa, prevalecendo os sítios de coordenação c8.

\subsubsection{Nanopartículas cubo-octaédricas}

As nanopartículas cubo-octaédricas (c-oct) são construídas ao redor de um átomo central da rede cristalina FCC da prata e apresentam na superfície 12 vértices, 24 arestas, 06 superfícies quadradas tipo [001] e 8 superfícies triangulares tipo [111], respectivamente com os sítios c5, c7, c8 e c9. Suas propriedades geométricas referentes as estruturas não relaxadas, em função do número de camadas $k$ utilizadas nas construção, foram apresentadas nas tabelas 2.1, 2.2, 2.3.

De acordo com a evolução dos sítios, representada na figura 2.9, observamos que os sítios c8 e c9 são predominantes para as nanopartículas maiores, devido ao crescimento quadrático das superfícies [001] e [111], com maior presença do sítio c8. A partir da terceira camada de átomos utilizada na construção, a superfície já 
apresenta todos os sítios característicos das NPs c-oct.

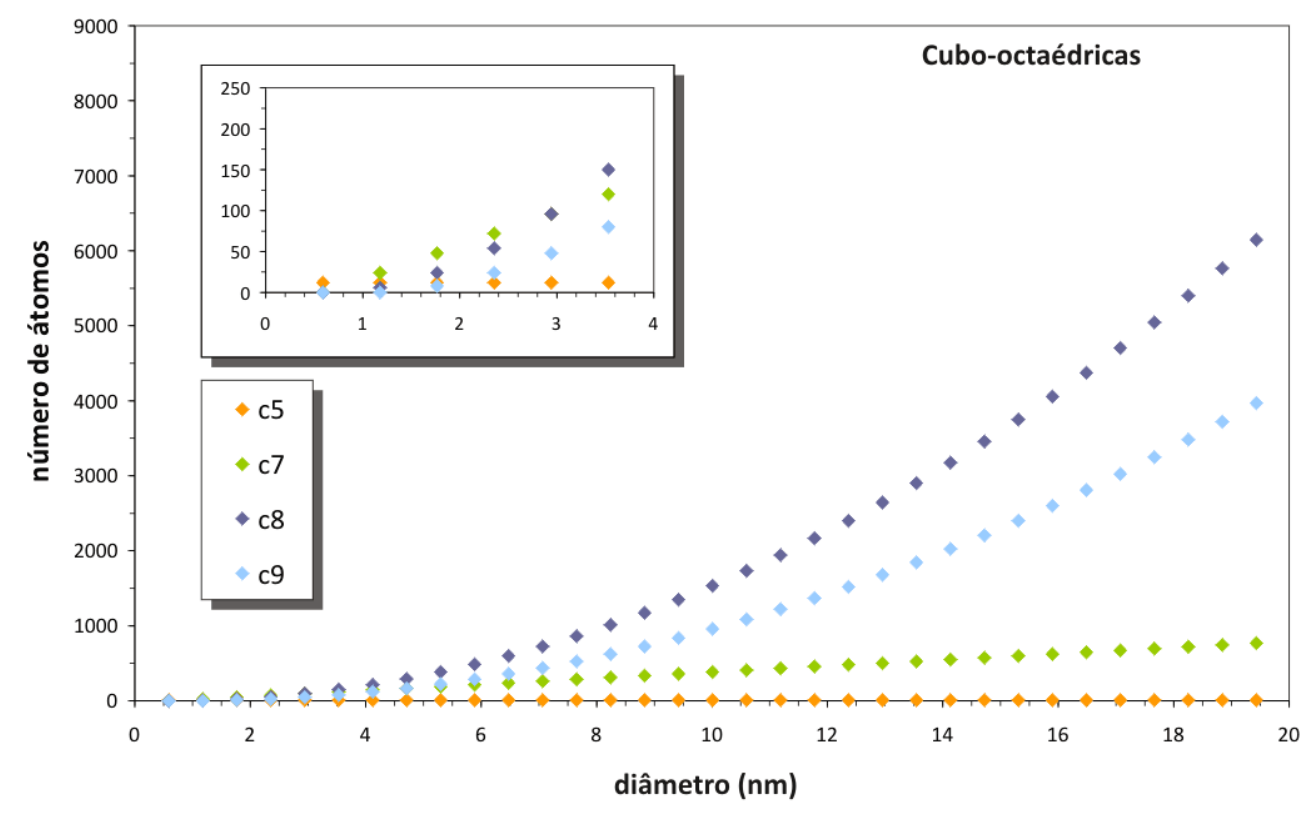

Fig. 2.9: Evolução dos sítios distintos presentes na superfície das nanopartículas cubooctaédricas

As NPs c-oct estudadas foram construídas considerando até a quinta camada de átomos e estão representadas na figura 2.10.
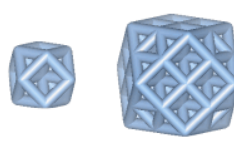

13

(1)

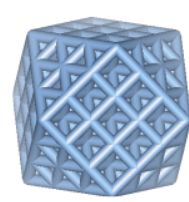

(3)

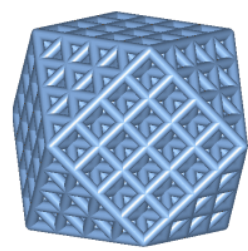

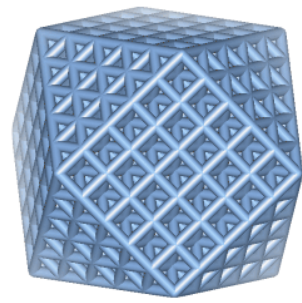

561

(5)

Fig. 2.10: Nanopartículas cubo-octaédricas estudadas, com o número total de átomos e, entre parênteses, o número de camadas utilizadas na construção.

A menor nanopartícula cubo-octaédrica é constituída pela primeira camada que recobre integralmente um átomo na configuração $\mathrm{FCC}$, formando uma estrutura com 13 átomos. A próxima nanopartícula cubo-octaédrica é obtida recobrindo a 
primeira com uma segunda camada de átomos, e assim sucessivamente.

\subsubsection{Nanopartícula icosaédrica}

As nanopartículas icosaédricas (ico) não apresentam análogo cristalino e, portanto, sua construção não é realizada a partir de corte da estrutura cristalina, mas sim, pela disposição dos átomos na conformação icosaédrica. Utilizamos como distância entre os átomos da superfície o mesmo valor de distância de ligação obtida para o cristal de prata.

A menor NP icosaédrica é composta de um átomo central e sua primeira vizinhança. Assim, como ocorre para as nanopartículas cubo-octaédricas, essa primeira vizinhança recobre o átomo central com camada de 12 átomos, formando uma nanopartícula com 13 átomos, figura 2.11.

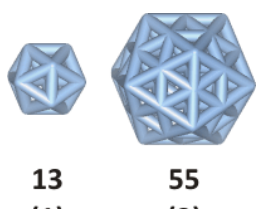

(1) (2)

Fig. 2.11: Nanopartículas icosaédricas (ico) estudadas, com o número total de átomos e, entre parênteses, o número de camadas utilizadas na construção.

As nanopartículas maiores são formadas pela incorporação das sucessivas camadas de átomos que recobrem por completo a nanopartícula anterior. Uma peculiaridade geométrica envolve as NP ico e c-oct, a saber, para cada NP ico existe uma NP c-oct com igual número de átomos no total, na superfície e, consequentemente, no interior.

A estrutura icosaédrica também apresenta 12 vértices como a estrutura c-oct, mas, diferentemente da c-oct, possui 30 arestas e 20 faces triangulares. Os vértices são compostos por sítios c6, as arestas por sítios c8 e as superfícies por sítios c9, semelhante à superfície [111] da estrutura FCC. As propriedades geométricas das 
estruturas não relaxadas, em função do número de camadas $k$ utilizadas nas construção, foram apresentadas nas tabelas 2.1, 2.2, 2.3. Estudamos as NPs ico com uma e duas camadas, representadas na figura 2.11.

\subsubsection{Comparação entre as nanopartículas poliédricas}

Uma propriedade relevante das nanopartículas é a fração significativa de átomos na superfície em relação ao total de átomos. Na figura 2.12 apresentamos a evolução da fração de átomos na superfície para as nanopartículas nos formatos oct-(i e p), t-oct, c-oct e ico com relação ao diâmetro das nanopartículas. Para diâmetros até 2,5 nm, que é a faixa de nanopartículas que estudamos, a superfície corresponde a mais que $70 \%$ do total de átomos. Ao redor de 5,0 nm essa fração ainda é representativa correspondendo a cerca de $30 \%$ a $40 \%$ do total de átomos. Próximo de um diâmetro de $25 \mathrm{~nm}$ a superfície já é bem menos representativa correspondendo a menos que $10 \%$ do total. Para as NPs com aproximadamente $100 \mathrm{~nm}$, correspondente à transição entre as escalas nanométrica e micrométrica, os átomos da superfície correspondem à $2 \%$ do total.

Como podemos observar para as nanopartículas octaédricas, a fração de átomos na superfície em relação ao total é levemente superior comparado com as demais. Por outro lado, como pode ser observado na figura 2.13, a superfície total das nanopartículas octaédricas é menor em relação aos outros formatos de nanopartículas com o mesmo diâmetro.

Em síntese, podemos observar, pelos gráficos das figuras 2.12 e 2.13, a equivalência estrutural entre as NPs-oct-i e NPs-oct-p e, também, a proximidade estrutural entre as NPs c-oct e t-oct. 


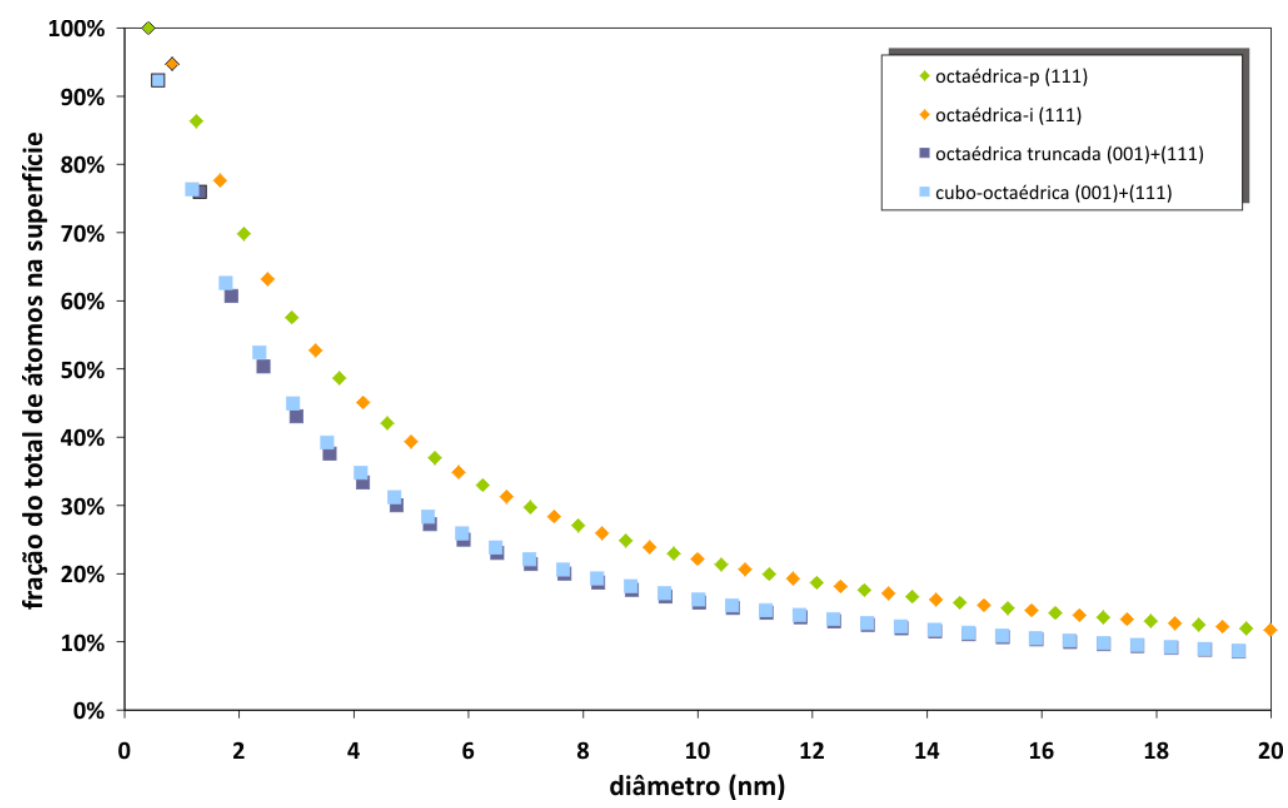

Fig. 2.12: Evolução da fração do número de átomos na superfícies em relação ao total para as nanopartículas octaédricas (i e p), que apresentam apenas as superfícies [111], e para as nanopartículas octaédricas truncadas e cubo-octaédricas, que apresentam tanto a superfície [001] quanto a [111].

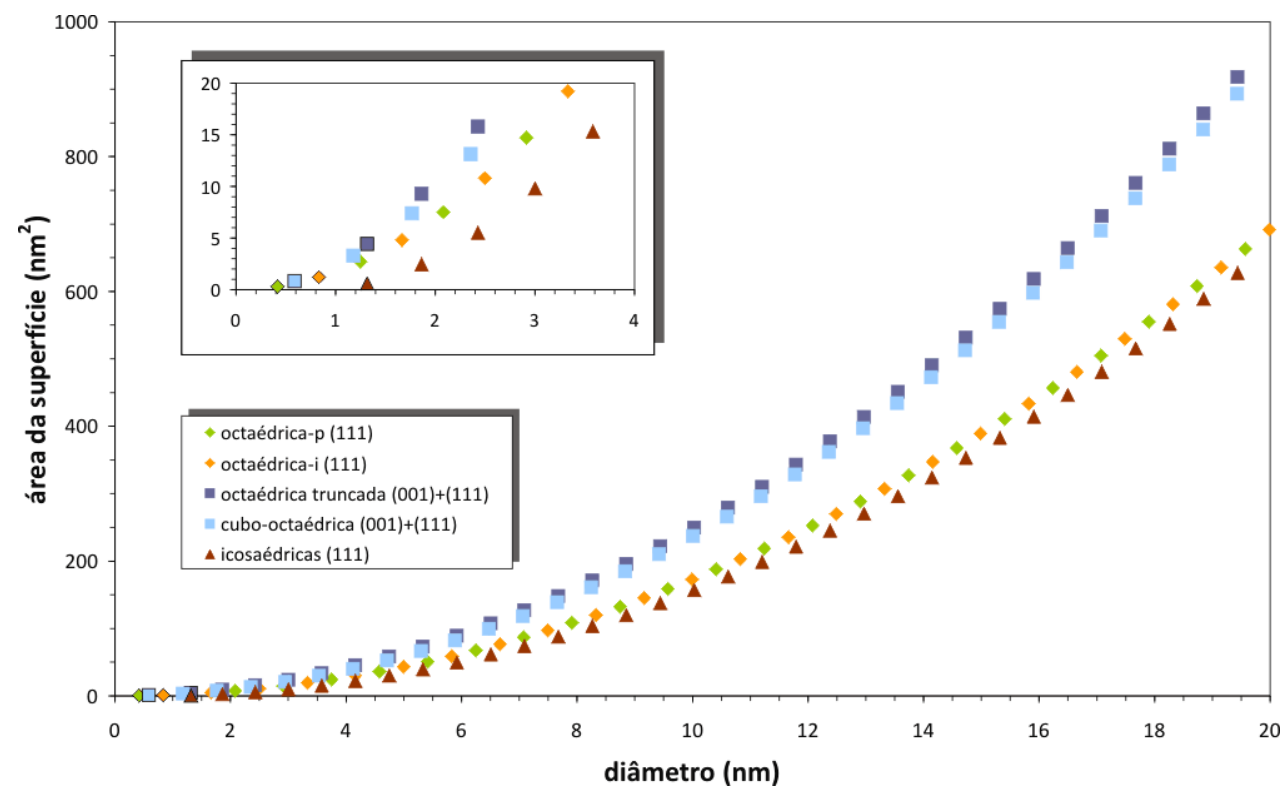

Fig. 2.13: Evolução da área total da superfície para as nanopartículas octaédricas (i e p), que apresentam apenas as superfícies [111], e para as nanopartículas octaédricas truncadas e cubo-octaédricas, que apresentam tanto a superfície [001] quanto a [111]. 


\subsection{Nanopartículas esféricas}

As nanopartículas esféricas são construídas a partir de cortes esféricos ao redor de um átomo da rede cristalina da prata. Esta construção é equivalente a incorporação das sucessivas vizinhanças deste átomo central. Na figura 2.14 estão representadas as nanopartículas construídas pelos recortes esféricos até a incorporação da quinta vizinhanças dos átomos da rede cristalina.
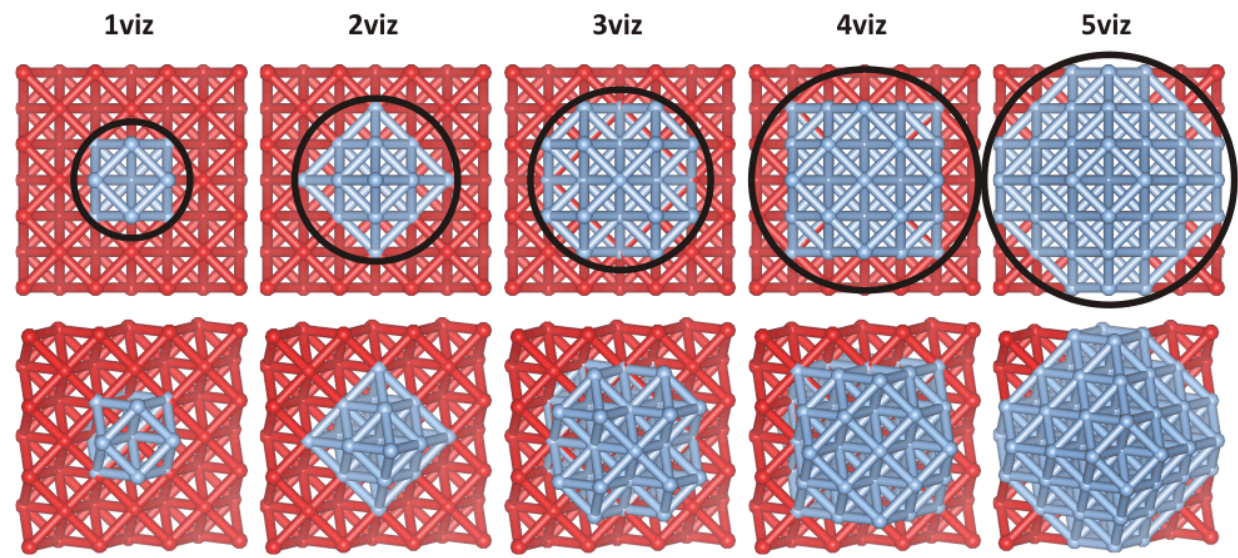

Fig. 2.14: Representação da construção das cinco primeiras nanopartículas esféricas que correspondem às cinco primeiras vizinhanças. Em vermelho uma secção da rede cristalina e em azul os átomos compreendidos dentro de um raio. As figuras inferiores representam o conjunto superior rotacionado.

Esta incorporação por vizinhança não apresenta uma regularidade no crescimento que possa ser expressa por meio de uma equação simples como é o caso das nanopartículas poliédricas. Assim, a análise da variação do número de sítios será realizada para as nanopartículas esféricas estudadas na próxima seção.

As nanopartículas construídas a partir dos cortes esféricos são simétricas e tendem assintoticamente à forma esférica com o aumento do raio. Essas nanopartículas podem ser decompostas em termos de uma nanopartícula poliédrica interna acrescida de átomos distribuídos igualmente sobre as superfícies equivalentes da nanopartícula poliédrica, como representado na figura 2.15. 


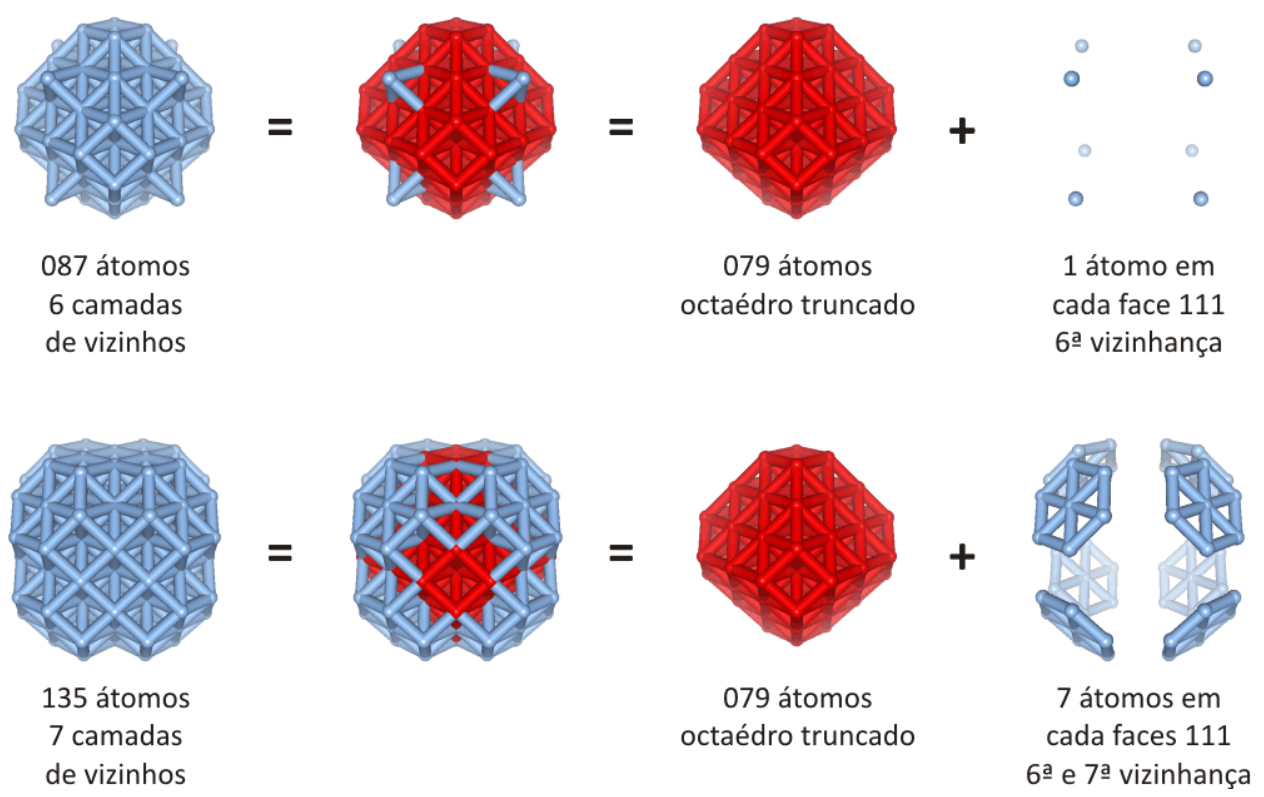

Fig. 2.15: Representação dos átomos adicionais sobre a superfície das nanopartículas poliédricas na formação das nanopartículas esféricas. Acima, está representada a nanopartícula esférica com 87 átomos, que é construída com seis camadas de vizinhos e pode ser decomposta em uma estrutura poliédrica (octaedro truncado em vermelho) mais oito átomos, sendo um átomo sobre cada uma das oito superfícies [111] da nanopartícula poliédrica. Abaixo, temos a nanopartícula com 135 átomos, que é formada por sete camadas de vizinhos e pode ser decomposta na mesma nanopartícula poliédrica agora com mais 56 átomos, sendo sete átomos em cada uma das oito superfícies [111].

Os átomos acrescidos sobre os planos tornam rugosas as superfícies das nanopartículas esféricas com a presença de degraus e vales. Devido a esta rugosidade apresentam um número grande de sítios distintos em sua superfície. Enquanto as nanopartículas poliédricas apresentam, independentemente do tamanho, o máximo de 4 sítios distintos em sua superfície com coordenações que variam entre c4 e c9, as nanopartículas esféricas estudadas chegam a apresentar até 6 sítios distintos com coordenações que variam entre c3 e c11. Os sítios de alta coordenação, como c10 e c11, estão associados aos vales e degraus presentes nas superfícies das nanopartículas esféricas. 


\section{Capítulo 3}

\section{Nanopartículas de prata livres}

As propriedades das nanopartículas variam com o aumento de sua dimensão devido à mistura das propriedades eletrônicas moleculares, de superfície e do cristal. Por outro lado, como o número de átomos na superfície cresce aproximadamente com o quadrado do diâmetro da nanopartículas $\left(N_{\text {sup }} \propto D^{2}\right)$ e a região interna cresce aproximadamente com o cubo do diâmetro $\left(N_{i n t} \propto D^{3}\right)$ é esperado uma influência cada vez maior da região interna com o aumento da nanopartícula, apresentado características cristalinas cada vez mais expressivas.

Neste capítulo analisamos as propriedades estruturais, energéticas, eletrônicas e vibracionais das nanopartículas livres de prata com o objetivo de identificar os padrões entre os diferentes formatos e tamanhos das nanopartículas. Estas propriedades também são utilizadas na análise das modificações decorrentes da adsorção de compostos moleculares realizadas sobre a superfície das nanopartículas, que será discutida no capítulo 4 .

As nanopartículas estudadas foram construídas nos formatos poliédricos e esféricos, conforme descrição no capítulo 2, com número total de átomos entre 6 e 561 . Na tabela 3.1 estão indicadas algumas propriedades das nanopartículas estudadas: o número total de átomos, formato, diâmetro, energia por átomo, média das coor- 
denações e número de átomos de cada coordenação presentes na nanopartícula.

Tab. 3.1: Parâmetros estruturais e energéticos das nanopartículas estudadas, cristal e superfícies: diâmetro $(\mathrm{D})$, energia por átomo $\left(E_{a t}\right)$, coordenação média $(\bar{c})$ e quantidade de átomos de cada coordenação. Os números no título das colunas de 12 à 3 são as coordenações possíveis nas nanopartículas. O número indicado na frente de cada formato corresponde a quantidade de camadas utilizadas na construção para as poliédricas ou a quantidade de vizinhanças utilizadas na construção das nanopartículas esféricas.

\begin{tabular}{|c|c|c|c|c|c|c|c|c|c|c|c|c|c|c|}
\hline \multirow[b]{2}{*}{ Estrutura } & \multirow[b]{2}{*}{ Formato } & \multirow[b]{2}{*}{$\mathrm{D}(\mathrm{nm})$} & \multirow[b]{2}{*}{$\mathrm{E}_{a t}(\mathrm{eV})$} & \multirow[b]{2}{*}{$\bar{c}$} & \multicolumn{10}{|c|}{ Número de átomo por tipo de coordenação } \\
\hline & & & & & $\mathrm{c} 12$ & $\mathrm{c} 11$ & $\mathrm{c} 10$ & c9 & $\mathrm{c} 8$ & $\mathrm{c7}$ & c6 & $\mathrm{c} 5$ & c4 & $\mathrm{c} 3$ \\
\hline Cristal & FCC & - & $-2,73$ & 12,00 & 1 & - & - & - & - & - & - & - & - & - \\
\hline Sup 111 & FCC & - & $-2,62$ & 11,00 & 32 & - & - & 16 & - & - & - & - & - & - \\
\hline Sup 001 & FCC & - & $-2,57$ & 10,67 & 32 & - & - & - & 16 & - & - & - & - & - \\
\hline 561 & $5 \mathrm{c}$-oct & 2,88 & $-2,50$ & 10,05 & 309 & - & - & 48 & 96 & 96 & - & 12 & - & - \\
\hline 531 & 18 esf & 2,57 & $-2,48$ & 9,94 & 249 & 72 & - & 72 & 6 & 36 & 72 & 24 & - & - \\
\hline 459 & 17 esf & 2,50 & $-2,47$ & 9,83 & 225 & - & 72 & 24 & - & 84 & 24 & 24 & 6 & - \\
\hline 429 & 16 esf & 2,43 & $-2,47$ & 9,85 & 201 & 24 & 24 & 48 & 24 & 60 & 24 & 24 & - & - \\
\hline 381 & 15 esf & 2,36 & $-2,47$ & 9,83 & 177 & 24 & - & 48 & 72 & - & 48 & 12 & - & - \\
\hline 369 & 14 esf & 2,28 & $-2,46$ & 9,82 & 165 & 36 & - & 48 & 24 & 48 & 48 & - & - & - \\
\hline 321 & 13 esf & 2,12 & $-2,44$ & 9,64 & 141 & 12 & 24 & 48 & - & 24 & 72 & - & - & - \\
\hline 309 & $4 \mathrm{c}-\mathrm{oct}$ & 2,31 & $-2,45$ & 9,63 & 147 & - & - & 24 & 54 & 72 & - & 12 & - & - \\
\hline 249 & 12 esf & 2,04 & $-2,42$ & 9,35 & 87 & 48 & - & - & 30 & 36 & 24 & 24 & - & - \\
\hline 231 & 3 oct $-\mathrm{i}$ & 2,50 & $-2,42$ & 9,45 & 85 & - & - & 80 & - & 60 & - & - & 6 & - \\
\hline 225 & $3(1) \mathrm{t}$-oct & 2,11 & $-2,43$ & 9,49 & 85 & - & - & 80 & - & 36 & 24 & - & - & - \\
\hline 225 & 11 esf & 1,95 & $-2,40$ & 9,28 & 87 & - & 48 & - & 6 & 36 & 24 & 24 & - & - \\
\hline 201 & $3(2) \mathrm{t}$-oct; 10 esf & 1,86 & $-2,42$ & 9,43 & 79 & - & - & 56 & 6 & 36 & 24 & - & - & - \\
\hline 177 & 9 esf & 1,73 & $-2,38$ & 9,08 & 55 & 24 & - & 8 & 54 & - & - & 36 & - & - \\
\hline 147 & $3 \mathrm{c}$-oct & 1,77 & $-2,36$ & 8,98 & 55 & - & - & 8 & 24 & 48 & - & 12 & - & - \\
\hline 146 & 3 oct-p & 2,08 & $-2,36$ & 9,04 & 44 & - & - & 48 & - & 48 & - & - & 6 & - \\
\hline 141 & 8 esf & 1,62 & $-2,36$ & 8,85 & 43 & 12 & - & 32 & - & - & 48 & - & 6 & - \\
\hline 135 & 7 esf & 1,52 & $-2,36$ & 8,89 & 43 & 12 & - & 8 & 24 & - & 48 & - & - & - \\
\hline 087 & 6 esf & 1,40 & $-2,28$ & 8,28 & 19 & - & 24 & - & - & 12 & 24 & - & - & 8 \\
\hline 085 & 2 oct-i & 1,61 & $-2,29$ & 8,47 & 19 & - & - & 24 & - & 36 & - & - & 6 & - \\
\hline 079 & 2(1) t-oct; 5 esf & 1,28 & $-2,29$ & 8,51 & 19 & - & - & 24 & - & 12 & 24 & - & - & - \\
\hline 055 & 2 c-oct; 4 esf & 1,14 & $-2,23$ & 7,85 & 13 & - & - & - & 6 & 24 & - & 12 & - & - \\
\hline 055 & 2 ico & 1,14 & $-2,26$ & 8,51 & 13 & - & - & - & 30 & - & 12 & - & - & - \\
\hline 044 & 2 oct-p & 1,25 & $-2,17$ & 7,64 & 6 & - & - & 8 & - & 24 & - & - & 6 & - \\
\hline 043 & 3 esf & 0,99 & $-2,12$ & 7,26 & 1 & 12 & - & - & 6 & - & - & 24 & - & - \\
\hline 019 & $1 \mathrm{oct} ; 2 \mathrm{esf}$ & 0,78 & $-1,97$ & 6,32 & 1 & - & - & - & - & 12 & - & - & 6 & - \\
\hline 013 & 1 esf & 0,59 & $-1,79$ & 5,54 & 1 & - & - & - & - & - & - & 12 & - & - \\
\hline 013 & 1 ico & 0,56 & $-1,77$ & 6,46 & 1 & - & - & - & - & - & 12 & - & - & - \\
\hline 006 & 1 oct-p & 0,42 & $-1,44$ & 4,00 & - & - & - & - & - & - & - & - & 6 & - \\
\hline
\end{tabular}

O estudo teórico de simulação das nanopartículas livres de prata foi realizado dentro do formalismo apresentado no capítulo 1, a fim de se obter a estrutura mais 
estável em cada um dos casos estudados. Cada sistema foi considerado relaxado quando a diferença na energia total entre dois ciclos de autoconsistência era menor que $0,0001 \mathrm{eV}$ e quando as forças entre os átomos eram menores que 0,01 eV/A. Utilizamos uma energia de corte de $200 \mathrm{eV}$ para os coeficientes da expansão em ondas planas. As nanopartículas que apresentam um átomo no centro foram relaxadas considerando apenas este átomo central fixo. Já as nanopartículas centradas no interstício foram relaxadas considerando todos os átomos livres.

No apêndice $\mathrm{C}$ apresentamos uma série de resultados preliminares de estruturas compostas por átomos de prata, obtidos através do formalismo do funcional da densidade e dinâmica molecular quântica no programa VASP, que fundamentam os parâmetros adotados. Foram analisadas as propriedades do cristal e das superfícies [001] e [111] da prata FCC, da molécula de $\mathrm{Ag}_{2}$ e de algumas nanopartículas.

\subsection{Propriedades estruturais}

Verificamos que todas as nanopartículas relaxadas mantiveram o seu formato inicial (FCC ou icosaédrico), apresentando apenas uma leve contração decorrente da acomodação de seus átomos, indicando que as configurações estudadas são estáveis, ou metaestáveis.

Para identificar como os átomos se acomodam na nanopartícula, analisamos a distância média de cada átomo a sua primeira vizinhança e comparamos com a distância interatômica inicial de $2,94 \AA$ da rede cristalina. Verificamos para todos os átomos que houve uma leve contração da distância média Ag-Ag com a vizinhança em relação a distância inicial cristalina.

Identificamos, ainda, que as intensidades das contrações são muito próximas para sítios de mesma coordenação nas diferentes nanopartículas e, neste sentido, calculamos a média das contrações para cada tipo de sítio entre as diferentes nano- 
partículas. Os resultados estão indicados na tabela 3.2.

Tab. 3.2: Contração média das distâncias entre o sítio e sua primeira vizinhança em relação a distância interatômica no cristal, 2,94 A. A última coluna indica as nanopartículas que foram consideradas no cálculo da contração média dos sítios. Os sítios c12 estão diferenciados pela profundidade em relação à superfície: c12 (1) são os sítios da primeira sub-camada; c12 (2) o da segunda sub-camada e c12 (>2) todos os sítios presentes abaixo da segunda sub-camada.

\begin{tabular}{|c|c|l|}
\hline Sítio & Contração média & Nanopartículas consideradas \\
\hline c3 & $5,9 \%$ & 087 \\
c4 & $4,8 \%$ & $019,044,085,141$ e 146 \\
c5 & $3,4 \%$ & $013,043,055,147$ e 309 \\
c6 & $2,8 \%$ & $079,087,135$ e 141 \\
c7 & $2,1 \%$ & $019,044,055,079,085,087,146,147$ e 309 \\
c8 & $1,0 \%$ & $043,055,135,147$ e 309 \\
c9 & $0,9 \%$ & $044,079,085,135,141,146,147$ e 309 \\
c10 & $1,4 \%$ & 087 \\
c11 & $1,4 \%$ & 043,135 e 141 \\
c12 (1) & $1,1 \%$ & $019,043,044,055,079,085,087,135,141,147$ e 309 \\
c12 (2) & $0,7 \%$ & $055,079,085,087,135,141,147$ e 309 \\
c12 (>2) & $0,6 \%$ & $079,085,087,135,141,147$ e 309 \\
\hline
\end{tabular}

Para os sítios c3 e c10 foram consideradas as contrações presentes apenas na NP 087. Não foram consideradas nesta análise as NPs 006 oct e 013 c-oct por serem muito pequenas e as nanopartículas icosaédricas por não apresentaram a geometria FCC.

Verificamos para os sítios de menor coordenação da superfície c3 a c9 que a contração média é maior quanto menor é a coordenação do sítio, variando de 5,9\% para o sítio c3 até $0,9 \%$ para o sítio c 9 .

Os sítios c8 e c9 apresentaram uma contração menor em relação aos demais sítios da superfície, se acomodando levemente acima e provocando uma pequena 
curvatura nas superfícies [001] e [111] da nanopartícula da qual fazem parte.

Os sítios c10 e c11 apresentaram uma contração levemente superior que as obtidas para os sítios c8 e c9 de 1,4\%, não seguindo o padrão de redução da contração apresentado para os sítios de c3 a c9 da superfície. Associamos a este comportamento diferenciado dos sítios c10 e c11 o fato de realizarem algumas de suas ligações com os sítios de baixa coordenação da superfície que, por apresentarem maior contração, provocam uma redução na média das distâncias de ligação entre os sítios c10 e c11 e suas vizinhanças.

Os sítios com coordenação c12 do interior das nanopartículas apresentaram contração distinta conforme a profundidade em relação à superfície. A contração foi maior para os sítios c12 presentes na primeira sub-camada logo abaixo da superfície, com uma redução na distância média aos vizinhos de 1,1\%. Para os sítios c12 da segunda sub-camada abaixo da superfície a contração média foi de $0,7 \%$ e para as camadas inferiores a contração média foi de 0,6\%. Para a NP 013 que apresenta apenas um sítio c12 no seu interior a contração foi de 3,1\%.

De maneira geral, observamos que os sítios de baixa coordenação entre c3 e c7 apresentam maior contração. Os sítios de c8 a c11 da superfície e os sítios c12 da primeira sub-camada abaixo da superfície apresentam uma contração menor. Para as regiões mais internas, as contrações são cada vez menores conforme a profundidade em relação à superfície, se aproximando da configuração cristalina da prata FCC. Isto é um indicativo de que para as grandes nanopartículas a região interna deve ter a mesma configuração da rede cristalina.

\subsection{Propriedades energéticas}

Uma análise importante no estudo das nanopartículas é a evolução da energia por átomo $\left(\varepsilon_{a t}\right)$ com relação a alguns parâmetros associados à dimensão das na- 
nopartículas. Podemos com essa evolução indicar a tendência das estruturas bem como diferenciar os regimes das nanopartículas pequenas que apresentam forte característica molecular.

A energia por átomo é calculada por,

$$
\varepsilon_{a t}=E_{t o t} / N
$$

onde $E_{t o t}$ e $N$ são, respectivamente, a energia total e o número total de átomos do sistema. A energia por átomo e o número de átomos de cada nanopartícula estão indicados na tabela 3.1 .

A evolução da energia por átomo com o número total de átomos $N$ é mostrada na figura 3.1 para todas as nanopartículas estudadas. Verificamos que a $\varepsilon_{a t}$ das

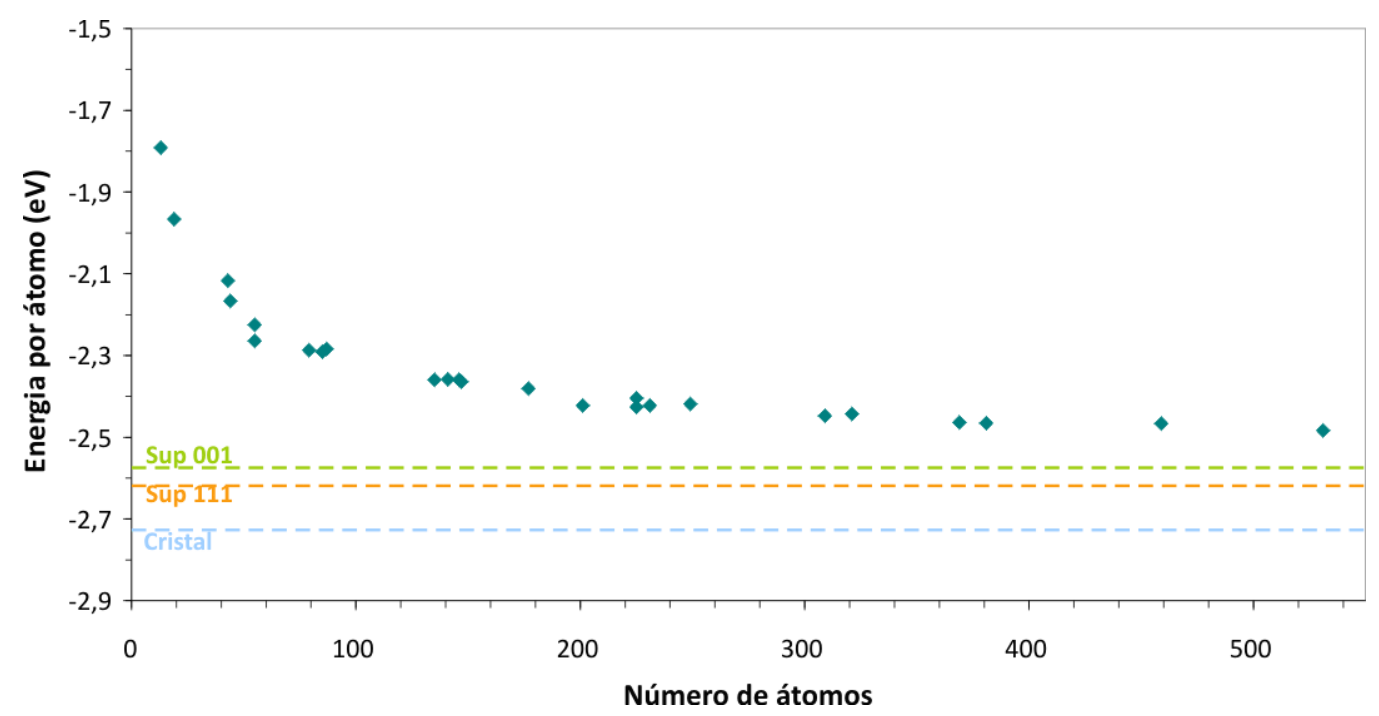

Fig. 3.1: Evolução da energia por átomo com o aumento das nanopartículas estudadas. As linhas tracejadas correspondem às energias por átomo das superfícies [001] (verde) e [111] (laranja) e do cristal (azul) para a prata no empacotamento FCC.

nanopartículas diminui continuamente com o aumento do número de átomos na direção das $\varepsilon_{a t}$ das superfícies e do cristal.

Para as nanopartículas com número de átomos até $N=100$ a variação da energia por átomo é bem mais acentuada, reduzindo-se em cerca de $0,85 \mathrm{eV}$. Na faixa 
entre $N=100$ e 300 a variação da energia por átomo já é bem menos expressiva, reduzindo-se cerca de $0,14 \mathrm{eV}$. Entre $N=300$ e 600 a variação da energia por átomo é menor ainda, reduzindo-se apenas de $0,05 \mathrm{eV}$.

Este comportamento da energia por átomo é um primeiro indicativo dos regimes de tamanhos para as nanopartículas estudadas: (i) pequenas, até 100 átomos, (ii) intermediárias, entre 100 e 300 e (iii) maiores, acima de 300 átomos.

A energia por átomo pode ser relacionada ao inverso da raiz cúbica do número total de átomos $\left(N^{-\frac{1}{3}}\right)$, figura 3.2, conforme uma lei de escala deduzida no apêndice E para grandes nanopartículas. Em primeira ordem temos um comportamento aproximadamente linear em $N^{-\frac{1}{3}}$ para a $\varepsilon_{a t}$,

$$
\varepsilon_{a t}=a+b \cdot N^{-\frac{1}{3}}
$$

onde o termo independente $a$ é a contribuição do volume do cristal puro e deve coincidir com a energia por átomo do cristal, pois o sistema tende ao cristal quando $N \rightarrow \infty$.

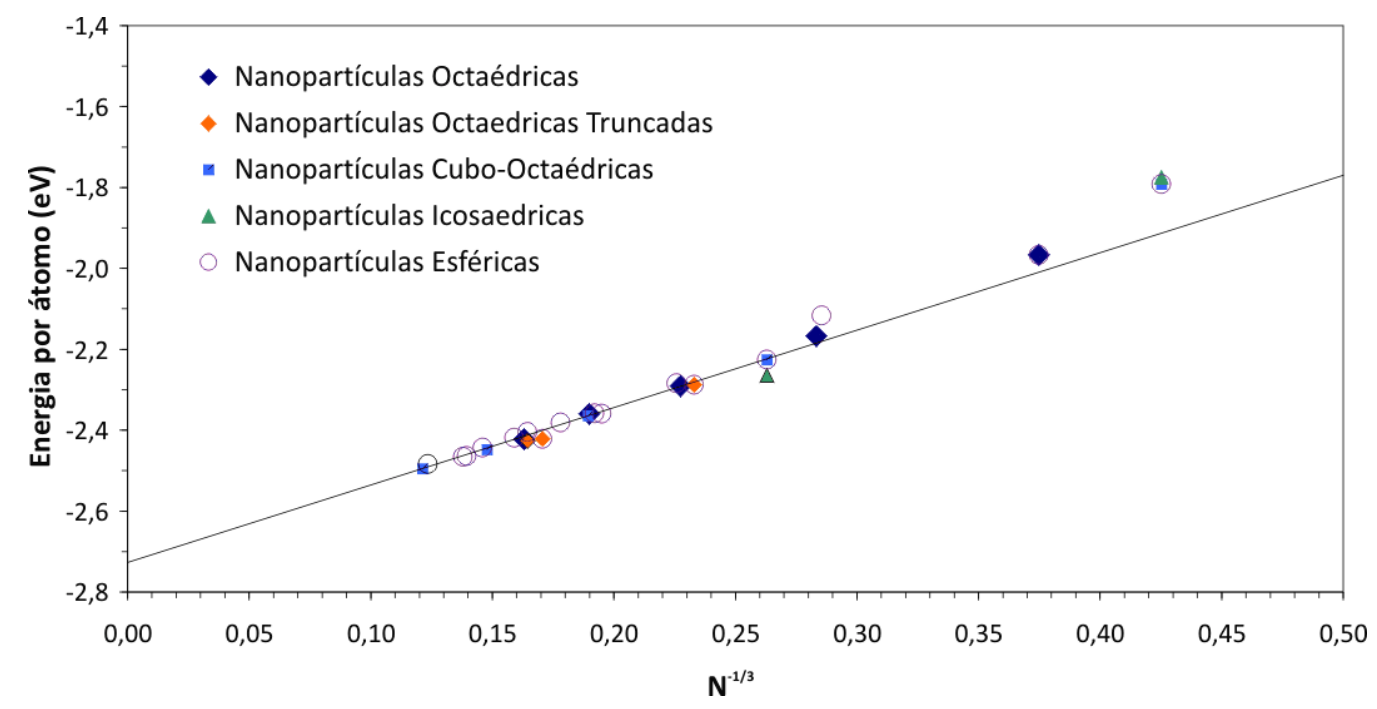

Fig. 3.2: Evolução da energia por átomo com o inverso da raiz cúbica do número de áto$\operatorname{mos}\left(N^{-\frac{1}{3}}\right)$ das nanopartículas estudadas. As nanopartículas estão separadas pelo formato, descrito na legenda. A linha sólida representa o ajuste linear para todas as nanopartículas com $N>100$. A equação do ajuste é $\varepsilon_{a t}^{\text {cristal }}=-2,73+1,91 \cdot N^{-\frac{1}{3}}$. 
Como esta dependência linear em $N^{-\frac{1}{3}}$ corresponde a uma aproximação para as grandes nanopartículas, realizamos o ajuste linear excluindo as nanopartículas com até 100 átomos. Obtivemos do ajuste os valores de $a=-2,73 \mathrm{eV}$ e $b=1,91 \mathrm{eV}$. O termo independente $a$ concorda muito bem com a energia por átomo que obtivemos para cristal de prata $\varepsilon_{a t}^{\text {cristal }}=-2,73 \mathrm{eV}$. Este comportamento linear tendendo ao termo independente $a$ obtido para a energia por átomo das nanopartículas é coerente com os resultados obtidos por Xie e Blackman, que realizaram um estudo teórico de nanopartículas de prata utilizando o método Tight Binding [78].

Um indicador da presença da região cristalina nas nanopartículas é a média do número de coordenação $(\bar{c})$ entre todos os átomos da nanopartícula, que tende à coordenação do cristal (c12) com o aumento da dimensão da nanopartícula. Isto ocorre devido a predominância dos átomos no interior da nanopartícula que apresentam coordenação c12, equivalente a coordenação do cristal. Este fato é coerente com nossa análise anterior, aonde vimos que a fração do número de átomos da superfície decresce com o aumento do diâmetro, figura 2.12. Pelo mesmo motivo, a energia por átomo das grandes nanopartículas tende à energia por átomo do cristal.

Na figura 3.3 relacionamos a energia por átomo com a média do número de coordenação para todas as nanopartículas estudadas e, também, para as superfícies [001] e [111] e para o cristal da prata FCC. O ajuste linear entre os pontos associados às superfícies e ao cristal delimita o regime das macroestruturas.

As superfícies foram calculadas com seis camadas de átomos, apresentando, portanto, quatro camadas no interior com átomos de coordenação c12 e duas camadas de superfície, superior e inferior, com átomos de coordenação característica. Os sítios característicos da superfície [001] apresentam coordenação c8, logo sua coordenação média é $\bar{c}_{[001]}=(2 \times 8+4 \times 12) / 6=10,67$. Os sítios característicos da superfície [111] apresentam coordenação c9 e sua coordenação média é $\bar{c}_{[111]}=(2 \times 9+4 \times 12) / 6=11,00$. Como o cristal possui apenas sítios c12, sua 


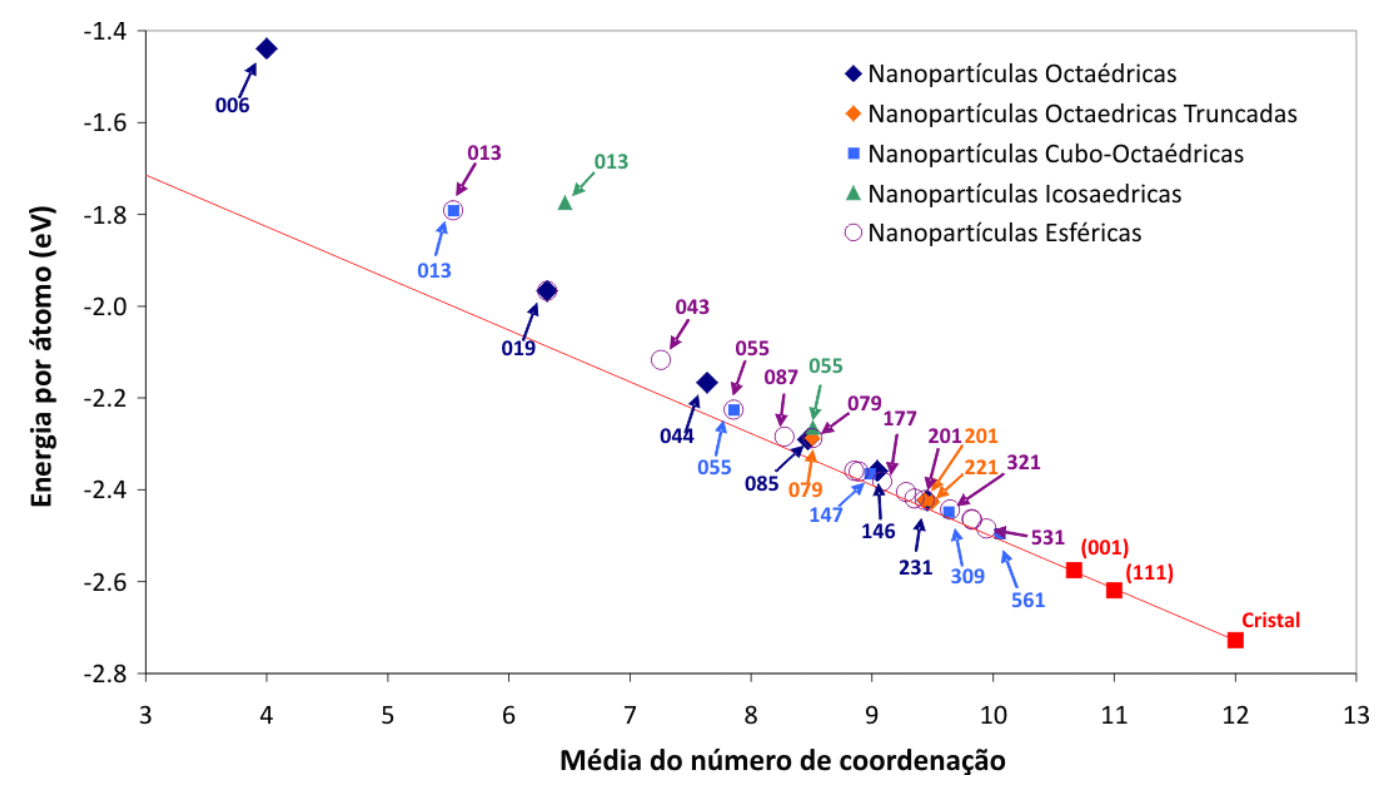

Fig. 3.3: Evolução da energia por átomo com a média do número de coordenação entre todos os átomos da nanopartícula. As nanopartículas estão separadas pelos formatos e para algumas estão indicadas o número total de átomos. Os quadrados vermelhos correspondem às superfícies livres [001] e [111] e ao cristal de prata. A linha sólida corresponde ao ajuste linear realizado entre estes três pontos.

coordenação média é $\bar{c}_{\text {cristal }}=12$.

O gráfico da $\varepsilon_{a t} \times \bar{c}$ demonstra claramente que as nanopartículas caminham com o aumento do seu tamanho na direção dos resultados obtidos para as superfícies e para o cristal de prata. Também podemos observar que as nanopartículas com cerca de 150 átomos ou mais já estão bem próximas ao ajuste linear das macroestruturas (superfícies e cristal), indicando que as nanopartículas com este tamanho representam um espécie de transição entre o regime molecular, de pequenas nanopartículas, e o cristalino, das nanopartículas maiores.

\subsection{Propriedades eletrônicas}

No estudo das propriedades eletrônicas analisamos a distribuição da densidade de carga total, o comportamento dos níveis de energia próximos ao nível de Fermi 
e a densidade de estados (DOS). A análise da DOS das nanopartículas foi realizada comparativamente com o cristal e as superfícies livres.

Na figura 3.4 estão representadas as densidades totais de carga nos planos que passam pelo centro e pela superfície das nanopartículas cubo-octaédricas 013, 055, 147 e 309. Podemos verificar que a densidade de carga total para todos os casos apresentou uma distribuição esfericamente simétrica ao redor dos átomos, típica das estruturas metálicas. Este tipo de distribuição da carga sem as ligações fortemente localizadas, como nos semicondutores, explica a pequena relaxação estrutural observada para todas as nanopartículas.

A quantidade de níveis de energia distintos para as nanopartículas livres cresce com o tamanho da nanopartícula. Esse efeito é decorrente da perda do caráter molecular com o aumento da estrutura e consequente quebra da degenerescência dos níveis atômicos. Na figura 3.5 estão representados os níveis de energia próximos ao nível de Fermi para as nanopartículas esféricas e cubo-octaédricas.

O caráter molecular é sinalizado pelo maior distanciamento entre os níveis de energia como podemos observar para as nanopartículas até 87 átomos. Para as nanopartículas entre 135 e 369 átomos é clara a redução das distâncias entre os níveis de energia com o aumento da nanopartículas. Os níveis de energia das nanopartículas com mais que 369 átomos já se apresentam quase como um contínuo nas energias possíveis, equivalente às faixas de energia nos cristais.

Outra característica interessante é a presença dos níveis parcialmente ocupados na região próxima ao nível de Fermi em todas as nanopartículas estudadas. Para as maiores nanopartículas estudadas esses níveis se assemelham as faixas de condução semi-preenchidas presentes nos metais.

Analisamos, também, a localização espacial dos níveis que compreendem uma faixa de $0,25 \mathrm{eV}$ em torno do nível de Fermi. Os níveis nesta faixa de energia estão fortemente relacionados com os processos de adsorção, e sua localização sobre 
013
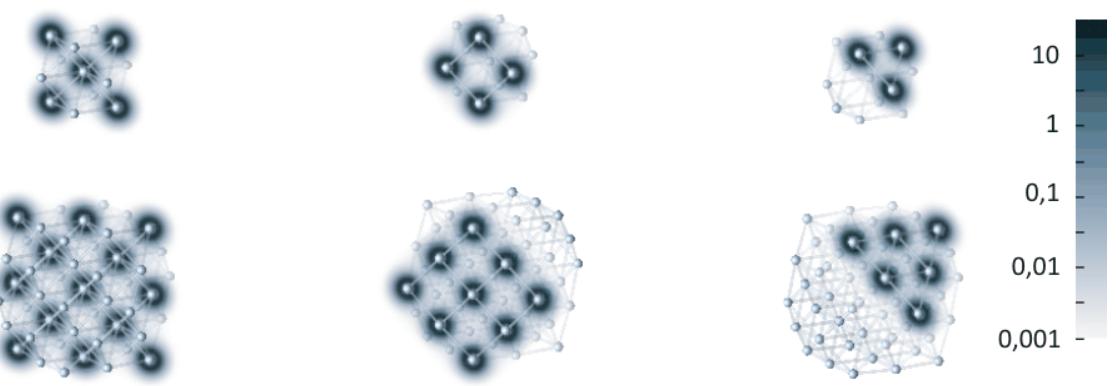

055
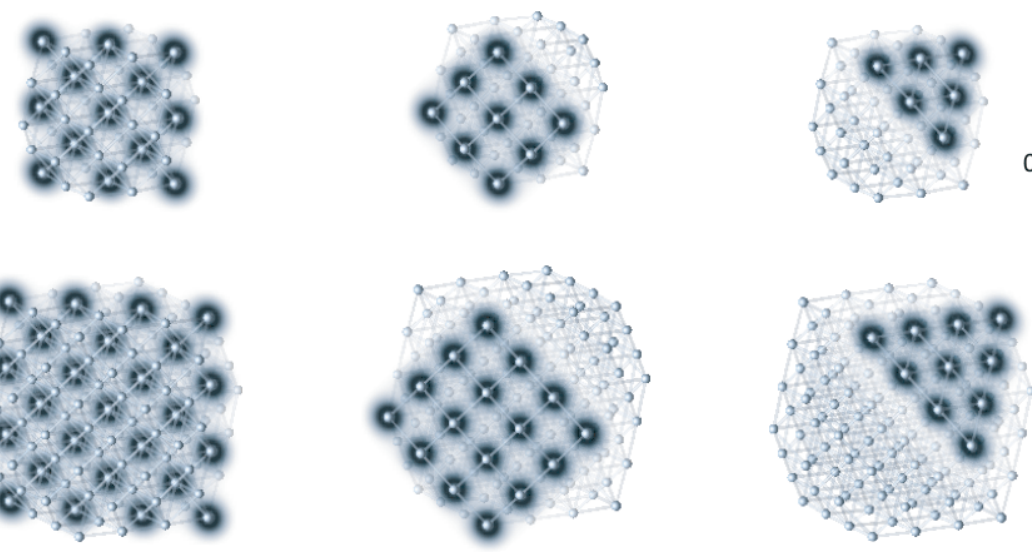

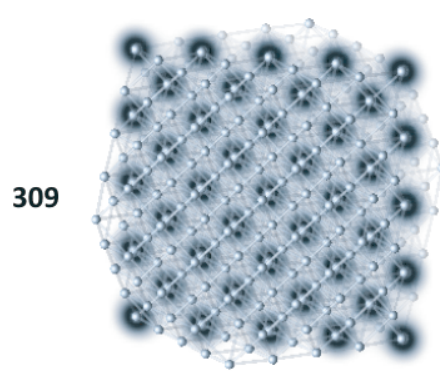

centro
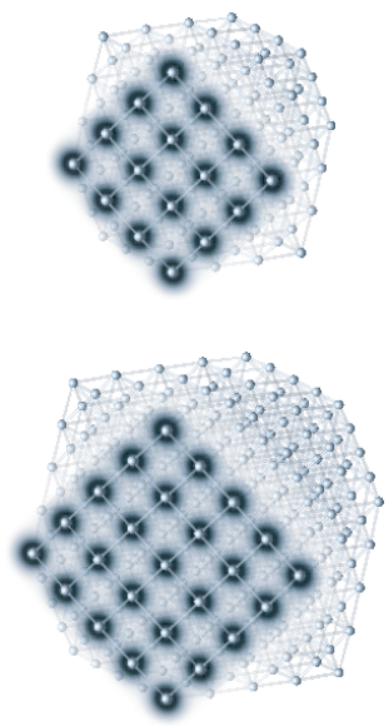

[001]

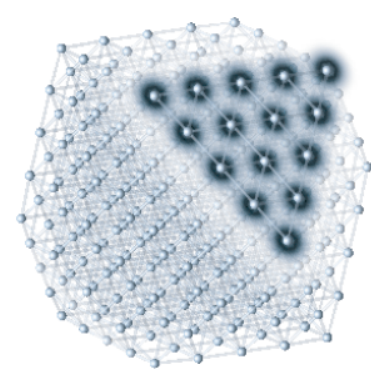

[111]

Fig. 3.4: Densidade de carga total das NPs c-oct 013, 055, 147 e 309. Os cortes planares foram realizados passando pelo centro da nanopartícula e pelas suas superfícies [001] e [111]. A densidade em elétrons/ $\AA^{3}$.

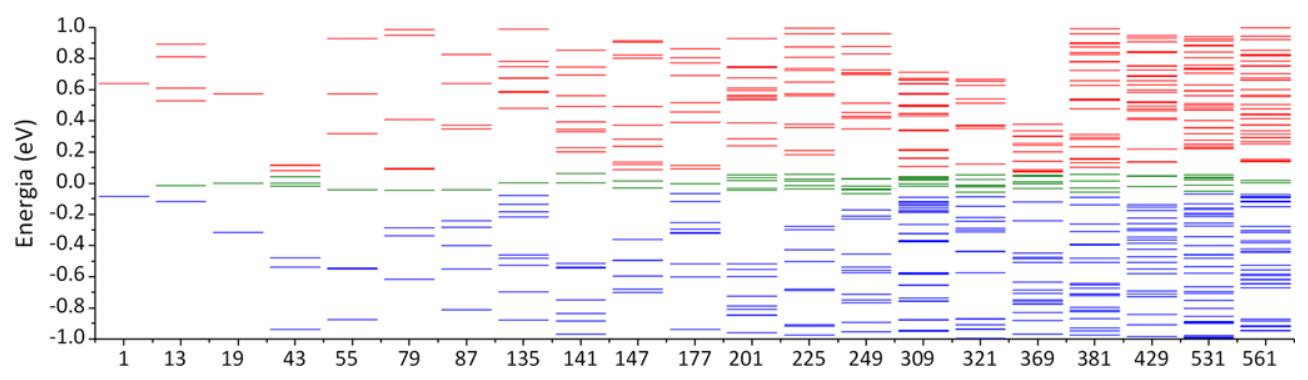

Fig. 3.5: Níveis de energia próximos ao nível de Fermi desde o átomo de prata isolado até a maior nanopartícula estudada. O nível de Fermi é a referência em zero na energia e a região de energia representada em torno do nível de Fermi é de $\pm 1,0 \mathrm{eV}$ em torno do nível de Fermi. Os níveis ocupados são representados em azul, em verde são os níveis parcialmente ocupados e em vermelho os níveis desocupados. 


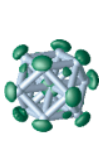

013

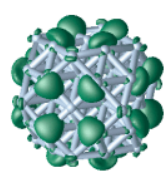

055

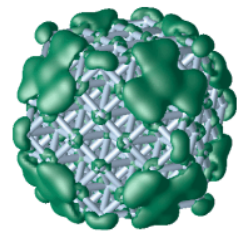

147

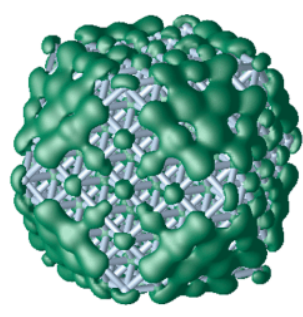

309

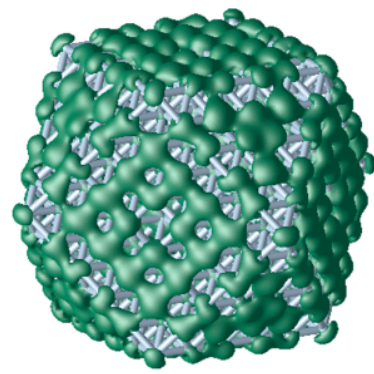

561

Fig. 3.6: Distribuição espacial da densidade de probabilidade dos níveis próximos ao nível de Fermi para as NP c-oct 013, 055, 147, 309 e 561. Os níveis foram agrupados dentro uma faixa de $\pm 0,25$ eV em torno do nível de Fermi.

os sítios das nanopartículas dá um indicativo da reatividade desses sítios. A localização espacial é obtida pelo mapeamento de uma isossuperfície de densidade de probabilidade para todos os níveis dentro desta faixa. A isossuperfície foi definida para uma densidade de probabilidade de $0,05 \AA^{-3}$. A localização dos níveis para algumas nanopartículas dentro dos regimes sugeridos estão representadas na figura 3.6.

Verificamos que a densidade de probabilidade dos níveis próximos ao nível de Fermi está predominantemente localizada sobre a superfície das nanopartículas, com pequenas contribuições na região central. Para a NP 013 estes níveis estão localizados sobre o sítio c5 da superfície. Já para a NP 055 a concentração é predominante sobre o sítio c7, enquanto pequenas contribuições são verificadas sobre o sítio c5 e valores pouco significativos sobre o sítio c8.

Na NP 147 os níveis próximos ao nível de Fermi se concentram de forma equivalente sobre os sítios c5, c7 e c9, com pouca contribuição sobre o sítio c8. A concentração desses níveis próximo ao nível de Fermi sobre determinados sítios são um forte indicativo da reatividade desses sítios e das regiões mais favoráveis para a realização das adsorções. Assim, nossos resultados sugerem um aumento de regiões ou sítios de maior probabilidade de adsorção nas maiores nanopartículas. 
Nesse contexto, o estudo de processos de adsorção sobre nanopartículas metálicas não podem se restringir a modelos que não permitam uma variedade de possíveis sítios reativos nos processos de surfactação, sob pena de não representarem os efeitos passivadores esperados. Cabe ressaltar que esse tópico é de vital importância na construção de carreadores de drogas e de biossensores, já que, na maior parte dos casos, os surfactantes devem possuir grupos funcionais capazes de reagir adequadamente com as drogas a serem carreadas ou com as moléculas a serem detectadas.

Para uma análise mais representativa dos níveis de energia, realizamos o estudo da densidade de estados (DOS) em torno do nível de Fermi para diferentes tamanhos e formatos das nanopartículas. Na figura 3.7 temos as DOS para todas as nanopartículas cubo-octaédricas estudadas $(013,055,147,309$ e 561), para algumas octaédricas $(019,044,085,146$ e 231) e, também, para duas nanopartículas esféricas grandes (381 e 531). A DOS está normalizada pelo número de elétrons do sistema que representa.

Para as nanopartículas com até cerca de 100 átomos $(\mathrm{D}<1,5 \mathrm{~nm})$, a característica molecular é muito expressiva com a presença de picos intensos e localizados, além de forte modulação das superfícies.

Com o aumento do número de átomos que compõem as nanopartículas, a característica molecular se reduz significativamente e a DOS passa a ter um comportamento misto com modulação tanto de superfície como de cristal, como é bem observado para as nanopartículas entre 100 e 300 átomos $(1,5 \mathrm{~nm}<\mathrm{D}<2,0 \mathrm{~nm})$.

Nas nanopartículas com mais de 300 átomos (D>2,0 nm) a influência da superfície na DOS está presente, mas a modulação do cristal passa a ser predominante, indicando o papel importante da região interna nas propriedades das nanopartículas.

Vale ressaltar que estes resultados foram observados tanto para as nanopartículas poliédricas, que preservam o formato com o tamanho, quanto para as nanopartículas esféricas que apresentam fortes flutuações no formato de suas superfícies, 

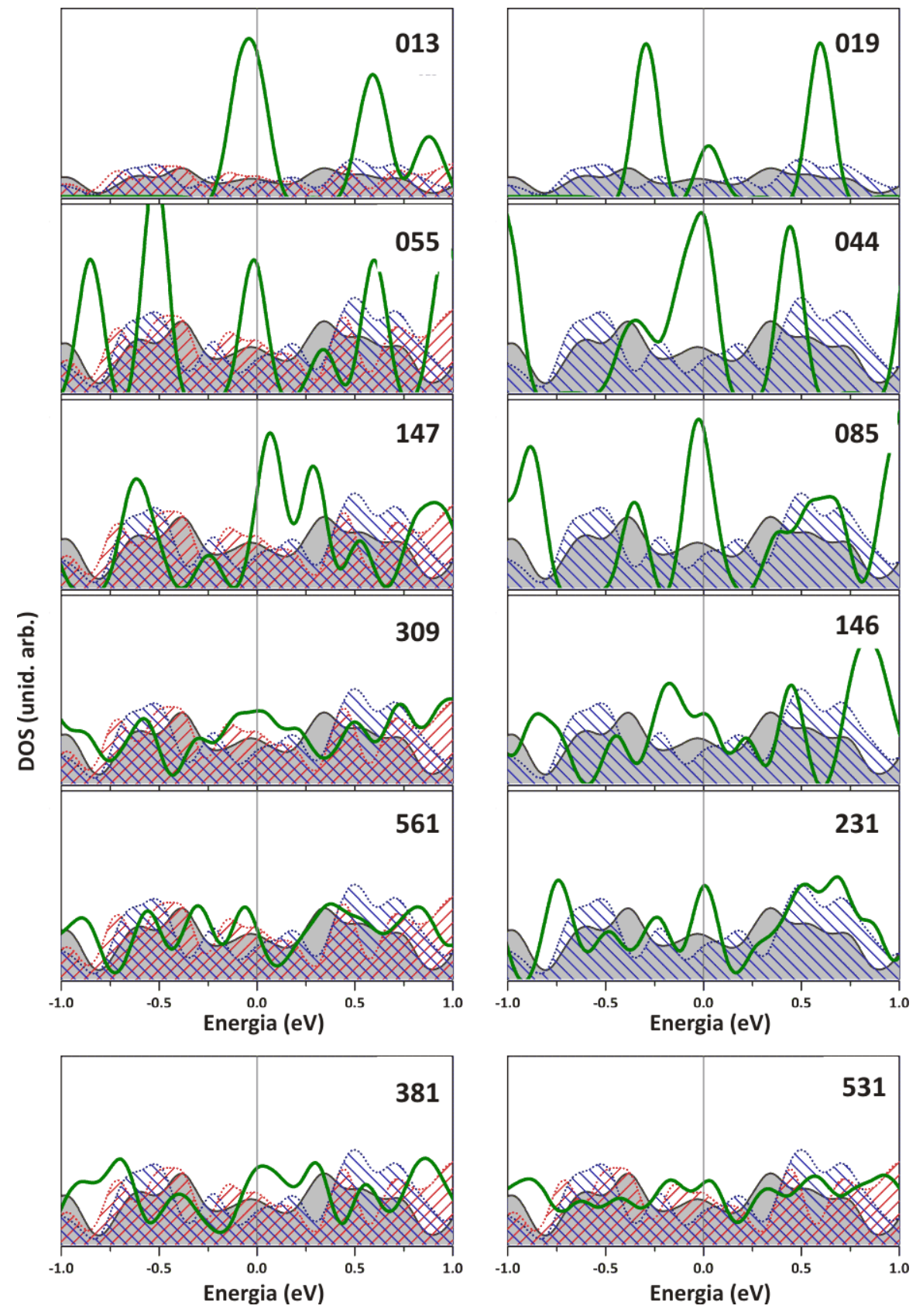

Fig. 3.7: Densidade de estados das nanopartículas (linha verde), comparadas com o cristal (região cinza), a superfície livre [001] (hachurado vermelho) e superfície livre [111] (hachurado azul). Acima à esquerda estão representadas a DOS das nanopartículas cubooctaédricas $(013,055,147,309$ e 561) e acima à direita a DOS das nanopartículas octaédricas $(019,044,085,146$ e 231). As duas DOS abaixo são de nanopartículas esféricas (381 e 531). Como as superfícies das nanopartículas octaédricas são do tipo [111] a comparação neste caso foi realizada apenas com a superfície livre [111]. Para as DOS das NPs 013 e 019 a escala na intensidade está dobrada em relação às demais DOS. 
indicando que se trata de uma propriedade geral associada ao aumento das nanopartículas. Além disso, é compatível com uma possível subdivisão para os regimes já verificados quando discutimos as propriedades energéticas das nanopartículas: com características fortemente moleculares $(\mathrm{N}<100)$, com características mistas $(100<\mathrm{N}<300)$ e com características fortemente cristalinas $(\mathrm{N}>300)$.

O crescimento da região interna, que é composta de átomos com coordenação c12 típica de estruturas cristalinas, reduz as características moleculares das nanopartículas. Como as superfícies estão sempre presentes com o aumento das nanopartículas, observamos a transição de um sistema com predominância de características moleculares para outro com predominância de características cristalinas. Todavia, em ambos os casos as propriedades das nanopartículas são moduladas pelas características da superfície, sendo essa influência mais significativa para as menores nanopartículas. Nesse sentido nossos resultados sugerem a existência de três regimes de nanopartículas:

- regime molecular: nanopartículas com poucos átomos na região interna. Apresentam forte característica molecular, devido ao seu tamanho reduzido, muita influência da superfície, que representa a maior parte da nanopartícula, e com poucas propriedades cristalinas devido a região interna muito pequena. Possuem até cerca de 100 átomos no total (menor que 2,0 nm);

- regime cristalino: nanopartículas maiores com uma região interna grande e estável. As características cristalinas e de superfície são predominantes em relação às moleculares. Possuem mais que 300 átomos (maior que 2,6 nm);

- regime misto: nanopartículas que estão no limite da transição do regime molecular para o regime cristalino. Apresentam características mistas de cristal, superfície e molécula. Possuem entre 100 e 300 átomos (entre 2,0 e 2,6 nm); 


\subsection{Propriedades vibracionais}

Realizamos o estudo comparativo dos espectros vibracionais, na região do infravermelho, das nanopartículas livres, das superfícies livres [001] e [111] e do cristal de prata. Neste estudo foram incluídas as NPs 006, 013, 055, 079, 147 e 309 . Os espectros obtidos estão representados na figura 3.8.

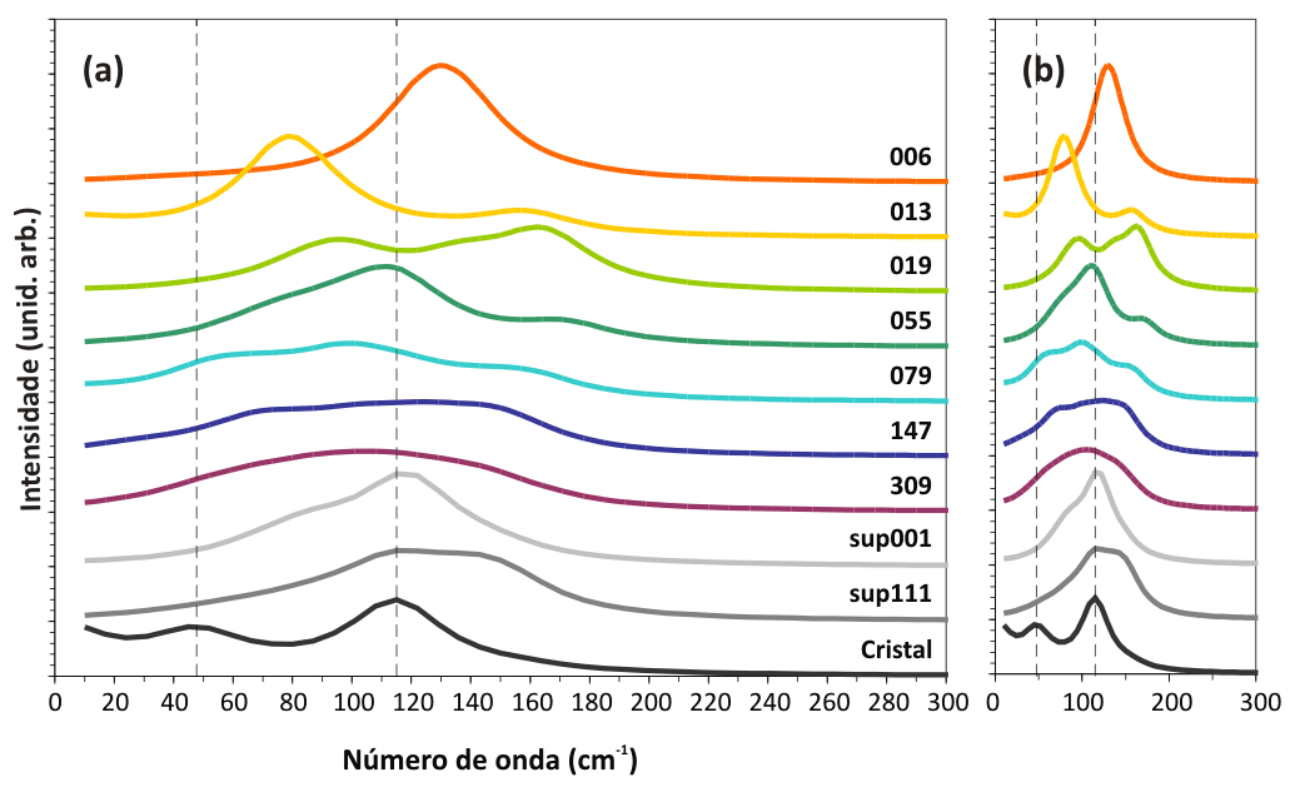

Fig. 3.8: (a) Espectros vibracionais das NPs 006, 013, 019, 055, 079, 147 e 309, das superfícies [001] e [111] e do cristal de prata. O espectro da NP 309 foi obtido considerando o movimento de 53 átomos, os demais espectros foram obtidos considerando todos os átomos. (b) Mesmo conjunto de espectros em escala adequada para acentuar a intensidade dos picos. As linhas tracejadas na vertical estão alinhadas com os picos mais intensos obtidos para o cristal de prata.

Os espectros vibracionais das nanopartículas com até 147 átomos, superfícies e o cristal foram obtidos considerando a movimentação de todos os átomos para construção da matriz Hessiana (seção 1.4). As superfícies [001] e [111] foram estudadas com seis camadas de átomos na reconstrução $2 \times 2$ e o estudo do cristal foi realizado para um cristal estendido com reprodução $4 \times 4 \times 4$ da célula unitária.

O espectro vibracional da NP 309 c-oct foi obtido considerando-se o movimento 
de um conjunto reduzido de átomos, devido às dificuldades, com respeito ao custo computacional do cálculo, para a obtenção do espectro completo que leva em consideração a movimentação de todos os átomos para a construção da matriz Hessiana. Foram, assim, considerados 53 átomos representativos que compreendem os átomos distintos da superfície, sua primeira vizinhança e mais alguns átomos da segunda vizinhança e interior da nanopartícula. Esta simplificação é discutida com maiores detalhes no capítulo 5 .

Os picos dos espectros vibracionais associados a todas as estruturas de prata analisadas estão localizados na faixa do espectro de até cerca de $200 \mathrm{~cm}^{-1}$, não apresentando sinais para as regiões de maiores energias. Estes resultados são compatíveis com outros estudos teóricos $[75,76]$ e experimentais $[79,80]$ para pequenos aglomerados de prata, que apresentaram modos vibracionais na faixa de energia entre $16 \mathrm{~cm}^{-1}$ e $190 \mathrm{~cm}^{-1}$. Estes resultados também são compatíveis com os espectros obtidos pela técnica SERS utilizando superfícies de prata, que não indicam a presença de sinais associados à estrutura de prata na faixa acima de $300 \mathrm{~cm}^{-1}[8,9]$.

Verificamos que os espectros das nanopartículas muito pequenas $(006,013,019$ e 055) são caracterizados por picos distintos entre si e bastante localizados em energia, com forte aspecto molecular. Na medida em que as nanopartículas são aumentadas (079 e 147), os picos se concentram na região em torno de $115 \mathrm{~cm}^{-1}$, levando à formação de um único pico largo representando a faixa de modos vibracionais ativos no espectro. Isto fica claro no espectro da NP 309 que já é caracterizado pela presença de um pico largo que se estende de 20 a $180 \mathrm{~cm}^{-1}$, centrado aproximadamente em $100 \mathrm{~cm}^{-1}$. Cabe destacar que o resultado obtido para o espectro vibracional da NP 309 indica, sob o aspecto qualitativo, que a simplificação adotada retém os elementos físicos fundamentais no que diz respeito ao comportamento do espectro vibracional. Esse aspecto será discutido mais detalhadamente no capítulo 5 . 
A identificação de um pico em torno de $115 \mathrm{~cm}^{-1}$ para as nanopartículas com mais que 79 átomos indica que as propriedades vibracionais das nanopartículas maiores tendem as propriedades vibracionais cristalinas, que apresenta um pico característico em $115 \mathrm{~cm}^{-1}$.

Os espectros obtidos para as superfícies apresentam um pico mais estreito que as nanopartículas, entretanto mais largo que o pico mais característico do cristal, correspondendo a uma situação intermediária entre este dois limites estruturais (nanopartícula $\leftrightarrow$ cristal)

Associamos o estreitamento do pico com o aumento da estrutura à limitação dos modos vibracionais possíveis, já que com o aumento da nanopartícula, ocorre a prevalência de sítios c12 (característico do cristal) e, consequentemente, os modos a ele associados. Esperamos, com o aumento das nanopartículas, que o pico secundário presente no cristal em $50 \mathrm{~cm}^{-1}$ seja cada vez mais explícito. A presença deste sinal em $50 \mathrm{~cm}^{-1}$ explicaria a maior dispersão do espectro para a NP $309 \mathrm{em}$ relação à NP 147 (figura 3.8).

Representando visualmente os átomos com maior amplitude de vibração da nanopartícula associados às energias dos modos vibracionais para a NP 147, figura 3.9, identificamos qualitativamente que existe uma maior concentração de modos associados à vibração dos átomos da superfície para a região do espectro na faixa de baixas energias. Com o aumento da energia associada aos modos de vibração verifica-se o deslocamento da distribuição de átomos com maior amplitude de vibração para as regiões internas da nanopartícula. Para as energias intermediárias os átomos com maior amplitude de vibração estão distribuídos tanto na superfície quanto no interior.

Estendemos esta análise por meio do cálculo da distância média ao centro da nanopartícula dos átomos com alta e baixa amplitude de vibração associados à cada modo vibracional para as NPs 079 e 147. Nesta análise valores maiores para a dis- 


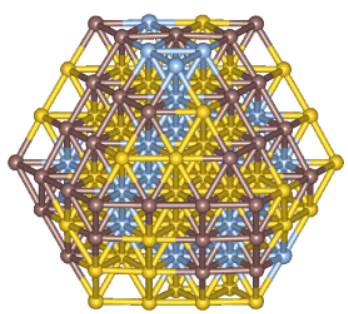

$30 \mathrm{~cm}^{-1}$

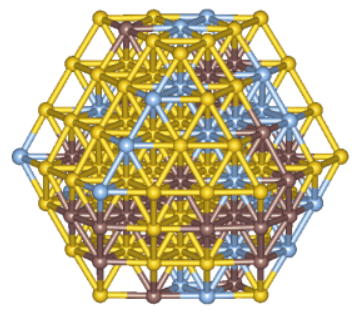

$120 \mathrm{~cm}^{-1}$

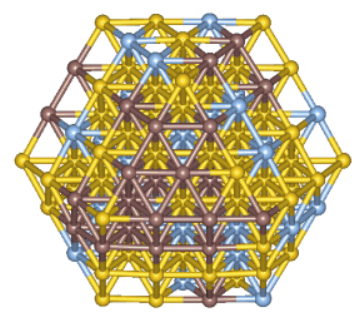

$60 \mathrm{~cm}^{-1}$

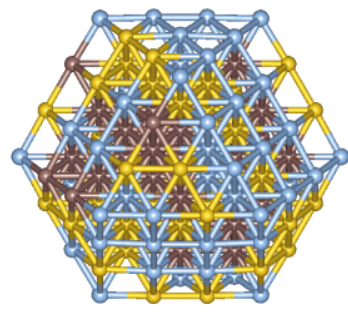

$150 \mathrm{~cm}^{-1}$

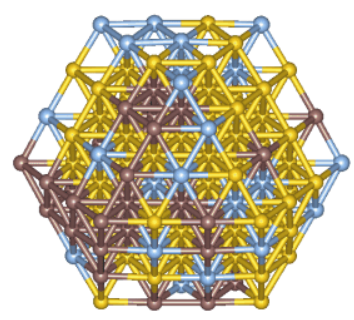

$90 \mathrm{~cm}^{-1}$

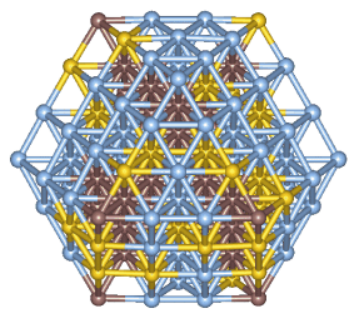

$170 \mathrm{~cm}^{-1}$

Fig. 3.9: Representação dos átomos que vibram para diferentes faixas entre 30 e $170 \mathrm{~cm}^{-1}$ na NP 147. Em marrom os átomos cuja oscilação assume valores mais elevados; em amarelo os átomos com amplitude de vibração intermediária e em azul os átomos cuja amplitude de vibração não é significativa.

tância média dos átomos com alta amplitude de vibração estão associados às vibrações na superfície da nanopartícula, enquanto que valores maiores para a distância média dos átomos com baixa amplitude de vibração estão associados às vibrações no interior da nanopartícula.

Na figura 3.10 representamos para as NPs 079 e 147 a evolução da distância média ao centro, relativa ao raio da nanopartícula, para os átomos com maior e menor amplitude de vibração com o aumento da energia dos modos vibracionais. Considerando o limite de grandes nanopartículas para esta análise a média da distância ao centro de uma distribuição esférica e homogênea de átomos é $75 \%$. Sendo assim, valores maiores que $75 \%$ dão um indicativo que a média está mais próxima da superfície da nanopatícula (100\%) e abaixo deste valor estão mais próximos de seu centro $(0 \%)$.

Para os dois casos analisados é observada a migração para o interior da na- 


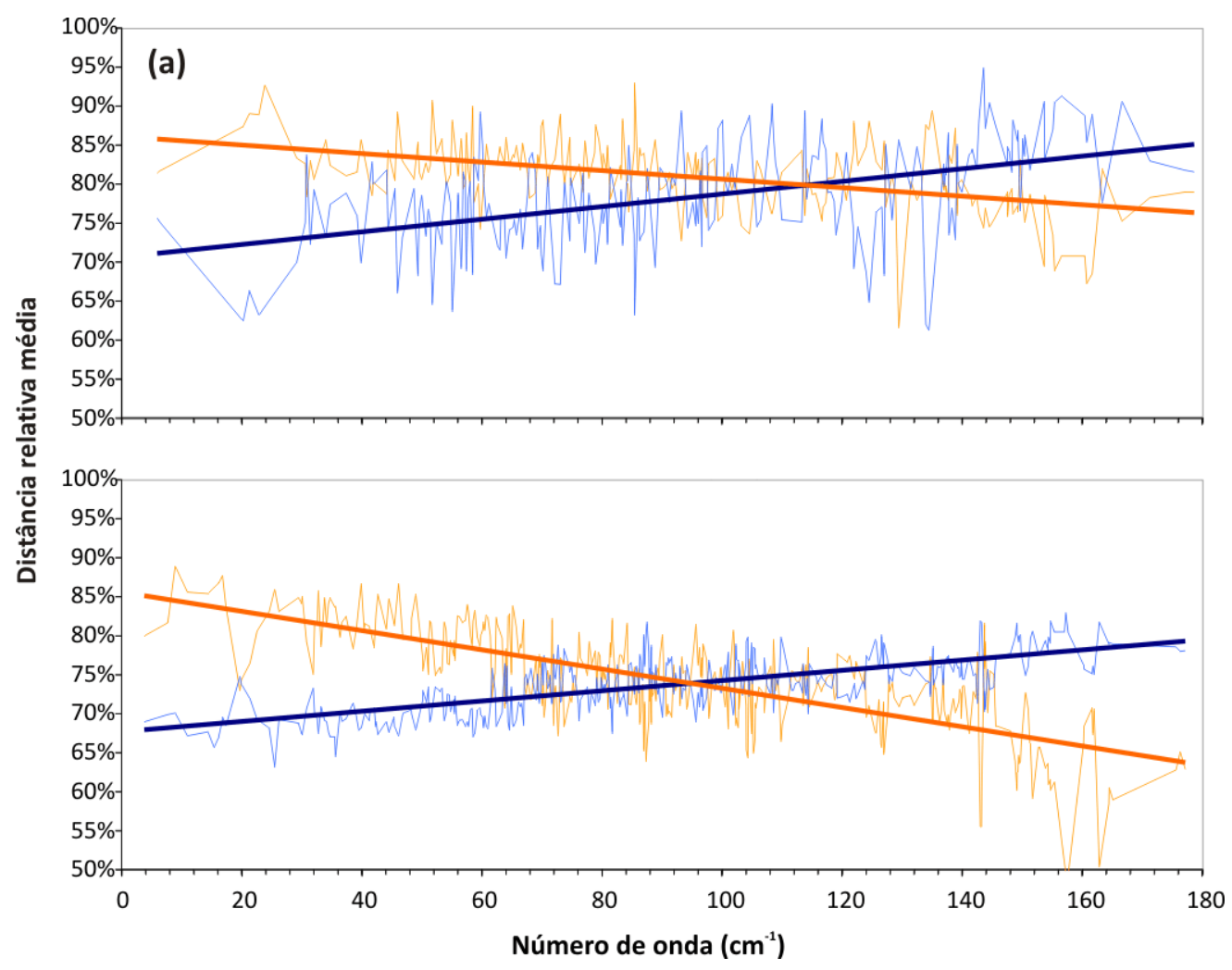

Fig. 3.10: Distâncias média ao centro da NP (relativa ao raio da NP considerada), calculada com respeito aos átomos de um mesmo modo vibracional que apresentam maior (laranja) e menor (azul) amplitude de vibração como função da energia do modo vibracional: (a) NP 079; (b) NP 147. O centro da nanopartícula está em $0 \%$ e a superfície em $100 \%$. As retas correspondem aos ajustes lineares em cada caso.

nopartícula dos modos mais energéticos, reproduzindo o padrão observado para a NP 147 na figura 3.9. Assim, na figura 3.10, obtemos uma quantificação de caráter estatístico desta separação gradual entre modos de oscilação de superfície (baixas energias) daqueles de caroço (maiores energias). $\mathrm{O}$ comportamento invertido entre as curvas de localização de átomos com maior ou menor intensidade de vibração é complementar como se vê, ocorrendo, simultaneamente à migração da mobilidade dos modos vibracionais para o interior da NP, a recíproca da maior imobilidade de átomos na superfície.

A quantidade maior de átomos na NP 147 faz com que o padrão estatístico seja 
menos flutuante, ao passo que para a NP 079 observamos que a flutuação é bem mais acentuada. Acreditamos que essa flutuação acentuada reflete o fato de que nas nanopartículas menores existe uma forte influência da superfície, o que inibe uma distinção clara entre as contribuições de caroço e superfície. Nesse contexto, nossa descrição baseada na mobilidade dos átomos de superfície e de caroço deixa de ser aplicável para pequenas nanopartículas.

O ponto onde estas duas curvas de tendência se encontram, nas figuras 3.10 (a) e (b), corresponde a uma distribuição equivalente de átomos de baixa e alta amplitude de vibração com respeito ao centro da NP, onde, portanto, não é verificada a separação acima mencionada entre modos vibracionais característicos de caroço ou de superfície. Este ponto goza, assim, de um aspecto muito semelhante à distribuição dos modos vibracionais cristalinos no interior da célula unitária, onde, naturalmente, não existe a separação em regiões de caroço e superfície, com vibrações presentes por toda a extensão do cristal. De modo que, o encontro das curvas de tendência na região próxima a $115 \mathrm{~cm}^{-1}$ para os dois casos estudados estabelece a correspondência com o modo típico cristalino com pico principal do espectro vibracional nesta região. Por outro lado, o deslocamento do encontro entre as retas para menores energias deve estar relacionado à contribuição cada vez mais significativa do pico secundário de cristal em $50 \mathrm{~cm}^{-1}$, provocando, inclusive o encontro abaixo de $115 \mathrm{~cm}^{-1}$ para a NP 147.

Vale ressaltar que para a NP 147 o encontro das retas se dá muito próximo de $75 \%$ se comparado com a NP 079, indicando que este tamanho já apresenta uma comportamento próximo ao esperado para o limite grandes nanopartículas.

Esta analogia pode ser estendida à análise da superfície, tomando agora a altura média a partir do plano central relativa a altura máxima da fatia da superfície dos átomos que vibram com maior ou menor intensidade. Como podemos observar na figura 3.11 a superfície [001] também exibe a mesma separação energética entre 
modos de superfície (de energia mais baixa) e modos interiores à fatia (de energia mais alta), verificadas para as nanopartículas.

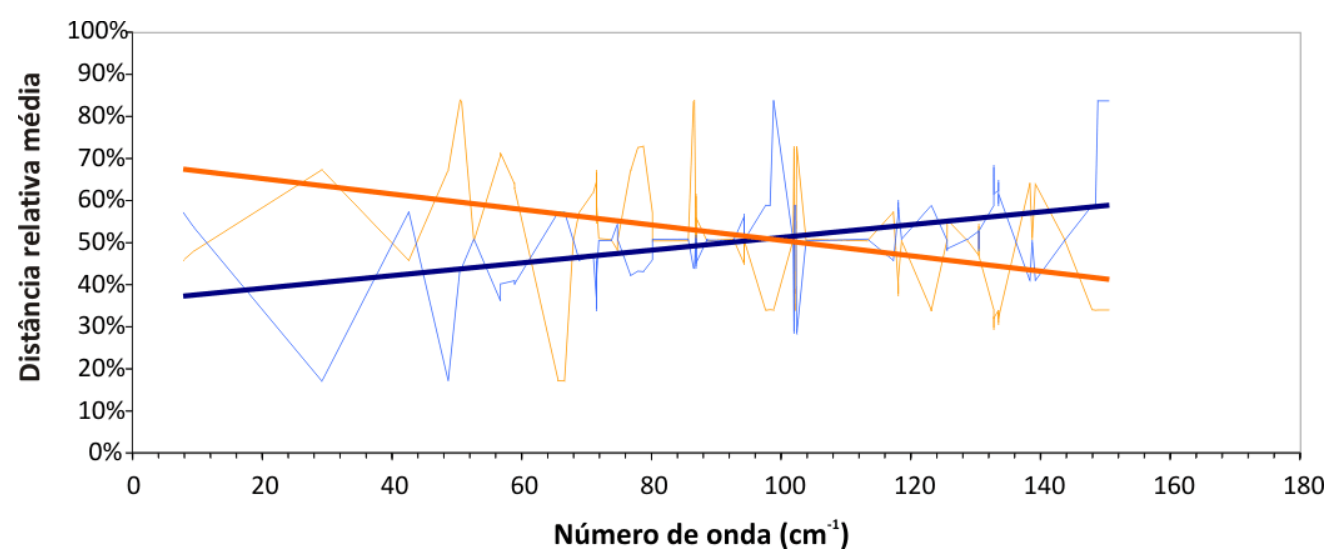

Fig. 3.11: Altura média a partir do plano central relativa a altura máxima da fatia da superfície calculada entre os átomos de um mesmo modo vibracional que apresentam maior (laranja) e menor (azul) amplitude de vibração como função da energia do modo vibracional para a superfície [001]. O plano central está em 0\% e a superfície em 100\%.

O encontro das retas em $98 \mathrm{~cm}^{-1}$ para a superfície [001], correspondendo aos modos coletivos sobre todo o sistema, está também em concordância com os modos vibracionais cristalinos, indicando inclusive a influência do pico em $50 \mathrm{~cm}^{-1}$ deslocando o cruzamento para a região abaixo de $115 \mathrm{~cm}^{-1}$.

Assim, podemos inferir que os picos largos presentes nos espectros vibracionais das nanopartículas está relacionada à presença dos estados associados aos modos vibracionais nos domínios extremos de vibrações na superfície (baixa energia) e de vibrações no interior (alta energia). Já o estreitamento da largura do pico com o aumento da nanopartícula está relacionado à redução da representatividade da superfície em relação a região interna cristalina, tornando as duas regiões indistinguíveis, com predominância dos modos de vibração internos semelhantes aos do cristal. 


\section{Capítulo 4}

\section{Adsorção nas nanopartículas de}

\section{prata}

Complementarmente ao estudo das nanopartículas livres de prata, realizamos a adsorção de alguns compostos sobre a superfície das nanopartículas de prata com o objetivo de identificar padrões nas propriedades associadas às adsorções para os diferentes tamanhos e formatos das nanopartículas. Analisamos as propriedades estruturais, energéticas, eletrônicas e vibracionais das adsorções.

Um estudo mais extenso foi realizado com a adsorção do radical metil $\left(\mathrm{CH}_{3}\right)$, sobre um conjunto grande de nanopartículas livres entre 006 e 309 átomos. A escolha do metil se dá por ser um radical orgânico pequeno, que simplifica o tratamento computacional e a análise das ligações Ag-C e C-H. Na figura 4.1 estão representadas as adsorções do metil realizadas sobre os sítios distintos presentes nas superfícies das NPs 147 e 309.

Estudamos também a adsorção do radical vinil $\left(\mathrm{C}_{2} \mathrm{H}_{3}\right)$ e da molécula de fosfina $\left(\mathrm{PH}_{3}\right)$ sobre as nanopartículas até 147 átomos. Possibilitando analisar a influência da adsorção na ligação C-C presente no radical vinil e, também, o interação da nanopartícula com uma molécula. 


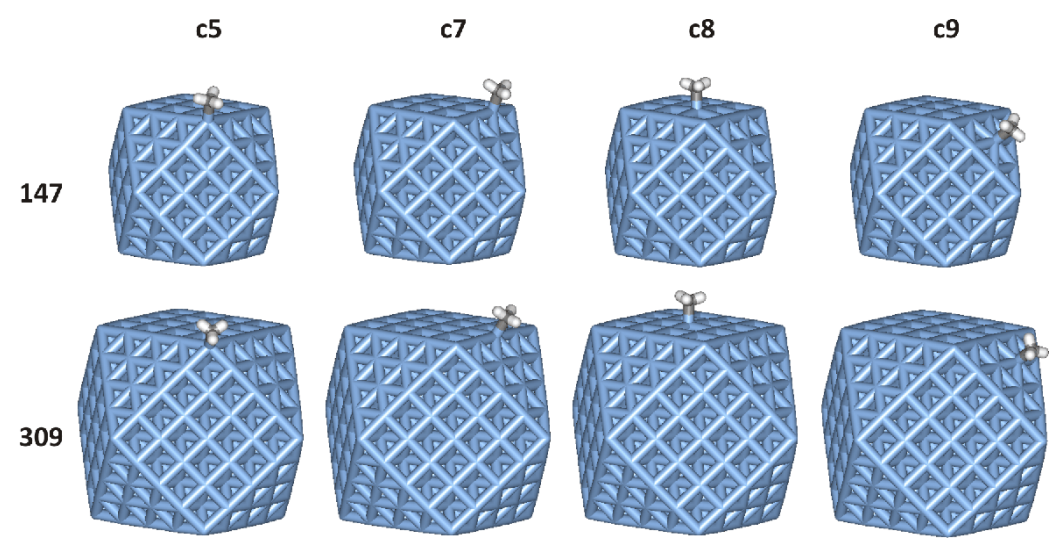

Fig. 4.1: Representação das adsorções de metil nos sítios c5, c7, c8 e c9 das NPs 147 (acima) e 309 (abaixo)

A escolha desses compostos está relacionada com a presença dos seus átomos em estruturas orgânicas que são frequentemente adsorvidas sobre superfícies e nanopartículas metálicas [81, 82, 83, 84, 85, 86, 87].

As simulações envolvendo átomos de carbono foram realizadas considerando 290 eV para a energia de corte na expansão da função de onda em ondas planas, e as simulações envolvendo átomos de enxofre foram realizada considerando $200 \mathrm{eV}$ para a energia de corte. Os resultados preliminares obtidos para os compostos livres através do modelamento teórico utilizado são apresentados no apêndice $\mathrm{D}$, fundamentando os parâmetros de cálculo utilizados nesta etapa do trabalho.

\subsection{Propriedades estruturais}

Verificamos as perturbações provocadas pela adsorção tanto nas nanopartículas quanto nos compostos adsorvidos em relação à configuração livre. Comparamos as propriedades estruturais decorrentes da adsorção para os diferentes tamanhos e formatos das nanopartículas. Analisamos ainda a distância de ligação entre o composto e o sítio adsorvido, a distância média entre o sítio adsorvido e seus vizinhos na nanopartícula e as distâncias de ligação entre os átomos do composto adsorvido. Os 
resultados obtidos para as distâncias de ligação Ag-Ag, Ag-C e C-H das adsorções do radical metil são apresentados na tabela 4.1.

Verificamos que as adsorções sobre as nanopartículas pequenas pode mudar de forma significativa a geometria da nanopartícula. Isto ocorreu para a adsorção sobre a NP 006 oct, para todas as adsorções realizadas sobre os diferentes sítios da NP 043 esf e para algumas adsorções realizadas sobre a NP 055 c-oct. Para estes casos retiramos o radical e relaxamos a nanopartícula modificada livre para verificar se recuperava a configuração inicial FCC. Em todos os casos não recuperaram a geometria inicial FCC e atingiram uma configuração livre mais estável. Estes resultados indicam, portanto, que as adsorções podem induzir as nanopartículas pequenas a transitarem de uma geometria metaestável para uma geometria mais estável.

Para as demais nanopartículas, acima de 55 átomos, a adsorção modificou muito pouco a sua configuração. A média da distância da ligação Ag-Ag entre o sítio adsorvido e os átomos da sua primeira vizinhança na nanopartícula variou, nesses casos, menos que $2 \%$ quando comparada a mesma média na nanopartícula livre.

As adsorções praticamente não modificaram a geometria do radical metil. O valor médio da distância de ligação C-H, considerando todas as adsorções do metil, foi de 1,09(0) Å. O desvio amostral, indicado entre parênteses, é nulo por se apresentar menor que a precisão adotada, indicando que a distância de ligação C-H praticamente não varia entre as diferentes adsorções. Esta distância é equivalente a distância C-H obtida para o radical metil livre (1,09 ̊) e para a molécula de metano livre (1,10 ̊), indicando, também, que a ligação C-H não é influenciada pelo processo de adsorção.

As distâncias de ligação Ag-C para as adsorções sobre sítios de mesma coordenação em nanopartículas diferentes apresentaram valores muito próximos. Por outro lado, entre sítios diferentes o valor médio das distâncias de ligação Ag-C cresceu sutilmente com o aumento da coordenação do sítio, variando de 2,14(1) 
Tab. 4.1: Parâmetros estruturais da adsorção do metil na nanopartícula de prata: média das distâncias das ligações Ag-Ag entre o sítio adsorvido e seus vizinhos na nanopartícula; distância de ligação Ag-C entre o sítio adsorvido e o átomo de carbono do radical metil; e média das distâncias das ligações $\mathrm{C}-\mathrm{H}$ no radical metil. Os resultados estão agrupados pela coordenação do sítio adsorvido. Ao final do grupo está calculada a média e o desvio amostral $(\sigma)$ das distâncias obtidas para as diferentes nanopartículas dentro do grupo. A distância para o sítio c3 foi obtida apenas para a NP 087. Para os sítios c8 e c9 também são indicados os resultados das distâncias obtidas, respectivamente, para as superfícies [001] e [111].

\begin{tabular}{|c|c|c|c|c|c|}
\hline Estrutura & Formato & Sítio & Ag-Ag $(\AA)$ & Ag-C $(\AA)$ & C-H $(\AA)$ \\
\hline 087 & esf & $\mathrm{c} 3$ & 2,82 & 2,15 & 1,10 \\
\hline 006 & oct & $\mathrm{c} 4$ & 2,80 & 2,14 & 1,09 \\
\hline 019 & oct & $\mathrm{c} 4$ & 2,83 & 2,14 & 1,10 \\
\hline 044 & oct & $\mathrm{c} 4$ & 2,84 & 2,14 & 1,09 \\
\hline 085 & oct & $\mathrm{c} 4$ & 2,83 & 2,14 & 1,10 \\
\hline 141 & esf & $\mathrm{c} 4$ & 2,86 & 2,15 & 1,10 \\
\hline \multirow[t]{2}{*}{146} & oct & $\mathrm{c} 4$ & 2,85 & 2,14 & 1,09 \\
\hline & Médias $(\sigma)$ & $\mathrm{c} 4$ & $2,83(2)$ & $2,14(0)$ & $1,09(0)$ \\
\hline 013 & c-oct & $\mathrm{c5}$ & 2,89 & 2,15 & 1,09 \\
\hline 055 & c-oct & $\mathrm{c} 5$ & 2,91 & 2,16 & 1,10 \\
\hline 147 & c-oct & c5 & 2,91 & 2,16 & 1,10 \\
\hline 177 & esf & $\mathrm{c} 5$ & 2,89 & 2,15 & 1,10 \\
\hline \multirow[t]{2}{*}{309} & c-oct & $\mathrm{c} 5$ & 2,89 & 2,16 & 1,09 \\
\hline & Médias $(\sigma)$ & $\mathrm{c5}$ & $2,90(1)$ & $2,15(0)$ & $1,10(0)$ \\
\hline 079 & oct & $\overline{c c 6}$ & 2,89 & 2,16 & 1,09 \\
\hline 087 & esf & c6 & 2,92 & 2,17 & 1,09 \\
\hline 135 & esf & c6 & 2,92 & 2,17 & 1,09 \\
\hline \multirow[t]{2}{*}{141} & esf & c6 & 2,95 & 2,18 & 1,09 \\
\hline & Médias $(\sigma)$ & $\mathrm{c6}$ & $2,92(2)$ & $2,17(1)$ & $1,09(0)$ \\
\hline 019 & oct & c7 & 2,90 & 2,17 & 1,09 \\
\hline 044 & oct & c7 & 2,91 & 2,17 & 1,09 \\
\hline 055 & c-oct & c7 & 2,96 & 2,18 & 1,09 \\
\hline 079 & t-oct & c7 & 2,93 & 2,17 & 1,09 \\
\hline 085 & oct & c7 & 2,91 & 2,17 & 1,09 \\
\hline 087 & esf & c7 & 2,92 & 2,18 & 1,09 \\
\hline 147 & c-oct & c7 & 2,95 & 2,18 & 1,10 \\
\hline \multirow[t]{2}{*}{309} & c-oct & c7 & 2,94 & 2,18 & 1,09 \\
\hline & Médias $(\sigma)$ & $\mathrm{c} 7$ & $2,93(2)$ & $2,17(0)$ & $1,09(0)$ \\
\hline 055 & c-oct & c8 & 3,01 & 2,19 & 1,10 \\
\hline 135 & c-oct & c8 & 2,98 & 2,19 & 1,09 \\
\hline 147 & c-oct & c8 & 2,99 & 2,19 & 1,09 \\
\hline 177 & esf & c8 & 2,98 & 2,19 & 1,09 \\
\hline \multirow[t]{2}{*}{309} & c-oct & c8 & 2,98 & 2,20 & 1,09 \\
\hline & Médias $(\sigma)$ & $\mathrm{c} 8$ & $2,99(1)$ & $2,19(0)$ & $1,09(0)$ \\
\hline s001 & FCC & c8 & 2,99 & 2,19 & 1,09 \\
\hline 079 & t-oct & c9 & 2,99 & 2,19 & 1,09 \\
\hline 135 & esf & c9 & 3,00 & 2,20 & 1,09 \\
\hline 147 & c-oct & c9 & 3,01 & 2,20 & 1,09 \\
\hline \multirow[t]{2}{*}{309} & c-oct & c9 & 2,99 & 2,22 & 1,09 \\
\hline & Médias $(\sigma)$ & c9 & $3,00(1)$ & $2,20(1)$ & $1,09(0)$ \\
\hline s111 & FCC & c9 & 2,99 & 2,20 & 1,09 \\
\hline
\end{tabular}


para o sítio c4 até 2.20(0) Å para o sítio c9. O valor médio das distâncias de ligação foi calculado a partir da média entre as distâncias de ligação das adsorções sobre o sítio de mesma coordenação realizadas em diferentes nanopartículas. O baixo valor obtido para o desvio padrão amostral, menor que $0,4 \%$ do valor da distância de ligação, mostra que a distância de ligação $\mathrm{Ag}-\mathrm{C}$ sofre pouca influência com a mudança do tamanho ou formato das nanopartículas, dependendo mais explicitamente da coordenação do sítio adsorvido.

Como observamos, a média da distância de ligação Ag-C aumenta com o número de coordenação. Entretanto, como a diferença na distância de ligação entre sítios adjacentes é da ordem do desvio padrão amostral, as adsorções são praticamente indistinguíveis. Por outro lado, entre sítios não adjacentes a diferença é superior ao desvio padrão, o que possibilitaria a distinção entre uma adsorção realizada sobre um sítio de alta ou de baixa coordenação.

As propriedades associadas à adsorção do radical vinil $\left(\mathrm{C}_{2} \mathrm{H}_{3}\right)$ foram muito semelhantes às obtidas para o radical metil. A ligação Ag-C se apresentou cerca de 2\% menor quando comparada a adsorção do metil sobre o mesmo sítio. A distância de ligação Ag-C também apresentou o padrão crescente com o aumento da coordenação do sítio, variando de 2,10 Å para os sítio de c3 até 2,15 Å para o sítio c9, que é da mesma ordem que o obtido para o caso da adsorção do metil.

Também nesse caso, adsorver sobre diferentes nanopartículas influencia muito pouco os parâmetros estruturais do radical adsorvido. O valor médio da distância de ligação C-C do radical sobre as diferentes nanopartículas foi de 1,34(1) A, cujo baixo valor amostral indica que a distância C-C praticamente não muda entre as diferentes adsorções. Este valor médio é cerca de $2 \%$ maior que a mesma distância no radical livre e, por outro lado, é equivalente a distância C-C obtida para a molécula isolada de etileno $\left(\mathrm{C}_{2} \mathrm{H}_{4}\right)$. Isto indica que a troca de carga devido a ligação levou a configuração do radical a se aproximar da configuração da molécula. 


\subsection{Propriedades energéticas}

A energia de ligação $\left(E_{l}\right)$ é calculada pela diferença entre a energia total do sistema adsorvido e a soma das energias dos sistemas livres,

$$
E_{l}=E_{a d s}-\left(E_{N P}+E_{c o m p}\right)
$$

onde $E_{a d s}$ é a energia total do sistema adsorvido e $E_{n p}$ e $E_{c o m p}$ são, respectivamente, as energias totais da nanopartícula livre e do composto em fase gasosa.

Na tabela 4.2 são apresentados os resultados das energias de ligação Ag-C obtidas para as adsorções do radical metil sobre as diferentes nanopartículas e sobre as superfícies de prata [001] e [111]. Todas as adsorções se apresentaram energeticamente favoráveis, com valores de energia de ligação entre $0,90 \mathrm{eV}$ e $1,71 \mathrm{eV}$, sendo mais favoráveis as adsorções sobre as nanopartículas menores.

Verificamos para as nanopartículas com mais que 79 átomos que a adsorção é mais favorável quanto menor o número de coordenação do sítio adsorvido. Isto pode ser compreendido pelo fato dos sítios de menor coordenação dividirem sua carga com um número menor de vizinhos, sobrando uma carga maior para realizar a ligação com o composto, fortalecendo a ligação e favorecendo a adsorção.

A exceção à ordem de favorecimento com respeito às coordenações dos sítios ocorre para o sítio c9 da NP 147 que é mais favorável que a adsorção sobre o sítio de coordenação menor c8. Por outro lado, este resultado é compatível com a distribuição espacial da densidade de probabilidade dos níveis em torno do nível de Fermi, figura 3.6, que se localizou fortemente sobre os sítios c9 e praticamente não apresentou contribuição sobre o sítio c8 da NP 147. Indicando, assim, que o sítio c9 deveria ser preferencial. Resultado análogo foi obtido para a NP 055, cuja ordem dos sítios mais favoráveis é compatível com a localização espacial dos níveis, sendo mais favorável a adsorção sobre o sítio c7, em seguida sobre o sítio c5 e por último sobre o sítio c8. 
O favorecimento observado para o sítio c9 em relação ao c8 se assemelha, também, aos resultados obtidos para as adsorções do metil sobre as superfícies de prata [001] e [111]. A adsorção foi mais favorável sobre a superfície [111], com terminação c9, do que sobre a superfície [001], com terminação c8. Esses resultados indicam, ainda, uma tendência das adsorções sobre as nanopartículas maiores se aproximarem das propriedades das adsorções sobre superfícies. Corrobora com esta tendência o fato das energias de ligação das adsorções sobre os sítios c8 e c9 das nanopartículas maiores, 147, 177 e 309, se aproximarem gradativamente com o aumento da nanopartícula e tenderem para os valores obtidos para a energia de ligação das adsorções sobre as superfícies, tabela 4.2.

Tab. 4.2: Energias de ligação do metil sobre os diferentes sítios das nanopartículas e sobre as superfícies [001] e [111]. Energias em eV.

\begin{tabular}{|cc|ccccccc|}
\hline Estrutura & Formato & $\mathrm{c} 9$ & $\mathrm{c} 8$ & $\mathrm{c} 7$ & $\mathrm{c} 6$ & $\mathrm{c5}$ & $\mathrm{c} 4$ & $\mathrm{c} 3$ \\
\hline 006 & oct & & & & & & $-1,71$ & \\
013 & c-oct & & & & & $-1,65$ & & \\
013 & ico & & & & $-1,70$ & & & \\
019 & oct & & & $-1,38$ & & & $-1,54$ & \\
044 & oct & & & $-1,35$ & & & $-1,60$ & \\
055 & c-oct & & $-0,97$ & $-1,29$ & & $-1,10$ & & \\
079 & t-oct & $-1,21$ & & $-1,30$ & $-1,35$ & & & \\
085 & oct & & & $-1,21$ & & & $-1,39$ & \\
087 & esf & & & $-1,18$ & & & $-1,28$ & $-1,27$ \\
135 & esf & $-0,90$ & & $-1,18$ & $-1,24$ & & & \\
141 & esf & & & & $-1,31$ & & & \\
147 & c-oct & $-1,32$ & $-1,13$ & $-1,38$ & & $-1,43$ & & \\
177 & esf & & $-1,09$ & & & & & \\
309 & c-oct & $-1,11$ & - & $-1,21$ & & $-1,37$ & & \\
\hline s001 & FCC & & $-0,97$ & & & & & \\
s111 & FCC & $-1,06$ & & & & & & \\
\hline
\end{tabular}

Resultados semelhantes, com respeito ao decréscimo da energia de ligação com o aumento da coordenação do sítio, foram obtidos para a adsorção do radical vinil $\left(\mathrm{C}_{2} \mathrm{H}_{3}\right)$ sobre a NP 135 e para a adsorção da molécula de fosfina $\left(\mathrm{PH}_{3}\right)$ sobre a NP 147. As energias de adsorção do radical do vinil foram de -1,56, -1,51 e - 
1,22 eV, respectivamente, para os sítios c6, c8 e c9, e as energias de adsorção para a molécula de fosfina foram de $-0,55,-0,43,-0,37$ e $-0,36 \mathrm{eV}$, respectivamente para as adsorções realizadas sobre os sítios c5, c7, c8 e c9.

\subsection{Propriedades eletrônicas}

A figura 4.2 apresenta a comparação entre as densidades de estados (DOS) na faixa de 1 eV em torno do nível de Fermi das NPs 079, 135 e 309 livres e adsorvidas com o radical metil sobre os diferentes sítios presentes em suas superfícies.

As DOS da NP 079 apresentaram maior influência com a adsorção do radical, incluindo estados nas regiões em torno de 0,5 eV acima do nível de Fermi e 0,75 eV abaixo do nível de Fermi. As adsorções sobre a NP 135 apresentaram uma influência menor sobre a DOS como um todo. Todavia, a adsorção claramente induz a formação de estados no meio da faixa proibida, na região $0,25 \mathrm{eV}$ acima do nível de Fermi. A NP 309 não apresentou mudanças significativas na sua DOS decorrentes das adsorções. Acreditamos que esse fato está relacionado à grande modulação da região interna cristalina presente nas maiores nanopartículas.

Nossos resultados sugerem que a influência da adsorção do radical na estrutura eletrônica diminui com o aumento da nanopartícula, sendo mais significativa para as nanopartículas dentro do regime molecular, pouco significativa para o regime misto e praticamente não influenciado nas nanopartículas do regime cristalino.

Na figura 4.3 comparamos para a mesma nanopartícula a DOS da adsorção sobre o sítio c6 do radical metil, com a DOS da adsorção sobre o mesmo sítio do radical vinil. Esta análise foi realizada para as NPs 079, 087, 135 e 141. Verificamos que a mudança do radical metil para o vinil praticamente não altera a DOS.

Analisamos também a variação da carga decorrente do processo de adsorção. Podemos verificar na figura 4.4 que a transferência da carga ocorre praticamente na 

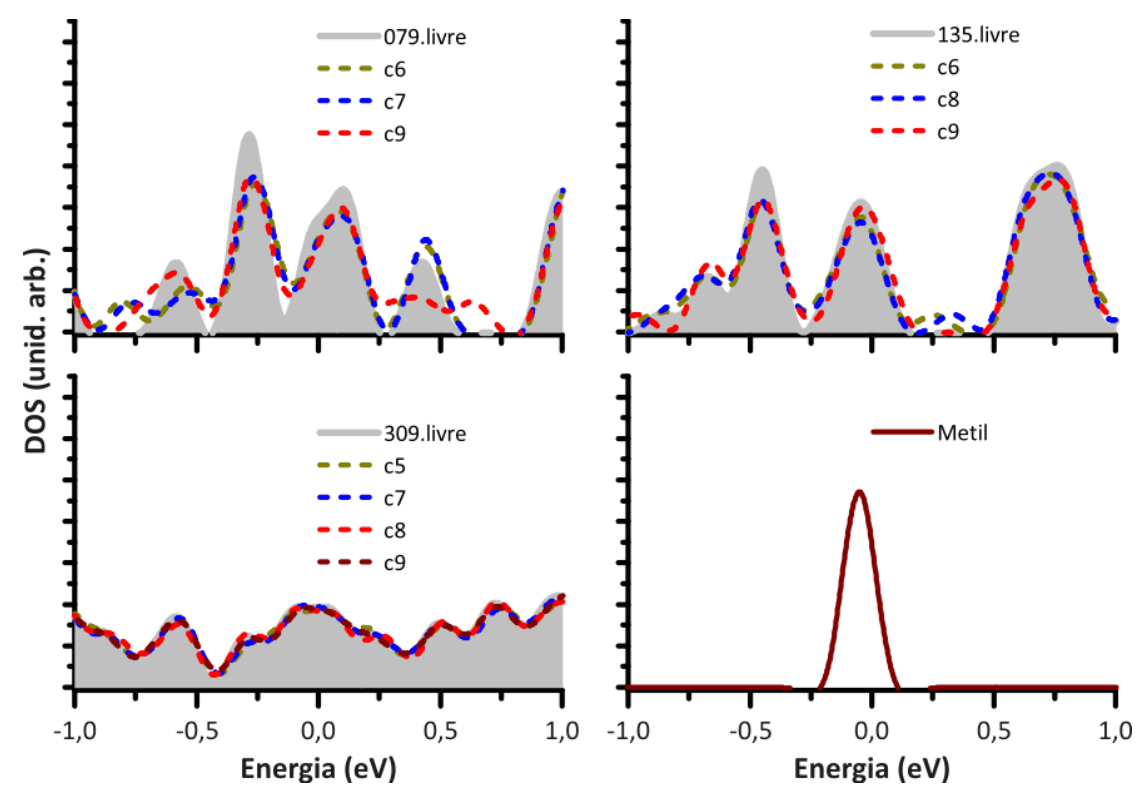

Fig. 4.2: DOS próxima ao nível de Fermi para as adsorções do radical metil sobre os diferentes sítios das NPs 079, 135 e 309, e para o radical metil livre. A região cinza corresponde a DOS da nanopartícula livre. Energia do níuvel de Fermi em 0,0 eV.

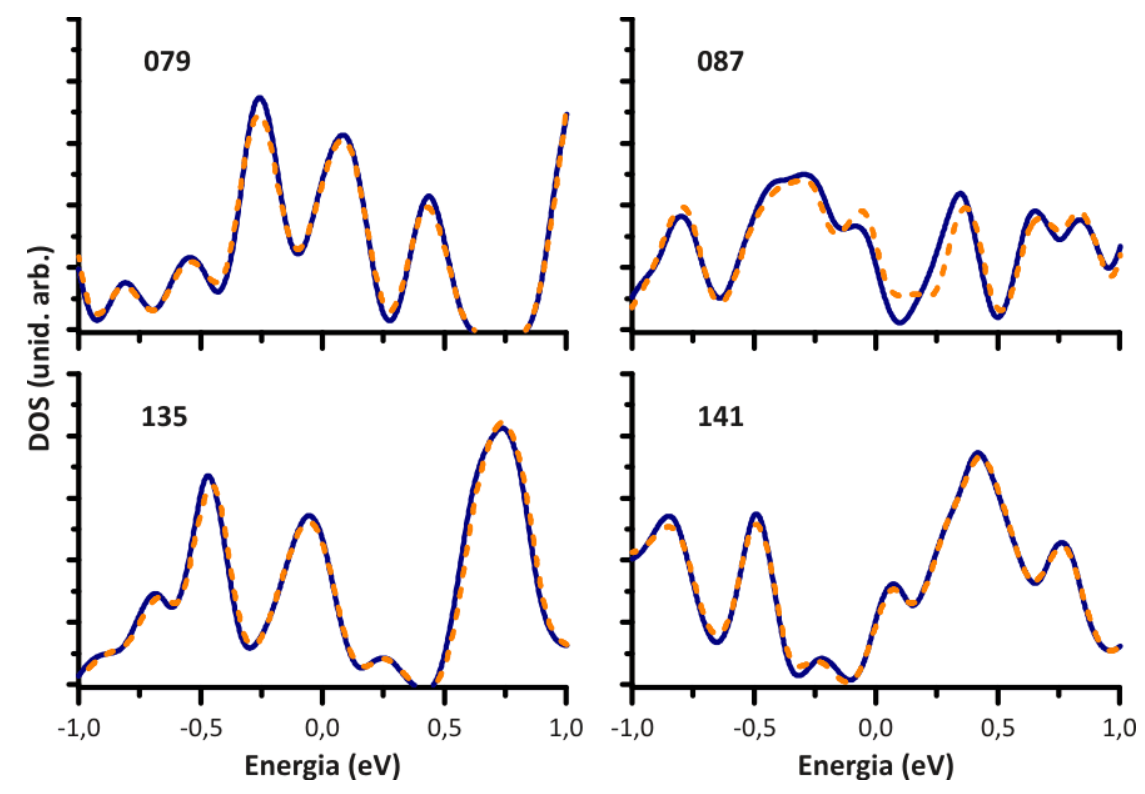

Fig. 4.3: Comparação entre a DOS da adsorção do metil (linha sólida) e a DOS da adsorção do vinil (linha tracejada) sobre o sítio c6 para as NP 079 (A), 087 (B), 135 (C) e 141 (D). Região da DOS próxima ao nível de Fermi. Energia do nível de Fermi em 0,0eV. 
região ao redor do sítio adsorvido para a ligação e para a molécula.

A equivalência nos resultados das transferências de carga para os diferentes tamanhos de nanopartículas demonstra que a adsorção destes radicais orgânicos introduz perturbações locais na distribuição de carga da nanopartícula, influenciando muito pouco as regiões mais distantes do sítio adsorvido. Além disso, podemos observar que a transferência de carga para a adsorção sobre o sítio c7 é muito parecida com as transferências de carga para as adsorções sobre os sítios c4, também indicando pouca influência do tipo de sítio no processo de adsorção.

\subsection{Propriedades vibracionais}

O estudo das propriedades vibracionais foi realizado para as adsorções do radical metil sobre algumas nanopartículas poliédricas com até 147 átomos. No cálculo das propriedades vibracionais foram consideradas para a construção da matriz Hessiana a movimentação todos os átomos do radical, do sítio adsorvido e da primeira vizinhança do sítio adsorvido. Os espectros vibracionais das adsorções realizadas estão representados na figura 4.5.

Como será discutido com mais detalhes no capítulo 5, esta aproximação é adequada para a descrição dos sinais espectroscópicos associados ao composto adsorvido e à ligação entre o composto adsorvido e a nanopartícula, que estão presentes na região de energia acima de $200 \mathrm{~cm}^{-1}$.

Verificamos que as intensidades dos picos variam significativamente entre as adsorções, não apresentando um padrão claro que correlacione o fato de um pico ser mais ou menos intenso de acordo com o tipo de sítio ou nanopartícula. De forma geral, observamos uma forte influência do tamanho da nanopartícula na intensidade dos picos, tornando-se menos intensos com o aumento da nanopartícula. Este resultado indica que os sinais espectroscópicos vibracionais devam ser sensivelmente 


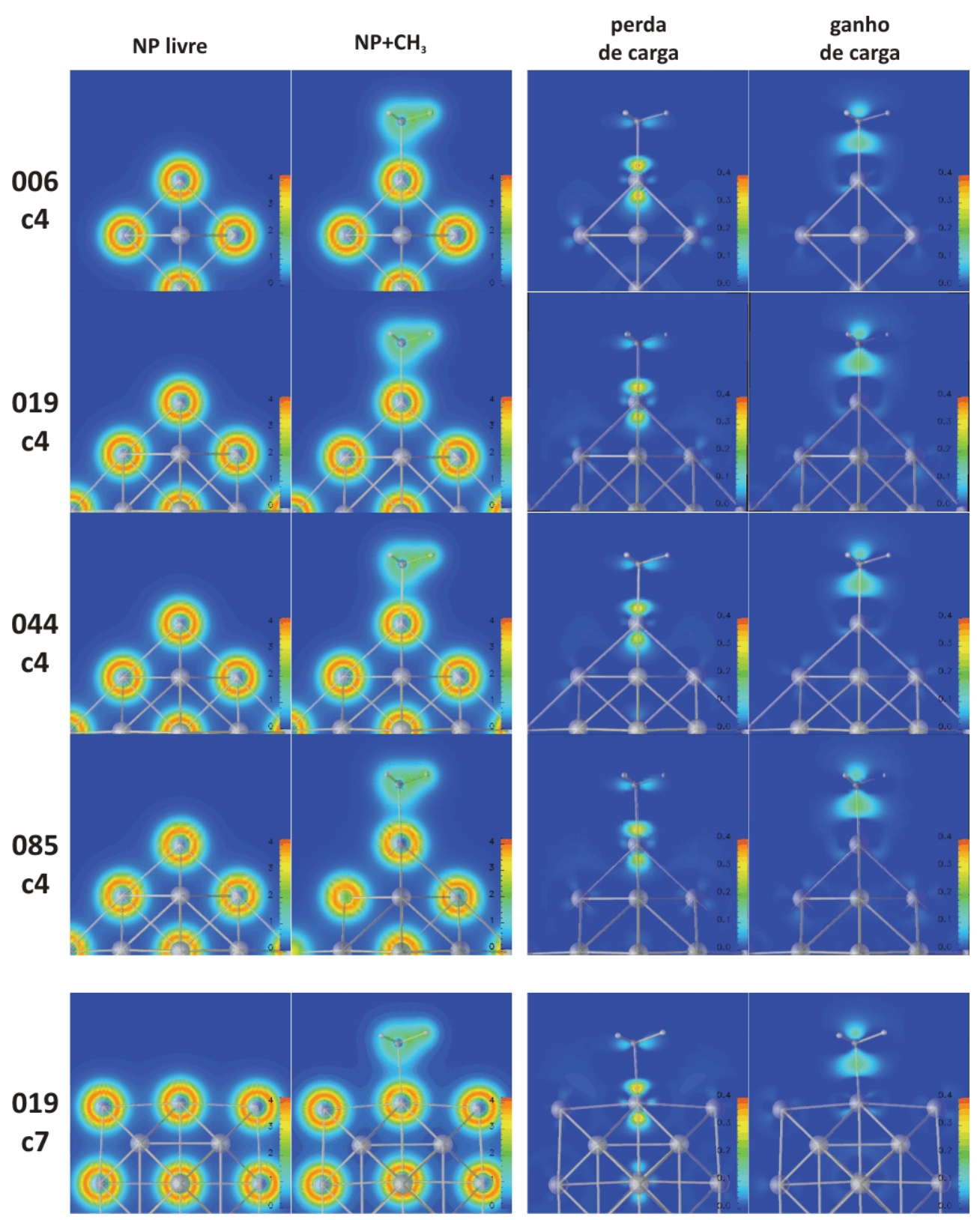

Fig. 4.4: Transferências de carga da nanopartícula para a ligação obtidas para as adsorções do radical metil sobre o sítio c4 das NPs 006, 019, 044 e 085 e sobre o sítio c7 da NP 019. As duas primeiras colunas à esquerda da figura representam a densidade de carga total, sendo a primeira para as nanopartículas livres (NP livre) e a segunda para as nanopartículas adsorvidas com metil $\left(\mathrm{NP}+\mathrm{CH}_{3}\right)$. As duas últimas colunas representam, respectivamente, a perda e o ganho de carga decorrente da transferência de carga no processo de adsorção. A escala de cor para a densidade total varia de 0,0 (azul) até 4,0 elétrons $/ \AA^{3}$ (vermelho) e para a transferência de carga varia de 0,0 (azul) até 0,4 elétrons $/ \AA^{3}$ (vermelho). 


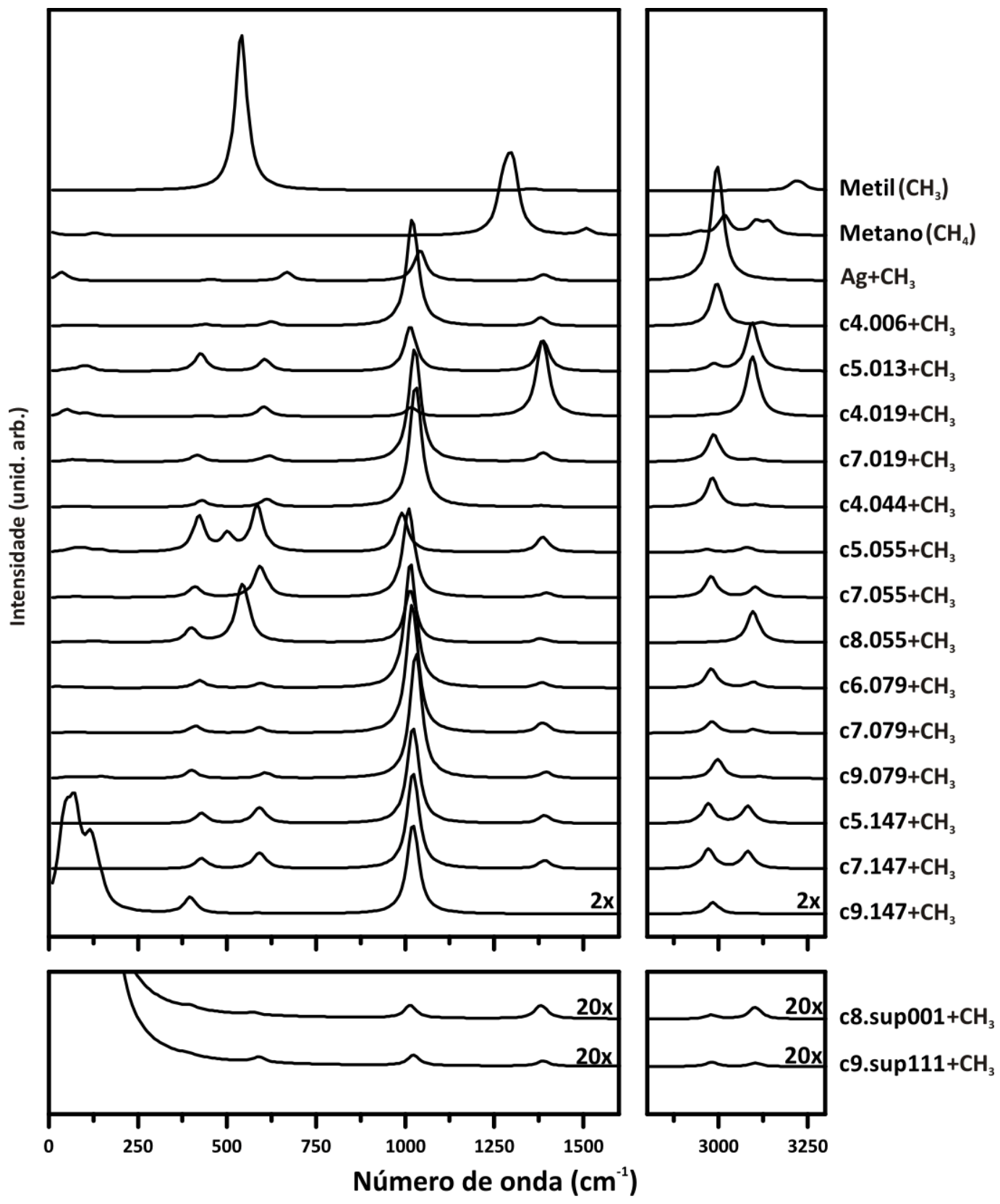

Fig. 4.5: Espectros vibracionais das adsorções do metil realizadas sobre diferentes sítios nas diferentes nanopartículas. Também estão representados os espectros do radical metil e da molécula de metano livres e da adsorção do radical metil sobre um átomo de prata (Ag) e sobre as superfícies [001] e [111]. Para melhor visualização as intensidades dos espectros das adsorções sobre o sítio c9 da NP 147 e sobre as superfícies foram amplificadas, respectivamente, em $2 x$ e 20x. 
mais intensos quando as adsorções das moléculas são realizadas sobre nanopartículas menores.

Em especial, para a adsorção sobre o sítio c9 da NP 147 os sinais espectroscópicos associados às ligações $\mathrm{Ag}-\mathrm{Ag}$ dentro da região até $200 \mathrm{~cm}^{-1}$ são muito intensos, diferentemente do que ocorre para todas as outras adsorções realizadas sobre as nanopartículas presentes nesta análise. Além disso, os picos nas regiões de 600,1390 e $3100 \mathrm{~cm}^{-1}$, que estão associados aos modos de torção, tesoura e estiramento assimétrico da ligação C-H do radical adsorvido, não estão presentes no espectro e os picos nas regiões de 400 e $1020 \mathrm{~cm}^{-1}$, associado ao estiramento da ligação Ag-C, e na região $2990 \mathrm{~cm}^{-1}$, associado ao estiramento simétrico do composto $\mathrm{C}-\mathrm{H}_{3}$, apresentaram suas intensidades reduzidas num fator de $10^{2}$.

Associamos à amplificação dos sinais relacionados às ligações Ag-Ag e redução dos sinais Ag-C e C-H quando o radical é adsorvido sobre o sítio c9, ao fato deste sítio corresponder a uma região plana da superfície desta nanopartícula, visto que não se observa resultado análogo para as adsorções realizadas sobre os sítios c5 e c7 da mesma nanopartícula. Corrobora com este resultado os espectros obtidos para as adsorções sobre as superfícies [001] e [111], cujas intensidades dos picos na região até $200 \mathrm{~cm}^{-1}$ são muito intensas, enquanto que as intensidades dos picos nas região acima desta faixa se apresentam reduzidas no fator de $10^{20}$ em relação às demais adsorções sobre as nanopartículas. Esse resultado também é compatível com as observações experimentais que obtiveram uma amplificação dos sinais espectroscópicos Raman de moléculas orgânicas da ordem de $10^{5}$ quando adsorvidas em superfícies metálicas rugosas $[5,6,7]$ e da ordem de $10^{14}$ quando adsorvidas sobre nanopartículas metálicas [8].

Por outro lado, a adsorção sobre o sítio c9 da NP 079 não apresenta a mesma amplificação dos sinais até $200 \mathrm{~cm}^{-1}$. Acreditamos que isto se deva ao fato de que, nesta nanopartícula, a superfície que contém o sítio c9 é muito pequena, composta 
apenas de um sítio c9 cercado pelos sítios c6 e c7, não caracterizando, assim, um plano como na NP 147 e nas superfícies [001] e [111].

Os modos vibracionais apresentaram energias muito parecidas para as diferentes adsorções realizadas nesta análise, sendo, de maneira geral, pouco influenciados pelo processo de adsorção. Os resultados mais distintos foram observados para a adsorção sobre o sítio c5 da NP 055, que apresentou três picos na região entre 400 e $700 \mathrm{~cm}^{-1}$ e para a adsorção sobre o sítio c8 da mesma nanopartícula que apresentou o segundo pico acima de $200 \mathrm{~cm}^{-1}$ na região de $550 \mathrm{~cm}^{-1}$, enquanto as demais adsorções apresentaram este pico na região de $600 \mathrm{~cm}^{-1}$. Associamos essas flutuações às distorções provocadas pela adsorção sobre essa nanopartícula.

Os picos presentes no espectro vibracional na região acima de $200 \mathrm{~cm}^{-1}$ estão associados a nove modos vibracionais característicos das ligações $\mathrm{C}-\mathrm{H}$ do radical e da ligação Ag-C entre o radical e a nanopartícula. Os valores médios dos modos vibracionais estão descritos na tabela 4.3 em comparação com os modos vibracionais do radical metil e da molécula de metano livres. Para o cálculo do valor médio dos modos não foram considerados as adsorções sobre os sítios c5 e c8 da NP 055, devido à maior variação presente nas energias dos modos dessas adsorções.

Para as nanopartículas consideradas foram analisados os valores médios das energias dos modos vibracionais obtidos tanto para as adsorções sobre todas as nanopartículas, como separadamente para cada tipo de sítio adsorvido. Os desvios amostrais foram pequenos, indicando que as energia dos modos vibracionais são muito parecidas.

Identificamos uma leve correlação do modo de estiramento Ag-C, próximo de $420 \mathrm{~cm}^{-1}$, com a coordenação do sítio adsorvido, apresentando uma energia vibracional menor para os sítios de maior coordenação. Isto fica claro quando observamos na tabela 4.3 a média dos modos vibracionais separados pelo tipo de coordenação do sítio. As energias médias decrescem de $432 \mathrm{~cm}^{-1}$ para o sítio c4 até 
$398 \mathrm{~cm}^{-1}$ para o sítio c9, indicando que a ligação Ag-C é mais forte para os sítios de menor coordenação. Este resultado é compatível com os resultados obtidos para as distâncias de ligação Ag-C, discutidas na seção de propriedades geométricas deste capítulo, que se apresentam menores e, portanto, mais fortes para os sítios de menor coordenação.

Verificamos, ainda, que os picos dos modos de estiramento simétrico e assimétrico, na região próxima à $3000 \mathrm{~cm}^{-1}$, se deslocaram para a região de energia mais baixa em relação ao radical livre, indicando uma redução na dureza da ligação. Por outro lado, estes picos estão bem próximos aos resultados obtidos para a molécula de metano. Assim como observado para as propriedades geométricas do radical vinil, este resultado também indica uma aproximação estrutural do radical adsorvido $\left(\mathrm{Ag}-\mathrm{CH}_{3}\right)$ para a configuração da molécula de metano $\left(\mathrm{H}-\mathrm{CH}_{3}\right)$. 


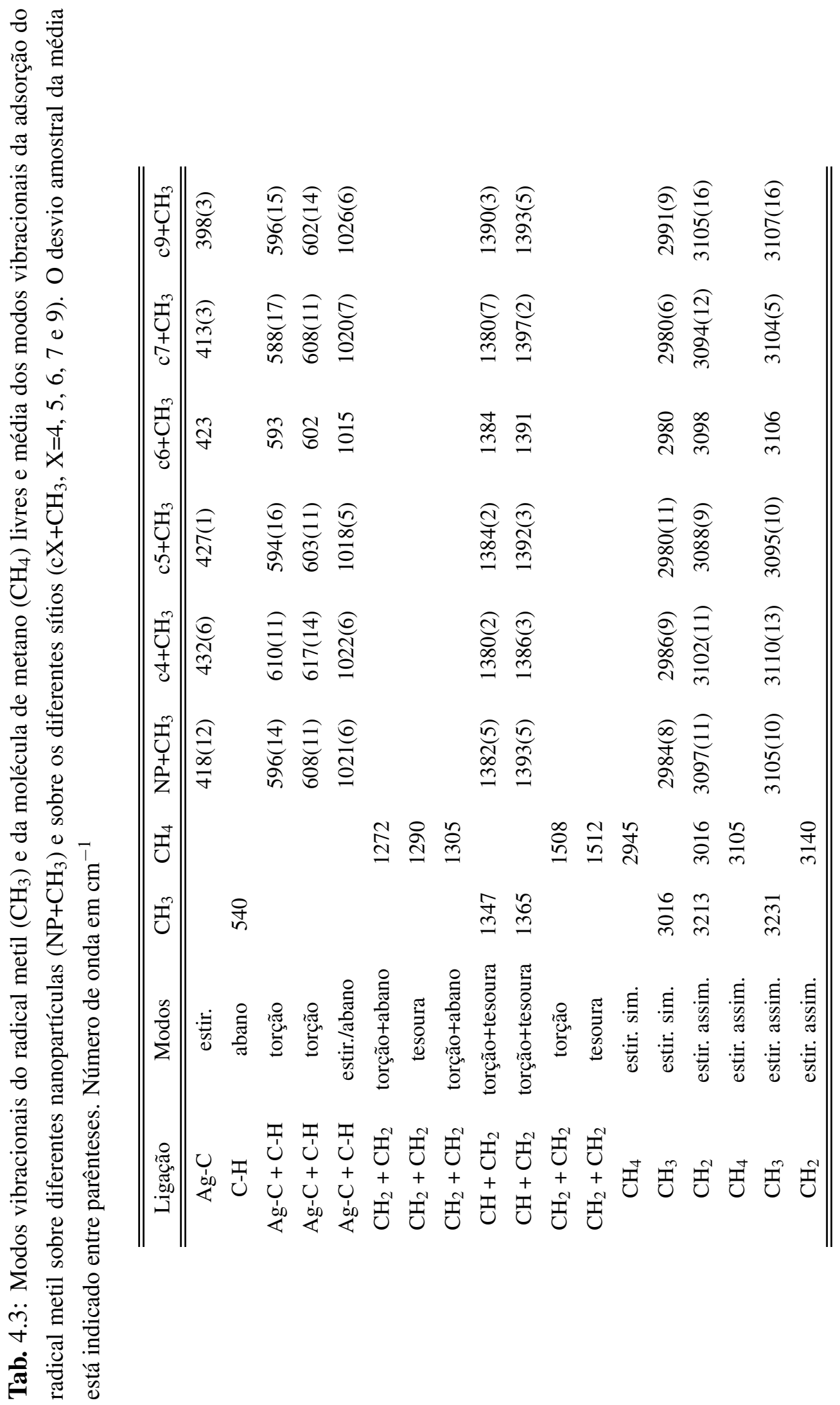




\section{Capítulo 5}

\section{Simplificações para os cálculos das}

\section{nanopartículas}

Com o intuito de reduzir o custo computacional no tratamento das estruturas, as nanopartículas são frequentemente simplificadas por um conjunto menor de átomos. Dessa forma, procuramos identificar em quais condições algumas simplificações reproduzem as propriedades das nanopartículas.

\subsection{Propriedades vibracionais utilizando sítios repre- sentativos}

As propriedades vibracionais são obtidas da matriz Hessiana construídas a partir das forças que agem nas estruturas sujeitas a pequenos deslocamentos de todos os seus $N$ átomos conforme descrito na seção 1.4. Contudo, para calcular a Hessiana incluindo todos os átomos são necessárias $6 N$ movimentações nucleares, e para cada movimentação nuclear é necessária uma convergência eletrônica.

Para a NP 309, por exemplo, utilizando um computador de alto desempenho do LCCA-USP (Laboratório de Computação Científica Avançada da Universidade de 
São Paulo), o tempo total de simulação realizada em paralelo com quatro processadores é de aproximadamente 230 dias. Tendo em vista esta dificuldade computacional, a movimentação dos átomos é geralmente realizada para um conjunto menor de átomos que seja representativo da estrutura.

\subsubsection{Propriedades vibracionais das nanopartículas livres}

Para verificar se os resultados das propriedades vibracionais das nanopartículas livres obtidas com um conjunto menor de átomos é compatível com os resultados utilizando todos os átomos, realizamos uma análise comparativa entre os espetros vibracionais obtidos para diferentes números de átomos utilizados na construção da matriz Hessiana.

O primeiro espectro é obtido utilizando um conjunto mínimo de átomos formado pelos átomos distintos presentes na superfície e no interior. Em seguida obtemos o espectro incorporando a primeira vizinhança ao redor deste conjunto mínimo. Adicionamos, então, a segunda vizinhança e assim por diante até que todos os átomos tenham sido incluídos no cálculo. Na figura 5.1 estão representados os átomos mínimos para a NP 147 e também a primeira e segunda vizinhança destes átomos mínimos. Este estudo foi realizado para as NPs 013, 055, 079, 147 e 309 e os espectros vibracionais obtidos estão representados na figura 5.2.

Para as NP 013, o conjunto mínimo de átomos distintos é composto de dois átomos, sendo um na superfície (c5) e um no centro (c12). A primeira vizinhança já incorpora todos os átomos. Portanto, para esta nanopartícula foram analisados dois espectros. Um espectro parcial, obtido considerando o conjunto mínimo de átomos, e o outro espectro já completo, considerando todos os átomos da nanopartícula. Os espectros obtidos são muito distintos e demonstram que a simplificação não é adequada para a obtenção das propriedades vibracionais da nanopartícula livre, sendo necessária a utilização de todos os átomos. 

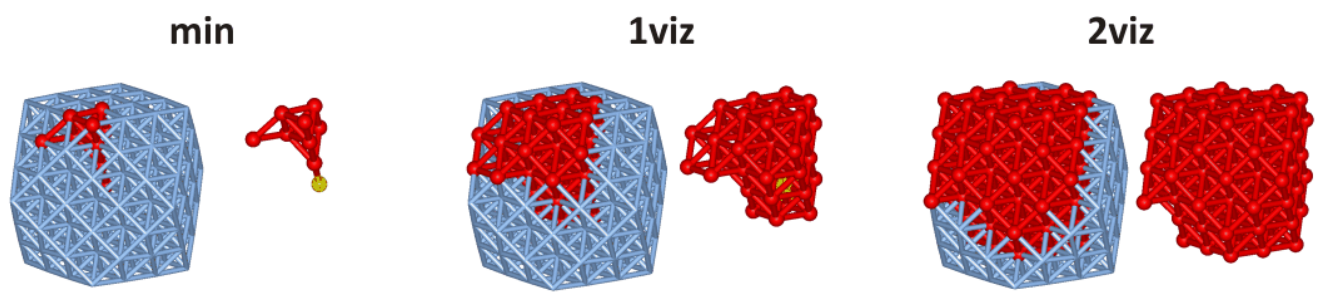

Fig. 5.1: Representação dos conjuntos de átomos utilizados para o cálculo da matriz Hessiana e obtenção das propriedades vibracionais para a NP 147. Os átomos azuis representam a NP 147 completa, os átomos vermelhos representam os conjuntos de átomos: (min) mínimos; (1viz) até a primeira vizinhança do conjunto mínimo; e (2viz) até a segunda vizinhança do conjunto mínimo. O conjunto mínimo é compostos dos átomos não equivalentes presentes na NP 147.

Para a NP 055, o conjunto mínimo de átomos distintos é composto de cinco átomos, sendo três de superfície (c5, c7 e c8) e dois no interior (sítio c12 da primeira sub-camada e o sítio c12 no centro). A primeira vizinhança deste conjunto mínimo é composta de 24 átomos, representando $44 \%$ do total de átomos. A terceira vizinhança já compreende todos os 55 átomos. Os três espectros também são muito distintos para esta nanopartícula, demonstrando que a simplificação também não é suficiente para a descrição adequada das propriedades vibracionais.

Para a NP 079, o conjunto mínimo de átomos distintos é composto de seis átomos, sendo três na superfície (c6, c7 e c9) e três no interior (dois sítios c12 da primeira sub-camada e o sítio c12 no centro). A primeira vizinhança é composta de 29 átomos, representando 37\% dos átomos da nanopartícula. A segunda vizinhança é composta de 65 átomos, representando $82 \%$ dos átomos da nanopartícula. A terceira camada já incorpora todos os átomos da nanopartícula. As simplificações que utilizam o conjunto mínimo ou a primeira vizinhança não são adequadas, pois seus espectros vibracionais não representam o espectro completo. Por outro lado, o espectro vibracional obtido com a segunda vizinhança já tem um perfil bem mais próximo do espectro completo com todos os átomos, indicando que para esta 


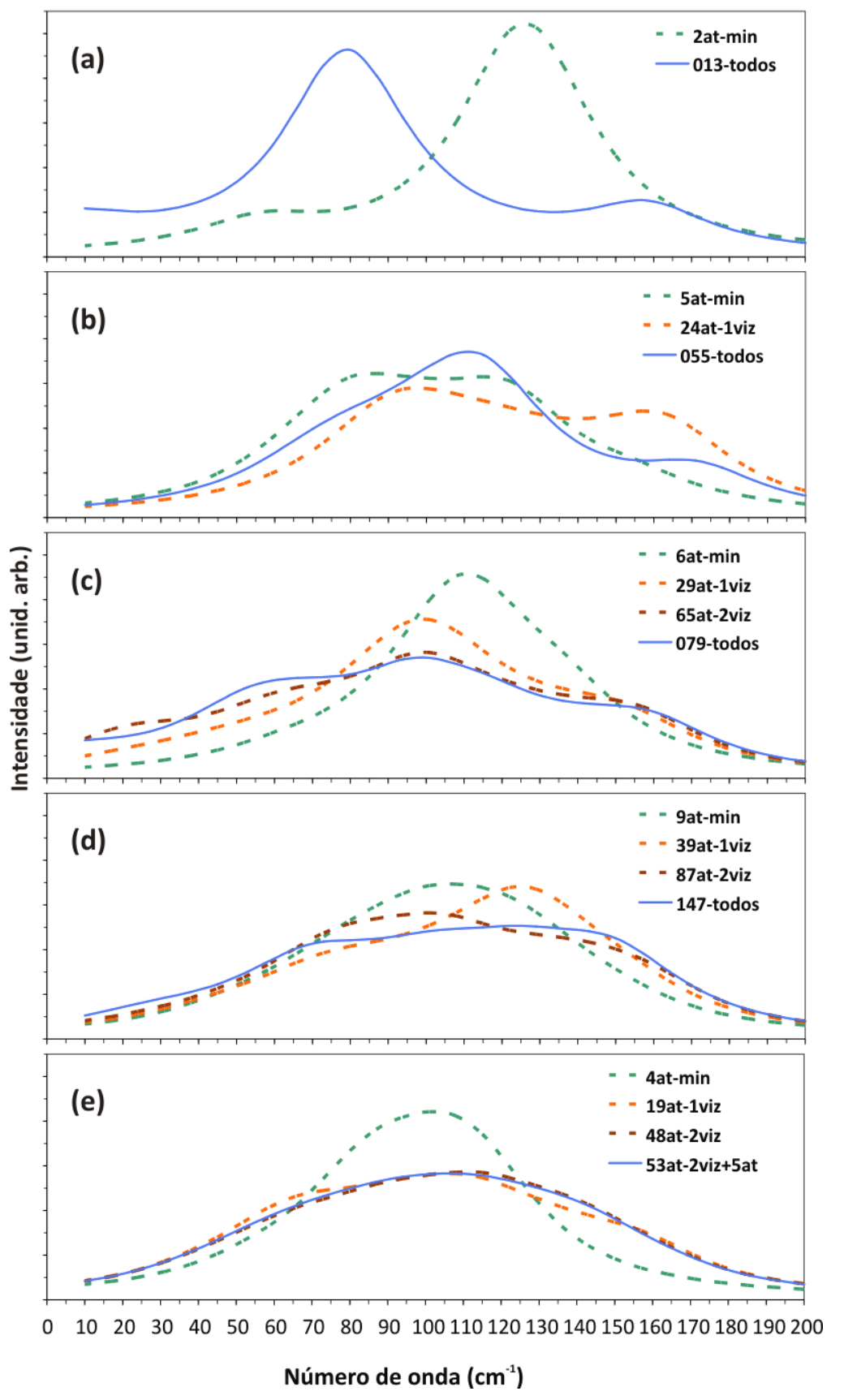

Fig. 5.2: Espectros vibracionais obtidos para as nanopartículas (a) 013 c-cot, (b) 055 c-cot, (c) 079 t-cot, (d) 147 c-cot e (e) 309 c-oct, considerando diferentes graus de liberdade para os átomos. 
dimensão de nanopartícula a simplificação utilizando até a segunda camada já é representativa.

Para a NP 147, o conjunto mínimo de átomos distintos é composto de nove átomos, sendo quatro na superfície (c5, c7, c8 e c9) e cinco no interior (três sítios c12 da primeira sub-camada, um sítio c12 da segunda sub-camada e o sítio c12 no centro). A primeira vizinhança é composta de 39 átomos, representando $27 \%$ dos átomos da nanopartícula. A segunda vizinhança é composta de 87 átomos, representando $59 \%$ dos átomos da nanopartícula. A terceira camada já incorpora todos os átomos da nanopartícula. Verificamos para esta nanopartícula que o espectro obtido com a segunda vizinhança já apresenta um perfil próximo ao espectro completo com todos os átomos, indicando que para este tamanho de nanopartícula a simplificação que utiliza até a segunda vizinhança já é representativa e pode ser utilizada para descrição do sistema completo.

Como a obtenção dos espectros vibracional da NP 309 incorporando as vizinhanças dos átomos distintos da superfície e interior até a inclusão de todos os átomos é extremamente custoso, optamos pelo estudo da inclusão de alguns átomos mais representativos, partindo do conjunto mínimo composto dos sítios de coordenação distinta presentes apenas na superfície (sítios c5, c7, c8 e c9). A primeira vizinhança é composta de 19 átomos, representando 6\% dos átomos da superfície. A segunda vizinhança é composta de 48 átomos e representa $16 \%$ dos átomos da nanopartícula. Na expectativa de aumentar o grau de liberdade que aproxime ainda mais o perfil do espectro com menor número de átomos ao espectro completo, adicionamos à segunda vizinhança alguns sítios distintos do tipo c12 presentes em todas as subcamadas e mais alguns sítios presentes na superfície, compreendendo ao total 53 átomos e representando $17 \%$ dos átomos da nanopartículas.

Verificamos que o espectro vibracional obtido com o conjunto mínimo composto apenas dos átomos da superfície para a NP 309 não é representativo, pois 
é muito distinto dos demais espectros com maior grau de liberdade obtidos para essa nanopartícula. O espectro obtido com a primeira vizinhança, por outro lado, já apresenta o perfil do espectro obtido com mais átomos. Apesar de não obtermos o espectro completo, estes resultados já indicam que neste regime é possível obter um espectro vibracional representativo com um conjunto reduzido de átomos.

Esta análise indica que a simplificação com a utilização de um conjunto reduzido de átomos para a obtenção dos espectros vibracionais das nanopartículas livres deve ser tratada de forma distinta para os três regimes:

- para as nanopartícula dentro regime molecular verificamos que é necessário a inclusão de todos os átomos para o cálculo do espectro vibracional.

- para as nanopartículas dentro do regime misto o espectro simplificado já é similar ao espectro completo quando são considerados os átomos até a segunda vizinhança dos átomos distintos.

- para as nanopartículas dentro do regime cristalino é esperado que o espectro simplificado seja similar ao espectro completo para um conjunto reduzido de átomos em relação ao total que incorporem, pelo menos, os átomos distintos da superfície e sua primeira vizinhança.

Para verificar a influência dos átomos mais internos e suas vizinhanças no espectro vibracional, realizamos a mesma análise, entretanto, considerando como conjunto mínimo apenas os átomos distintos da superfície. Em seguida, calculamos os espectros para as vizinhanças sucessivas deste conjunto mínimo.

Apesar dos átomos internos de coordenação c12 não estarem presentes neste conjunto mínimo, eles são incorporados quando incluímos as vizinhanças. Na figura 5.3 temos os espectros obtidos para as NPs 079, 147 e 309 utilizando esta análise, comparados com o espectro completo para os dois primeiros casos e com o 
maior conjunto de átomos para a NP 309. Os espectros para a NP 309 são os mesmos obtidos na análise anterior que, para esta nanopartícula, já considerava como conjunto mínimo apenas os átomos da superfície.

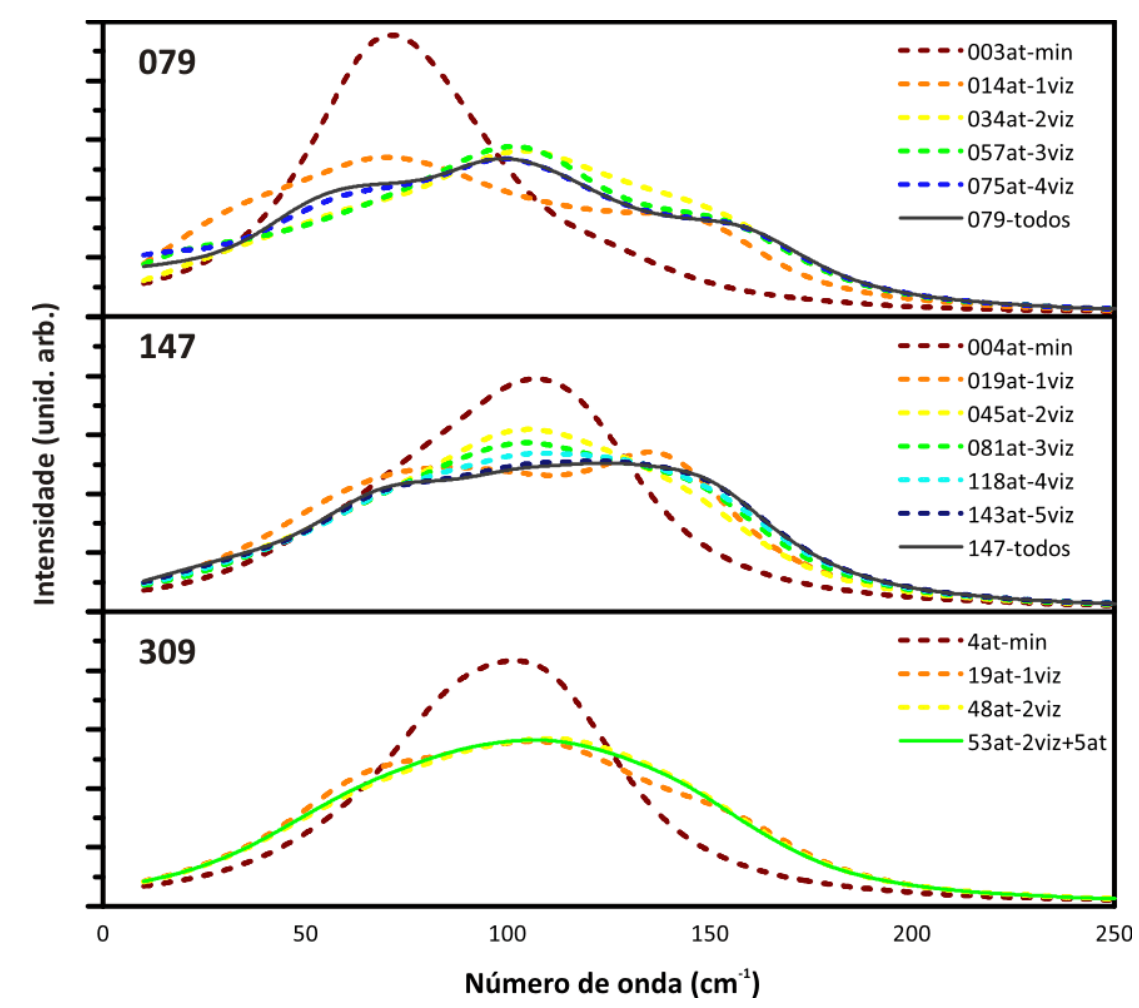

Fig. 5.3: Espectros vibracionais obtidos para as NPs 079, 147 e 309 considerando diferentes números de átomos representativos. O espectro do conjunto mínimo (-min) foi obtido considerando apenas os átomos distintos da superfície. Os demais espectros foram obtidos incluindo as sucessivas vizinhanças (-1viz, -2viz, -3viz etc.) até o espectro obtido considerando todos os átomos (-todos). Na legenda está indicado o número de átomos considerados para a obtenção do espectro do conjunto mínimo e de cada vizinhança. As linhas sólidas representam os espectros completos e as linhas tracejadas os espectros parciais.

O conjunto mínimo e as vizinhanças construídos assim apresentam menor quantidade de átomos em relação a análise realizada anteriormente, que também incluíam os átomos do interior da nanopartícula no conjunto mínimo. Esta análise simplifica ainda mais o cálculo das propriedades vibracionais reduzindo o custo computacional. 
Verificamos para esse estudo que com a inclusão da segunda vizinhança dos átomos distintos da superfície já é possível se obter um espectro vibracional que apresenta perfil semelhante àquele do espectro completo. Isto indica que é possível se obter um espectro representativo sem a necessidade de incluir as vizinhanças dos átomos mais internos, incluindo apenas os átomos internos que são vizinhos aos átomos da superfície.

Com este procedimento é possível obter as propriedades vibracionais com um número menor de átomos, reduzindo o custo computacional e facilitando o estudo de estruturas maiores.

\subsubsection{Propriedades vibracionais das adsorções}

Realizamos a mesma análise da seção anterior, comparando os espetros vibracionais obtidos para diferentes números de átomos utilizados na construção da matriz Hessiana, para verificar se as propriedades vibracionais das nanopartículas adsorvidas são influenciadas quando considerado um conjunto menor de átomos. Analisamos os espectros vibracionais das adsorções do radical metil sobre o sítio c5 da NP 013, sobre os sítios c4 e c7 da NP 019 e sobre o sítio c5 da NP 147. Os espectros obtidos estão representados na figura 5.4.

Para todos os casos determinamos o espectro considerando todos os átomos da molécula e o sítio adsorvido além do espectro considerando também a primeira vizinhança do sítio adsorvido. Para as adsorções sobre os sítios c5 da NP 013 e c4 da NP 019 também determinamos os espectros completos, obtidos quando são considerados todos os átomos da nanopartícula e da molécula.

Nossos resultados indicam que a inclusão de todos os átomos da nanopartícula induz mudanças no espectro apenas na região até $200 \mathrm{~cm}^{-1}$, que corresponde aos modos de vibração internos à nanopartícula e que estão associados às vibrações Ag-Ag. Os demais modos vibracionais associados às ligações $\mathrm{Ag}-\mathrm{C}$ e C-H não são 
influenciados.

Neste sentido, identificamos que a inclusão de todos os átomos da molécula com o sítio adsorvido da nanopartícula já é suficiente para a análise dos sinais espectroscópicos associados a molécula, inclusive do sinal associado a ligação da molécula com o sítio adsorvido da nanopartícula.

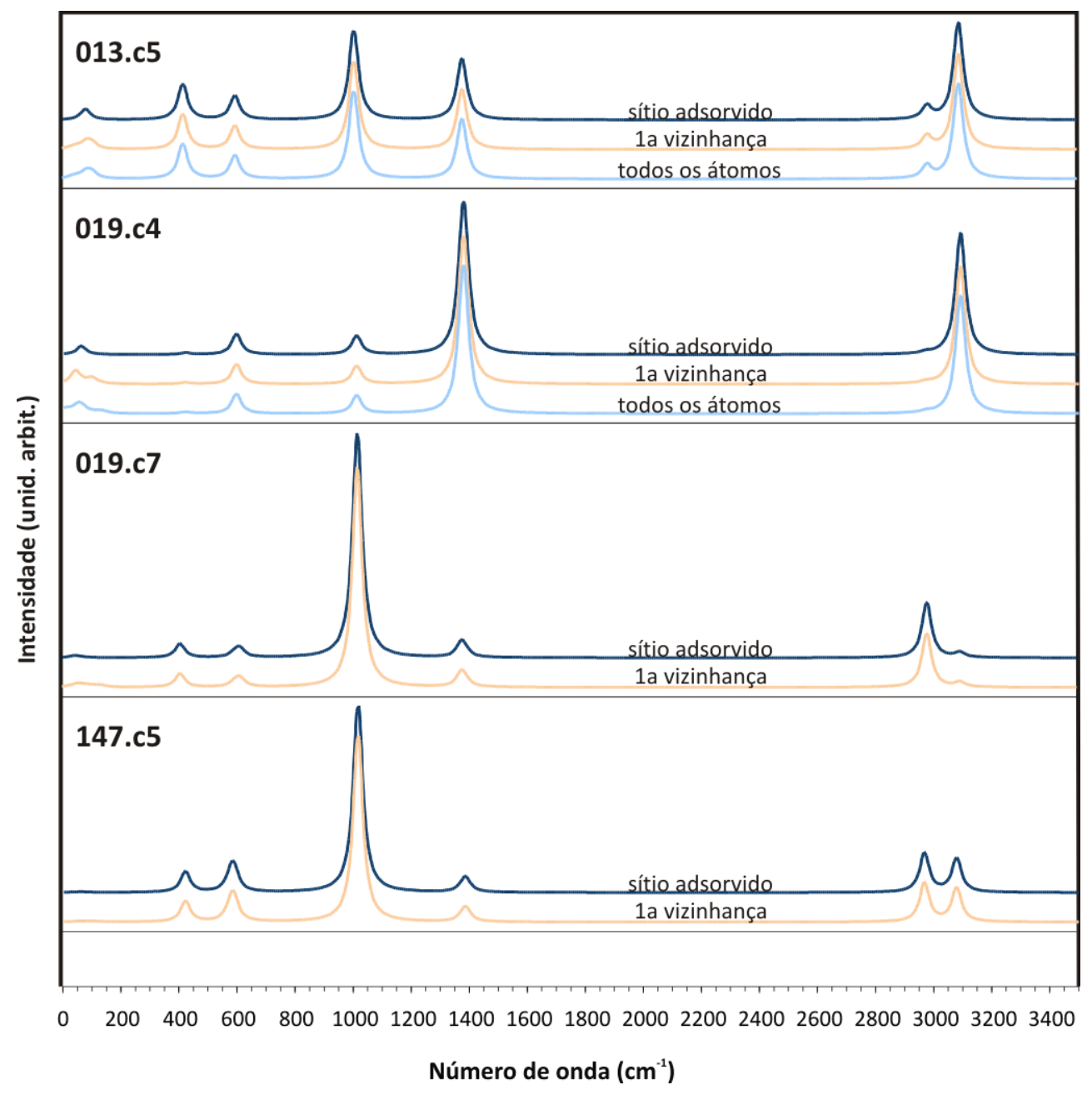

Fig. 5.4: Espectros vibracionais das adsorções sobre os sítios c5 da NP 013, c4 e c7 da NP 019 e c5 da NP 147 obtidos considerando além da movimentação de todos os átomos do radical para a construção da matriz Hessiana também a movimentação do sítio adsorvido (linha azul escura), do sítio adsorvido e de sua primeira vizinhança (linha laranja) e de todos os átomos (linha azul clara). 


\subsection{Recorte da nanopartícula em hemisfério}

Na simplificação em hemisfério são considerados na construção da estrutura todos os átomos de um dos hemisférios da nanopartícula mais uma camada do outro hemisfério, como representado na figura 5.5. Como as nanopartículas estudadas apresentam a simetria especular em relação ao plano do recorte, todos os sítios distintos presentes na nanopartícula completa estão presentes nesta simplificação, inclusive a curvatura da superfície oposta ao recorte é preservada.
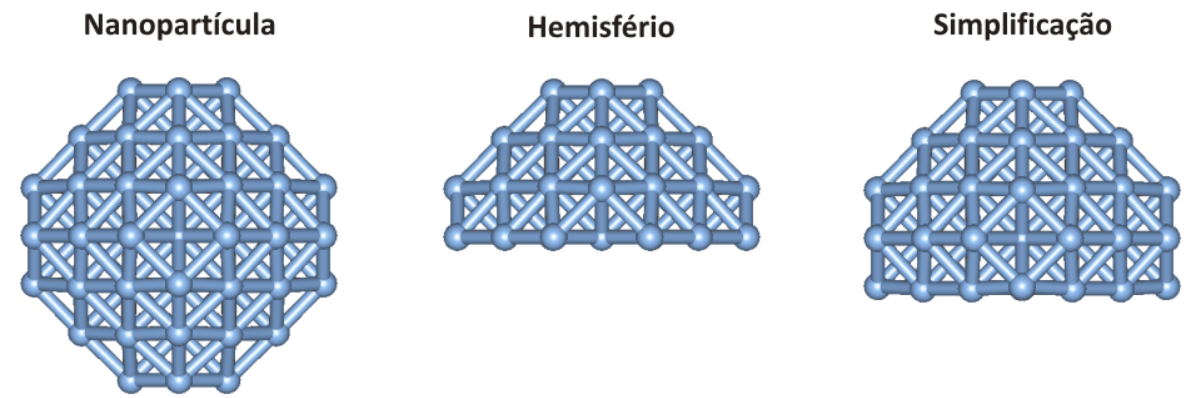

Fig. 5.5: Representação da simplificação em hemisfério utilizada. A esquerda a nanopartícula, ao centro o recorte do hemisfério superior da nanopartícula e à direita a simplificação utilizada que é composta de um hemisfério mais uma camada do outro hemisfério.

Realizamos este estudo para as NPs 055 e 079 e analisamos a densidade de estados, e o espectro vibracional dos hemisférios livres comparativamente às nanopartículas livres completas. Os recortes em hemisférios apresentaram respectivamente, 46 e 66 átomos. A DOS, representada na figura 5.6, apresenta uma faixa de $\pm 2,0 \mathrm{eV}$ em torno do nível de Fermi.

A simplificação da NP 055 não representa adequadamente a DOS da nanopartícula, apresentando novos estados na região entre 1,0 e 2,0 eV abaixo do nível de Fermi e não apresentando um estado característico da nanopartícula em $0,5 \mathrm{eV}$ abaixo do nível de Fermi. Por outro lado, a simplificação da NP 079 apresentou a DOS muito semelhante à obtida para a nanopartícula, exceto na região entre 0,6 e $1,0 \mathrm{eV}$ onde houve um deslocamento de um pico para energias mais baixas dentro 
da faixa proibida.

Este resultado indica para as nanopartículas com 079 átomos que a DOS obtida com a simplificação utilizando o recorte em hemisfério já apresenta um espectro com perfil similar ao obtido quando todos os átomos são considerados, sugerindo o uso desta simplificação para a descrição de suas propriedades eletrônicas.

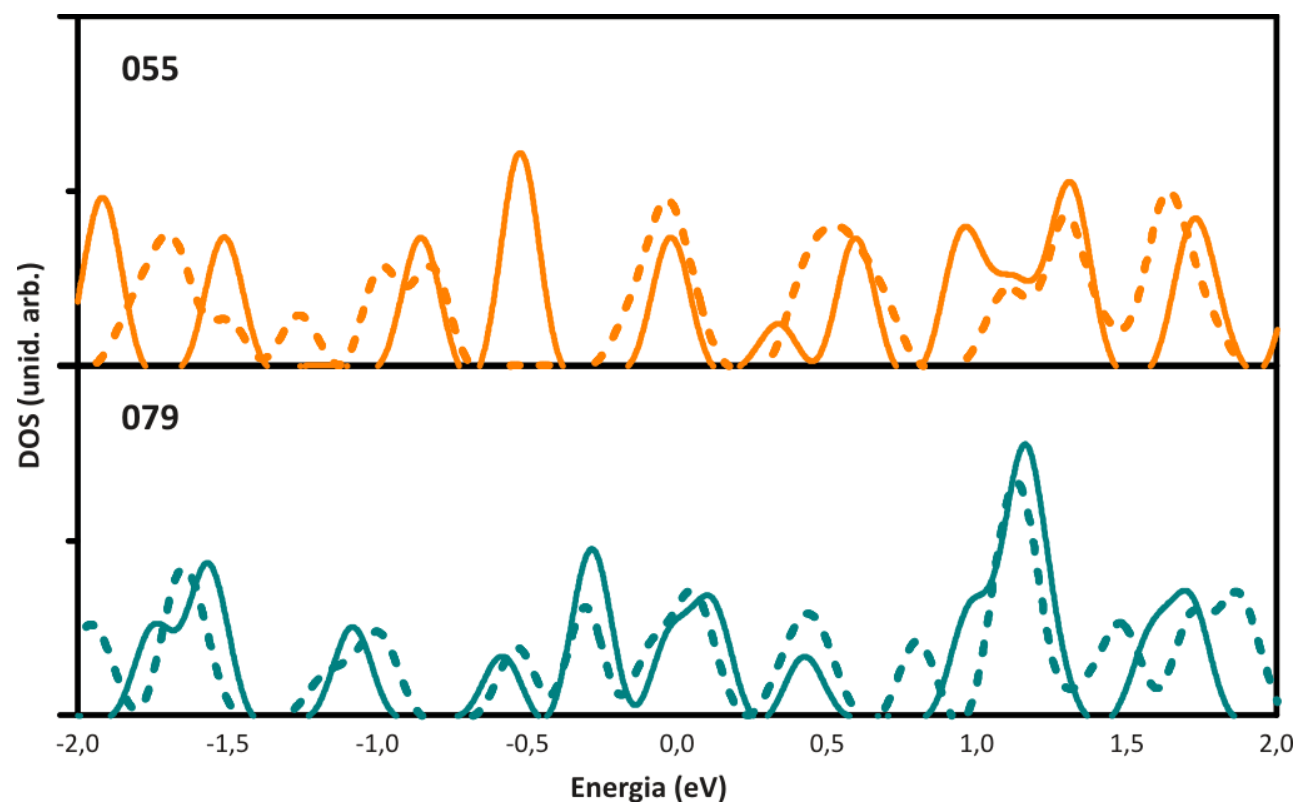

Fig. 5.6: Densidades de estados obtidas para as nanopartículas completas 055 e 079 (linhas solidas) e suas correspondentes simplificações no formato de hemisfério (linhas tracejadas)

Com respeito às propriedades vibracionais, verificamos que os espectros vibracionais obtidos com as simplificações em hemisférios apresentaram diferenças quando comparados aos espectros obtidos para as nanopartículas, figura 5.7. Entretanto, o espectro obtido para a simplificação em hemisfério da NP 079 tem perfil semelhante àquele obtido para a nanopartícula, indicando a possibilidade do uso desta simplificação, podendo se demonstrar adequada para sistemas maiores.

Este resultado é compatível com a análise realizada anteriormente da movimentação de um conjunto reduzido de sítios representativos da nanopartícula para a obtenção da matriz Hessiana. Na construção por hemisfério o conjunto já com- 


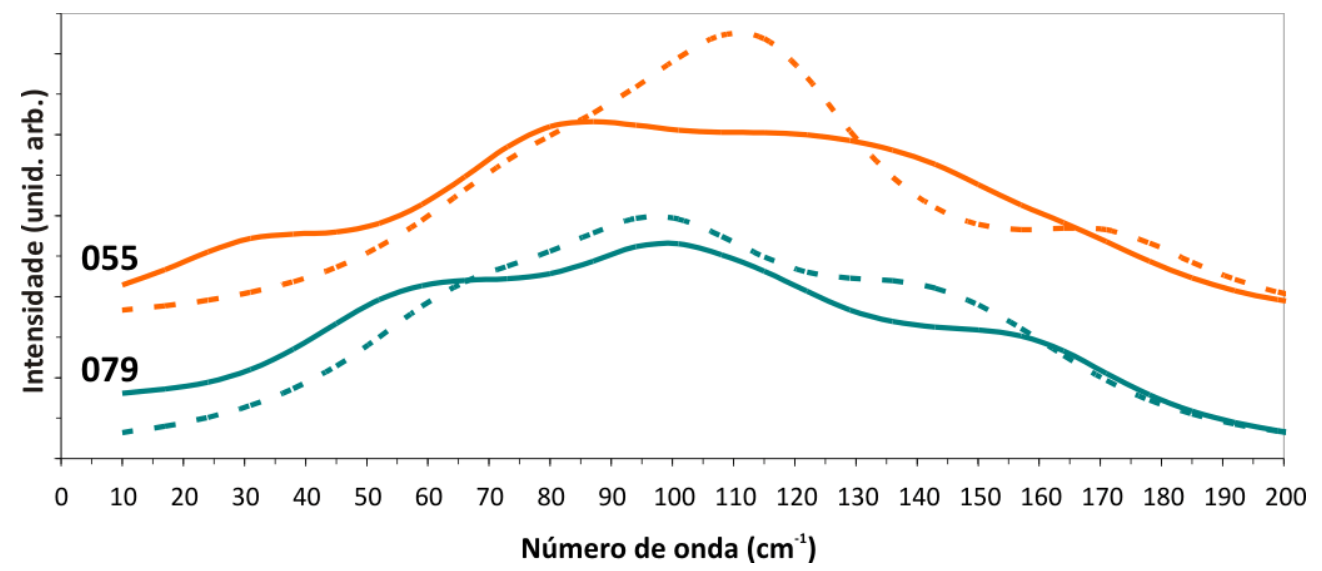

Fig. 5.7: Espectros vibracionais obtidos para as nanopartículas completas 055 e 079 (linhas solidas) e suas correspondentes simplificações no formato de hemisfério, 055.hemisf e 079.hemisf (linhas tracejadas).

preende tanto os átomos distintos de superfície como um conjunto significativo de átomos do interior, assegurando a adequação de sua representatividade.

\section{3 Átomo de prata}

Uma simplificação bastante utilizada para a determinação das propriedades de adsorções é considerar um único átomo para representar a estrutura da nanopartícula. Neste sentido comparamos as propriedades da adsorção do radical metil sobre as nanopartículas com a adsorção sobre um único átomo de prata.

Obtivemos para a distância da ligação Ag-C o valor de $2.11 \AA$ A que está entre $2 \%$ e $5 \%$ menor que os valores obtidos para as distâncias de ligação entre as adsorções realizadas sobre as nanopartículas. Este valor concorda com a expectativa de redução da distância de ligação com a redução da coordenação do sítio adsorvido que, no caso de um único átomo de prata, não apresenta vizinhança.

Para a energia de ligação obtivemos o valor de 2,07 eV, que é pelo menos $20 \%$ maior que as energias de ligação obtidas para as adsorções sobre as nanopartículas. Este resultado também é compatível com a relação de aumento da energia de ligação 
com a redução da coordenação obtidos para as adsorções sobre as nanopartículas.

Com respeito às propriedades vibracionais verificamos que os modos vibracionais de mais baixa energia, até cerca de $1000 \mathrm{~cm}^{-1}$, associados ao estiramento e torção da ligação Ag-C, se deslocaram no sentido de maiores energias. Os modos vibracionais acima $1000 \mathrm{~cm}^{-1}$, associados aos modos de estiramento, torção e tesoura das ligações $\mathrm{C}-\mathrm{H}$, praticamente não sofreram alterações como observados nas adsorções sobre as nanopartículas, tabela 5.1.

Tab. 5.1: Modos vibracionais médios da adsorção do radical metil sobre as nanopartículas $\left(\mathrm{NP}+\mathrm{CH}_{3}\right)$ e modos vibracionais da adsorção do radical metil sobre um único átomo de prata $\left(\mathrm{Ag}+\mathrm{CH}_{3}\right)$. $\mathrm{O}$ desvio amostral da média está indicado entre parênteses. Número de onda em $\mathrm{cm}^{-1}$

\begin{tabular}{cccc}
\hline \hline Ligação & Modos & $\mathrm{NP}+\mathrm{CH}_{3}$ & $\mathrm{Ag}+\mathrm{CH}_{3}$ \\
\hline \hline $\mathrm{Ag}-\mathrm{C}$ & estir. & $418(12)$ & 454 \\
$\mathrm{Ag}-\mathrm{C}+\mathrm{C}-\mathrm{H}$ & torção & $596(14)$ & 668 \\
$\mathrm{Ag}-\mathrm{C}+\mathrm{C}-\mathrm{H}$ & torção & $608(11)$ & 668 \\
$\mathrm{Ag}-\mathrm{C}+\mathrm{C}-\mathrm{H}$ & estir./abano & $1021(6)$ & 1042 \\
$\mathrm{CH}+\mathrm{CH}_{2}$ & torção+tesoura & $1382(5)$ & 1386 \\
$\mathrm{CH}+\mathrm{CH}_{2}$ & torção+tesoura & $1393(5)$ & 1394 \\
$\mathrm{CH}_{3}$ & estir. sim. & $2984(8)$ & 2997 \\
$\mathrm{CH}_{2}$ & estir. assim. & $3097(11)$ & 3100 \\
$\mathrm{CH}_{3}$ & estir. assim. & $3105(10)$ & 3110 \\
\hline \hline
\end{tabular}

Além disso, o estudo realizado da adsorção do metil sobre um único átomo representando a nanopartícula, apresenta de maneira geral uma inversão em relação às nanopartículas na intensidade dos dois picos principais próximos à 1000 e $3000 \mathrm{~cm}^{-1}$, respectivamente, associados ao estiramento $\mathrm{Ag}-\mathrm{C}$ e ao estiramento simétrico da ligação $\mathrm{C}-\mathrm{H}_{3}$, figura 4.5 , sendo mais intenso o pico em $3000 \mathrm{~cm}^{-1}$.

Verificamos, portanto, que esta simplificação segue a tendência da energia e distância de ligação e que os modos vibracionais associados à molécula são pouco influenciados. Por outro lado, os modos vibracionais relacionados à ligação Ag-C 
apresentaram variações significativas. Assim, a utilização de um único átomo na determinação das propriedades vibracionais deve ser feito de forma restritiva. 


\section{Capítulo 6}

\section{Conclusões}

Realizamos com este trabalho um estudo das propriedades estruturais, eletrônicas, energéticas e vibracionais das nanopartículas de pratas na situação livre e adsorvida, na busca de padrões que as caracterizem entre os diferentes tamanhos e formatos. As investigações foram realizadas através de cálculos ab-initio dentro da teoria do funcional da densidade associada ao método de pseudopotenciais ultrassuaves.

Neste estudo identificamos três regimes característicos associados às dimensões das nanopartículas: (i) o regime com forte característica molecular para nanopartículas até 1,5 nm (até 100 átomos); (ii) o regime com característica mista entre molécula e cristal para nanopartículas entre 1,5 e 2,0 nm (entre 100 e 300 átomos); e (iii) o regime com forte característica cristalina para as nanopartículas acima de 2,0 nm (mais que 300 átomos). As propriedades de superfície estão presentes nos três regimes estudados.

Estruturalmente, verificamos que os sítios de mesma coordenação na superfície se acomodaram de forma muito semelhante independentemente do tamanho ou formato da nanopartículas. Para os sítios c12, presentes no interior da nanopartícula, verificamos que quanto mais internos mais se aproximam da configuração cúbica de 
face centrada do cristal de prata. Apresentando, portanto, uma tendência à estrutura cristalina com o seu aumento.

Todos os formatos estudados mantiveram sua configuração estrutural, indicando que as nanopartículas livres estudadas representam configurações estáveis ou metaestáveis.

As densidades de estados e os níveis de energia são fortemente influenciados pela dimensão da nanopartícula, expressando claramente a transição do regime molecular para o regime cristalino. As propriedades cristalinas já são significativas para as nanopartículas com cerca de 350 átomos, cujas densidades de estados e níveis de energia já se apresentam uniformemente distribuídos em torno do nível de Fermi, equivalente às faixas de energia dos metais.

A distribuição da carga total é esfericamente simétrica em torno de cada átomo, independentemente se são átomos de superfícies ou do caroço, apresentando comportamento semelhante para as nanopartículas nos três regimes analisados.

Os sinais espectroscópicos das nanopartículas livres se apresentam dentro da região de energia até $200 \mathrm{~cm}^{-1}$, sendo que os modos de energia mais baixa estão associados às vibrações na superfície, enquanto que os modos de energia mais próximos a $200 \mathrm{~cm}^{-1}$ estão associados exclusivamente às vibrações do interior das estruturas. Para as nanopartículas dentro de regime molecular, esta região de energia é caracterizada por picos distintos no espectro vibracional que se misturam com o aumento da nanopartícula formando um único pico largo equivalente a uma faixa continua de modos vibracionais. Este pico tende a se estreitar se aproximando ao pico estreito mais característico do cristal com maior intensidade em $120 \mathrm{~cm}^{-1}$.

As adsorções do radical metil sobre os diferentes sítios de diferentes nanopartículas se apresentaram energeticamente favoráveis com energia entre 0,90 e 1,71 eV (entre 20,8 e 39,4 kcal/mol), sendo mais favoráveis as adsorções sobres as nanopartículas menores. As adsorções sobre os sítios c8 e c9 das superfícies das na- 
nopartículas tendem, respectivamente, às adsorções realizadas sobre as superfícies livres [001] e [111] com terminações de mesma coordenação.

As nanopartículas dentro do regime molecular podem sofrer forte influência do processo de adsorção. Nossos resultados apresentaram mudanças estruturais, com transição para uma configuração mais estável e inclusão de estados na região próxima ao nível de Fermi. As influências das adsorções no regime misto são muito reduzidas, com pequenas perturbações na densidade de estados. Para o regime cristalino não são verificadas perturbações significativas decorrente do processo de adsorção. A adsorção pouco interfere, também, nas propriedades estruturais do composto adsorvido.

Verificamos que a transferência de carga, para a realização da adsorção, ocorre quase exclusivamente da região ao redor do sítio adsorvido para a ligação e para a molécula, se apresentando equivalente para as adsorções realizadas nos sítios de diferentes nanopartículas.

A densidade de estados das nanopartículas adsorvidas com os radicais metil e vinil sobre o mesmo sítio de uma nanopartícula não apresentam diferenças significativas, indicando nesse caso que o tamanho do radical orgânico não deva interferir significativamente nas propriedades eletrônicas do sistema adsorvido. Por outro lado, as adsorções do radical vinil apresentaram uma ligação $\mathrm{Ag}-\mathrm{C}$ levemente mais forte, sendo a distância da ligação cerca de $2 \%$ menor em relação a mesma distância para adsorções do metil. As energias de ligação da adsorção do radical vinil se apresentam levemente mais favoráveis em relação a adsorção do metil, com uma diferença na energia entre 0,20 e 0,40 eV (entre 4,6 e 9,2 kcal).

A distância de ligação Ag-C independe do tamanho da nanopartícula em que o composto é adsorvido, mas se apresenta menor para as adsorções realizadas sobre os sítios de menor coordenação. As energias de ligação dos sítios de baixa coordenação se apresentaram, em geral, mais favoráveis que os sítios de maior coordenação. 
Verificamos que as intensidades dos picos nos espectros vibracionais variam significativamente entre as adsorções, não apresentando um padrão claro que indique o que provoca estas flutuações. Mas, de forma geral, observamos uma forte influência do tamanho da nanopartícula na intensidade de todos dos picos, se apresentando menos intensos com o aumento da nanopartícula. Este resultado indica que é possível obter sinais espectroscópicos mais intensos com nanopartículas menores.

Com respeito às simplificações, verificamos que as propriedades vibracionais das nanopartículas livres podem ser fortemente influenciadas quando utilizado um conjunto menor de átomos da construção da matriz Hessiana. Em especial, as propriedades vibracionais das nanopartículas dentro do regime molecular não foram adequadamente reproduzidas, se mostrando necessária a inclusão de todos os átomos para uma descrição adequada. Para as nanopartículas dentro do regime misto, verificamos que é necessária a inclusão dos átomos que compreendam, pelo menos, até a terceira vizinhança de átomos ao redor do conjunto de átomos não equivalente da superfície. Nossos resultados para as nanopartículas dentro do regime cristalino, que necessitam estudos mais profundos, indicam que a inclusão dos átomos até a segunda vizinhança dos átomos equivalentes da superfície pode reproduzir suas propriedades vibracionais.

A densidade de estados e o espectro vibracional para a simplificação do recorte da nanopartícula 079 no formato de hemisfério já apresentam seus perfis próximos aos obtidos para a nanopartícula completa, indicando que uso desta simplificação para a representação das nanopartículas maiores, dentro dos regimes misto e cristalino, deva se apresentar adequado para o estudo das propriedades eletrônicas e vibracionais.

A simplificação utilizando apenas um átomo de prata para descrever o processo de adsorção, como utilizado por vários autores, segue a tendência da energia e distância de ligação e que os modos vibracionais associados à molécula são pouco 
influenciados. Por outro lado, os modos vibracionais relacionados à ligação Ag$\mathrm{C}$ apresentou variações significativas. Assim, a utilização de um único átomo na determinação das propriedades vibracionais deve ser feito de forma restritiva. 


\section{Apêndice A}

\section{Demonstração do primeiro teorema}

\section{de Kohn-Sham}

O primeiro teorema de Kohn-Sham está associado a relação unívoca entre a densidade eletrônica do estado fundamental $(\rho)$ e o potencial externo do sistema $\left(V_{\text {ext }}\right)$. A prova dessa relação unívoca é feita por contradição e, por simplicidade e sem perda de generalidade, esta demonstração está feita para um sistema sem polarização de spin e não degenerado.

Suponha que existam dois sistemas em seus estados fundamentais sujeitos a potenciais diferentes,

$$
\left[V_{\text {ext }, 1}(\mathbf{r})-V_{\text {ext }, 2}(\mathbf{r})\right] \neq \text { constante }
$$

mas com a mesma densidade eletrônica no estado fundamental, $\rho_{1}(\mathbf{r})=\rho_{2}(\mathbf{r})=$ $\rho(\mathbf{r})$. Sendo $\Psi_{e, 1}^{0}$ e $\Psi_{e, 2}^{0}$ as funções de onda do estado fundamental destes sistemas, temos pelo princípio variacional que

$$
\left\langle\Psi_{e, 1}^{0}\left|T_{e}+V_{e e}+V_{e x t, 1}\right| \Psi_{e, 1}^{0}\right\rangle<\left\langle\Psi_{e, 2}^{0}\left|T_{e}+V_{e e}+V_{e x t, 1}\right| \Psi_{e, 2}^{0}\right\rangle
$$

A energia correspondente ao potencial externo pode ser calculada separada- 
mente,

$$
\left\langle\Psi_{e, 1}^{0}\left|V_{e x t, 1}\right| \Psi_{e, 1}^{0}\right\rangle=\int V_{e x t, 1}(\mathbf{r}) \rho_{1}(\mathbf{r}) d \mathbf{r}
$$

e

$$
\left\langle\Psi_{e, 2}^{0}\left|V_{e x t, 1}\right| \Psi_{e, 2}^{0}\right\rangle=\int V_{e x t, 1}(\mathbf{r}) \rho_{2}(\mathbf{r}) d \mathbf{r}
$$

Como as densidades são iguais os dois termos acima se cancelam na equação A.2,

$$
\left\langle\Psi_{e, 1}^{0}\left|T_{e}+V_{e e}\right| \Psi_{e, 1}^{0}\right\rangle<\left\langle\Psi_{e, 2}^{0}\left|T_{e}+V_{e e}\right| \Psi_{e, 2}^{0}\right\rangle
$$

De forma análoga, temos para a função $\Psi_{e, 2}^{0}$ que,

$$
\left\langle\Psi_{e, 2}^{0}\left|T_{e}+V_{e e}+V_{e x t, 2}\right| \Psi_{e, 2}^{0}\right\rangle<\left\langle\Psi_{e, 1}^{0}\left|T_{e}+V_{e e}+V_{e x t, 2}\right| \Psi_{e, 1}^{0}\right\rangle,
$$

de onde obtém-se o seguinte resultado:

$$
\left\langle\Psi_{e, 1}^{0}\left|T_{e}+V_{e e}\right| \Psi_{e, 1}^{0}\right\rangle>\left\langle\Psi_{e, 2}^{0}\left|T_{e}+V_{e e}\right| \Psi_{e, 2}^{0}\right\rangle
$$

Neste procedimento as equações A.5 e A.7 são contraditórias, impondo que no estado fundamental não é possível obter a mesma densidade se o potencial externo for diferente. Demonstrando a relação unívoca entre a densidade do estado fundamental $\rho$ e o potencial externo $V_{\text {ext }}$ do sistema. 


\section{Apêndice B}

\section{Termo $F_{x}(s)$ e $H\left(r_{s}, \xi, t\right)$ da energia de}

\section{troca e correlação PW91}

A função $F_{x}(s)$ está presente no termo da energia de troca na aproximação proposta Perdew e Wang [36, 37, 38], não depende da polarização de spin, e é definida por,

$$
F_{x}(s)=\frac{1+0.19645 s \sinh ^{-1}(7.7956 s)+\left(0.2743-0.1508 e^{-100 s^{2}}\right) s^{2}}{1+0.19645 s \sinh ^{-1}(7.7956 s)+0.004 s^{4}}
$$

$\operatorname{com} s=\frac{|\nabla n(\mathbf{r})|}{2 \phi k_{F} n(\mathbf{r})}$ e $k_{F}=\frac{1}{r_{s}}\left(\frac{9 \pi}{4}\right)^{\frac{1}{3}}$. Onde o raio Wigner-Seitz é definido em função da densidade eletrônica, $r_{S}(\mathbf{r})=[3 / 4 \pi n(\mathbf{r})]^{\frac{1}{3}}$.

A função $H(n, t, r, \xi)$ presente no termo da energia de correlação, por outro lado, é dependente da polarização de spin. Sua expressão é dividida nos seguintes termos,

$$
H(r, \xi, t)=H_{0}(t, r, \xi)+H_{1}(n, t, r, \xi),
$$

onde,

$$
H_{0}=\frac{g_{s}^{3} \beta^{2}}{2 \alpha} \ln \left(1+\frac{2 \alpha}{\beta}\left[\frac{1+A t^{2}}{1+A t^{2}+\left(A t^{2}\right)^{2}}\right]\right)
$$

e

$$
H_{1}=\mathrm{v}\left(C_{c}-C_{c 0}-\frac{3}{7} C_{x}\right) g_{s}^{3} t^{2} \exp ^{-1}\left(\frac{10 g_{s}^{2} k_{s} t}{k_{F}}\right)^{2}
$$


112 F. D. Kiss Termo $F_{x}(s)$ e $H\left(r_{s}, \xi, t\right)$ da energia de troca e correlação PW91

com os seguintes termos dependentes da densidade e da polarização de spin,

$$
\begin{gathered}
C_{c}=\frac{1}{1000} \frac{2,568+23,266 r+0,007389 r^{2}}{1+8,723 r+0,472 r^{2}+0,073890 r^{3}}-C_{x}, \\
A=\frac{2 \alpha}{\beta} \exp ^{-1}\left(\frac{-2 E_{c}}{g_{s}^{3} \beta^{2}}\right)
\end{gathered}
$$

$\mathrm{e}$

$$
g_{s}=\frac{1}{2}\left[(1+\xi)^{\frac{2}{3}}+(1-\xi)^{\frac{2}{3}}\right]
$$

As constantes presentes relacionadas com os termos acima são definidas por $\beta=$ $v C_{c 0}, v=16(3 / \pi)^{\frac{1}{3}}, C_{c 0}=0,004235, C_{x}=-0,001667$ e $\alpha=0.09$. 


\section{Apêndice C}

\section{Resultados preliminares para a prata}

Realizamos alguns cálculos preliminares para o cristal perfeito, a molécula de $\mathrm{Ag}_{2}$ e as superfícies livres [001] e [111] a fim de verificar a qualidade do modelo teórico utilizado. Utilizamos $200 \mathrm{eV}$ de energia de corte para a expansão das funções de ondas em ondas planas, sendo este valor de energia suficiente para descrever adequadamente as propriedades das estruturas estudadas. Utilizamos $0,1 \mathrm{eV}$ como parâmetro de espalhamento que define a largura da gaussiana associada ao fator de ocupação de cada orbital de Kohn-Sham.

O parâmetro de rede teórico do cristal de prata obtido foi de 4,16 $\AA$, cerca de $2 \%$ maior que o valor experimental 4,09 $\AA$ [74] e concorda com outros cálculos utilizando a aproximação GGA, 4,14 ̊ [88] e 4,16 ̊ [89]. Este cálculo foi realizado com a célula unitária da estrutura cúbica de face centrada utilizando uma malha $12 \times 12 \times 12$ pontos especiais para o mapeamento da primeira zona de Brillouin $\left(1^{a} \mathrm{ZB}\right)$.

Para a molécula de $\mathrm{Ag}_{2}$ obtivemos 2,57 ̊̊ para a distância equilíbrio e 1,79 eV para a energia de ligação. Estes resultados concordam muito bem com os resultados experimentais $(2,53 \AA$ e $1,57 \mathrm{eV}$ [90], 2,48 ̊ e 1,65 eV [91]) e teóricos (2,58 e $1,74 \mathrm{eV}$ [66] ). Para o modo de estiramento obtivemos o valor de $179 \mathrm{~cm}^{-1}$, 
em concordância com o valor experimental de $192 \mathrm{~cm}^{-1}$ [91]. Utilizamos, para este caso, uma caixa cúbica de $20 \AA ̊$ e um ponto especial central no mapeamento da $1^{a} \mathrm{ZB}$.

A superfície livre de prata [111] foi construída em uma supercélula com 6 camadas na geometria (2x2), com um total de 48 átomos, e uma região de vácuo $17 \AA$ entre as imagens adjacentes, equivalente a mais 7 camadas de átomos. A camada inferior foi mantida fixa na relaxação estrutural para mimetizar a geometria da região cristalina. A relaxação estrutural é pequena, implicando em uma redução na distância interplanar para 2,38 ̊, 0,8\% menor em relação ao cristal perfeito $(2,40 \AA)$. A distância de ligação dos átomos da superfície permaneceu inalterada, 2,94 Å. A superfície [001] foi estudada nas mesmas condições, mantendo a mesma região de vácuo, que nesta configuração é equivalente a 8 camadas de átomos. A relaxação estrutural também foi pequena, sendo que a distância entre a primeira e segunda camada ficou em 2,09 $\AA$, revelando um pequeno aumento de $0,5 \%$ em relação ao cristal (2,08 ̊̊). A distância de ligação dos átomos da superfície também não sofreram alteração. Nossos resultados para as relaxações estruturais das superfícies são compatíveis com as observações experimentais [92, 93] e teóricas [94, 95]. Esse estudo se apresentou convergido para uma malha de $4 \times 4 \times 1$ pontos especiais no mapeamento da $1^{a} \mathrm{ZB}$.

Para verificar qual o tamanho mínimo necessário para a região de vácuo que garanta que as nanopartículas não interajam, analisamos a dispersão nos níveis de energia da NP 013 na direção $\Gamma$-X da $1^{a}$ ZB. A presença da dispersão nos níveis de energia indica que a região de vácuo é pequena e que a supercélula está interagindo com suas imagens. Nesse sentido, buscamos a situação na qual a dispersão seja desprezível.

A dispersão foi analisada para as distâncias mínimas da região de vácuo entre 6 Å e $11 \AA$ A. Os resultados desta análise estão representados na figura C.1. A densi- 
dade de carga utilizada para o cálculo da dispersão foi obtida considerando apenas um ponto especial no centro da $1^{a} \mathrm{ZB}$. Verificamos que uma região de vácuo da ordem de 9 Å já não há dispersão significativa nos níveis de energia, sendo, portanto, um limite mínimo aceitável para a região de vácuo entre as imagens.
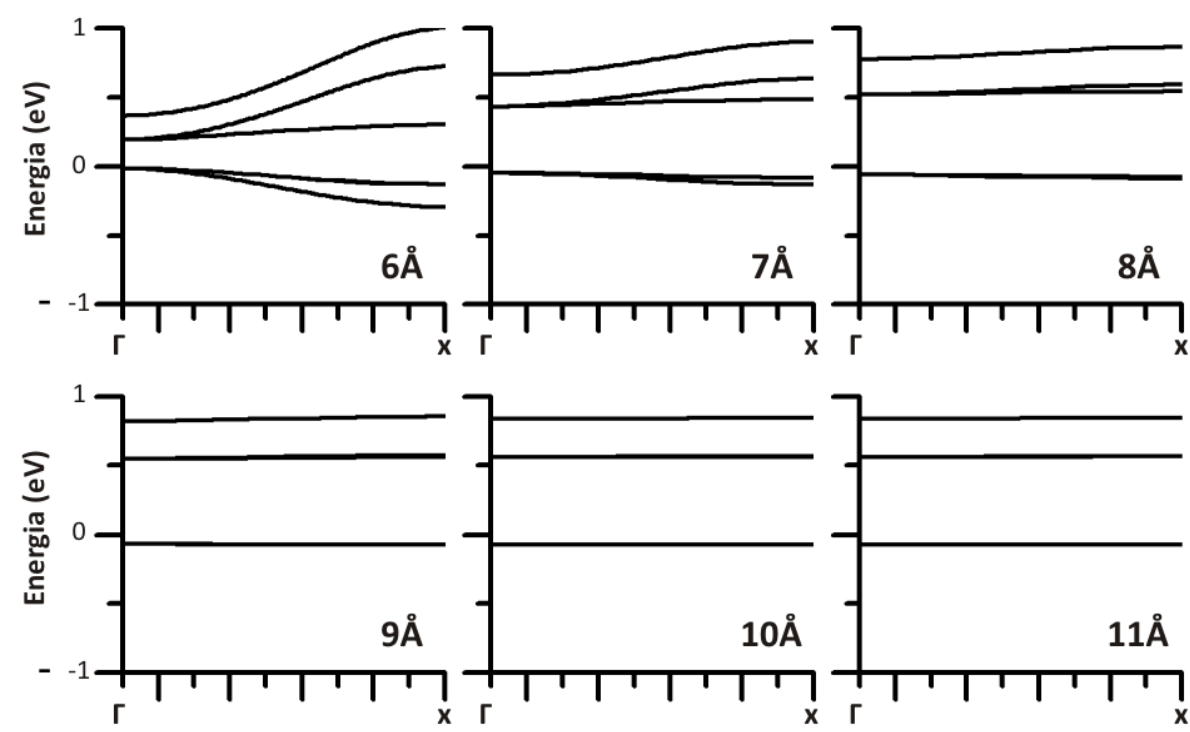

Fig. C.1: Comportamento dos níveis de energia na direção $\Gamma-\mathrm{X}$ da $1^{a} \mathrm{ZB}$ para a NP 013 considerando diferentes distâncias mínimas entre as imagens. A região de energia apresentada corresponde a uma faixa de $\pm 1,0 \mathrm{eV}$ em torno do nível de Fermi. As distâncias entre as imagens variam $6 \AA$ até $11 \AA$.

Analisamos também a influência do número de pontos especiais para o mapeamento $1^{a} \mathrm{ZB}$ na dispersão dos níveis da NP 055 na direção $\Gamma$-X. O estudo foi realizado com uma região de vácuo de $11,7 \AA$ e para as seguintes malhas para o mapeamento $1^{a} \mathrm{ZB}$ : (i) com uma malha de $2 \times 2 \times 2$ pontos especiais que por simetria foi reduzida para apenas um ponto $\mathrm{k}$; (ii) com uma malha de $2 \times 2 \times 2$ pontos especiais que, considerando uma simetria menor, foi reduzida para 4 pontos especiais; e (iii) com uma malha de $6 \times 6 \times 6$ pontos especiais que, por simetria, foi reduzida para 10 pontos especiais. Os resultados estão representados na figura C.2. Verificamos que a NP 055 não apresentou dispersão nos níveis e que os resultados foram equivalentes para as três malhas de pontos especiais estudadas. Isto indica que um único 


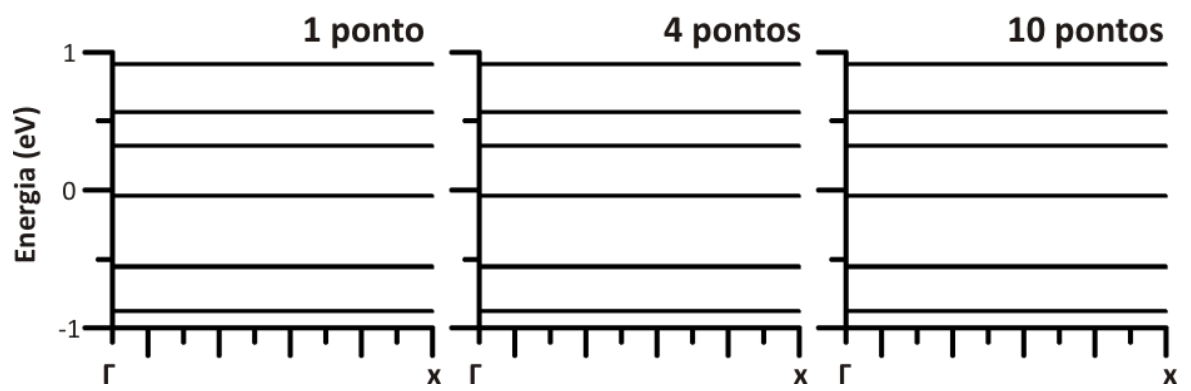

Fig. C.2: Comportamento dos níveis de energia na direção $\Gamma-\mathrm{X}$ da $1^{a} \mathrm{ZB}$ para a NP 055. As densidades de carga foram obtidas considerando 1,4 e 10 especias na $1^{a} \mathrm{ZB}$. A região de energia apresentada corresponde a uma faixa de $\pm 1,0 \mathrm{eV}$ em torno do nível de Fermi. A distância entre as imagens foi de $11,7 \AA$.

ponto especial pode ser considerado para a descrição das nanopartículas de prata.

Os níveis de energia da NP 147 também não apresentaram dispersão na direção $\Gamma$-X da $1^{a} \mathrm{ZB}$ para o cálculo realizado com apenas um ponto especial no mapeamento da $1^{a} \mathrm{ZB}$ e com uma região mínima de vácuo de 11,5 Å, figura C.3

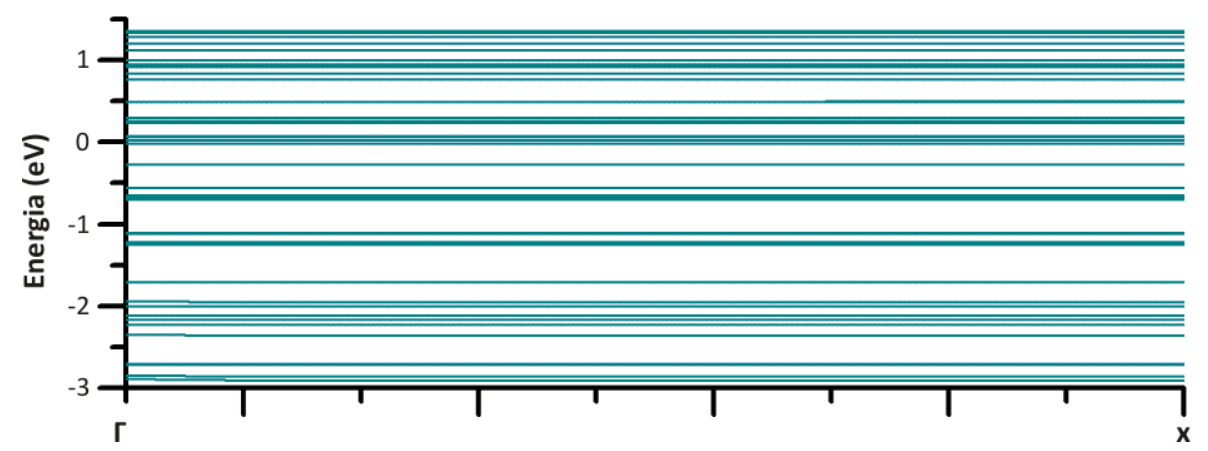

Fig. C.3: Comportamento dos níveis de energia na direção $\Gamma-\mathrm{X}$ da $1{ }^{a} \mathrm{ZB}$ para a NP 147. A densidade de carga foi obtida considerando apenas 1 ponto especial no centro da $1^{a} \mathrm{ZB}$. A região de energia apresentada corresponde a uma faixa de $-3,0 \mathrm{eV}$ até $+1,0 \mathrm{eV}$ em torno do nível de Fermi, que está no zero da energia. A distância entre as imagens foi de 11,5̊.

Podemos inferir destas análises que o uso de $200 \mathrm{eV}$ para energia de corte, uma região de vácuo com pelo menos $9,0 \AA$ e um ponto especial no mapeamento da primeira zona de Brillouin se demonstram suficientes para a descrição das nanopartículas de prata. 


\section{Apêndice D}

\section{Resultados preliminares para as}

\section{moléculas e radicais livres}

Realizamos o estudo das moléculas livres de metano $\left(\mathrm{CH}_{4}\right)$, etileno $\left(\mathrm{C}_{2} \mathrm{H}_{4}\right)$, fosfina $\left(\mathrm{PH}_{3}\right)$, amônia $\left(\mathrm{NH}_{3}\right)$ e sulfeto de hidrogênio $\left(\mathrm{H}_{2} \mathrm{~S}\right)$, e dos radicais metil $\left(\mathrm{CH}_{3}\right)$ e vinil $\left(\mathrm{C}_{2} \mathrm{H}_{3}\right)$. Analisamos as distâncias, ângulos, energia de ligação, magnetização e energia entre o mais alto orbital molecular ocupado (HOMO - "Highest Occupied Molecular Orbital") e o mais baixo orbital molecular desocupado (LUMO - "Lowest Unoccupied Molecular Orbital"). Os resultados estão apresentados na tabela D.1 e a representação estrutural na figura D.1.
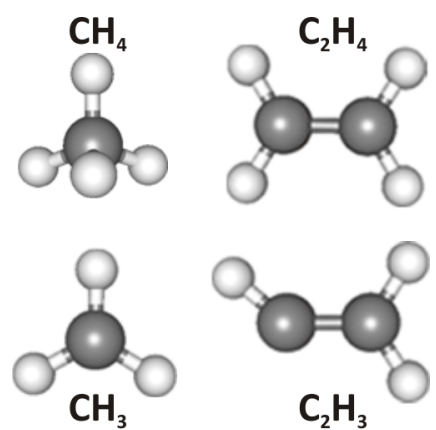

$\mathrm{C}_{2} \mathrm{H}_{3}$
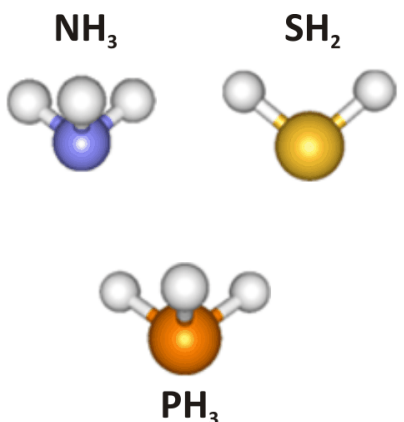

$\mathrm{PH}_{3}$

Fig. D.1: Representação estrutural das moléculas e radicais estudados. 
118 F. D. Kiss Resultados preliminares para as moléculas e radicais livres

Tab. D.1: Parâmetros calculados para os compostos livres: distância da ligação do hidrogênio $\left(\mathrm{d}_{X H}\right.$ onde $\mathrm{X}=\mathrm{C}, \mathrm{P}, \mathrm{N}$ ou $\left.\mathrm{S}\right)$, distância da ligação entre os carbonos $\left(\mathrm{d}_{C C}\right)$, ângulo entre os hidrogênios $\mathrm{HXH}(\alpha)$, ângulo entre a ligação $\mathrm{C}-\mathrm{C}$ e o hidrogênio $\mathrm{CCH}(\beta)$, energia de ligação $\left(\mathrm{E}_{l}\right)$, magnetização (mag) e intervalo de energia HOMO-LUMO $\left(\mathrm{E}_{H L}\right)$. As distâncias estão em $\AA$, as energia estão em eV, os ângulos em graus e a magnetização em unidades de magneton de Bhor $\left(\mu_{B}=e \hbar / 2 m_{e} c=5.79 \cdot 10^{-5} \mathrm{eV} / T\right.$ ). Referências: (a) [96]; (b) [97]; (c) [98]; (d) [99]

\begin{tabular}{|c|ccccccc|}
\hline Composto & $\mathrm{d}_{X H}(\AA)$ & $\mathrm{d}_{C C}(\AA)$ & $\alpha\left(^{o}\right)$ & $\beta\left(^{o}\right)$ & $\mathrm{E}_{l}(\mathrm{eV})$ & $\operatorname{mag}\left(\mu_{B}\right)$ & $\mathrm{E}_{H L}(\mathrm{eV})$ \\
\hline Metil $\left(\mathrm{CH}_{3}\right)$ & 1,08 & - & 120 & - & $-13,50$ & 1,00 & 2,4 \\
\hline Metano $\left(\mathrm{CH}_{4}\right)$ & 1,10 & - & $107 / 110$ & - & $-18,29$ & 0,05 & 8,8 \\
\hline Vinil $\left(\mathrm{C}_{2} \mathrm{H}_{3}\right)$ & $1,08 / 1,09 / 1,10$ & 1,30 & 116 & $121 / 140$ & $-19,98$ & 1,00 & 2,3 \\
\hline Etileno $\left(\mathrm{C}_{2} \mathrm{H}_{4}\right)$ & 1,09 & 1,33 & 117 & 122 & $-24,94$ & 0,06 & 5,6 \\
$\mathrm{GGA}^{a}$ & 1,09 & 1,33 & 116 & 122 & - & - & 5,7 \\
Exp. $^{b}$ & 1,09 & 1,34 & 117 & 121 & - & - & - \\
\hline Sulfeto de $\mathrm{H}_{\left(\mathrm{H}_{2} \mathrm{~S}\right)}$ & 1,33 & - & 100 & - & $-8,1$ & 0,05 & 5,3 \\
Exp. & $1,34^{c}$ & - & $92^{c}$ & - & $-7,6^{d}$ & - & - \\
\hline Fosfina $\left(\mathrm{PH}_{3}\right)$ & 1,42 & - & 97 & - & $-10,46$ & 0,06 & 5,8 \\
Exp. ${ }^{b}$ & 1,42 & - & 93,3 & - & - & - & - \\
\hline Amônia $\left(\mathrm{NH}_{3}\right)$ & 1,04 & - & 100 & - & $-12,61$ & 0,04 & 6,1 \\
Exp. ${ }^{b}$ & 1,02 & - & 103,3 & - & - & - & - \\
\hline
\end{tabular}

A energia de ligação foi calculada com a diferença entre a energia total da composto ligado $\left(E_{\text {comp }}\right)$ e a soma das energias dos átomos do sistema desligado $\left(E_{\text {atom }}\right)$.

$$
E_{l}=E_{c o m p}-\sum_{i} E_{\text {atom }, i}
$$

onde $i$ representa cada um dos átomos presentes no composto.

Utilizamos para a energia de corte da expansão em ondas planas da função em onda eletrônica os valores de $200 \mathrm{eV}$ para os compostos que apresentam átomos de fósforo ou enxofre, $290 \mathrm{eV}$ para as aqueles que apresentam átomos de carbono e $320 \mathrm{eV}$ para aqueles que apresentam átomos de nitrogênio.

Nossos resultados reproduzem muito bem os resultados experimentais [97, 98, 100] e outro cálculo de primeiros princípios [96], com diferenças menores que $2 \%$ para os comprimentos de ligação, menores que $8 \%$ para os ângulos e menor que $2 \%$ 
para o intervalo de energia HOMO-LUMO.

Como esperado, as moléculas são mais estáveis que seus radicais. A molécula de metano apresentou um energia de formação 4,8 eV mais favorável que o seu radical metil, e entre a molécula de etileno e seu radical esta diferença foi de $4,9 \mathrm{eV}$

Todas as moléculas estudadas apresentaram momento magnético total desprezível. Por outro lado, os radicais metil e vinil apresentaram um momento magnético total de $1,0 \mu_{B}$. Este resultado fica evidente quando observamos a densidade de estados, figura D.2, apresentaras apresentam temos que os radicais $\mathrm{O}$ momento magnético total das moléculas pode ser considerado nulo dentro da precisão considerada. Os radicais, por outro lado, apresentaram momento magnético total.

$\mathrm{Na}$ figura D.2 estão representadas as densidade de estados dos radicas metil $\left(\mathrm{CH}_{3}\right)$ e vinil $\left(\mathrm{C}_{2} \mathrm{H}_{3}\right)$ e de suas moléculas correspondentes, respectivamente, o metano $\left(\mathrm{CH}_{4}\right)$ e o etileno $\left(\mathrm{C}_{2} \mathrm{H}_{4}\right)$. A DOS do etileno concorda muito bem com outro cálculo DFT-GGA [96]. A diferença nas DOS de cada componente de spin para os radicais metil e vinil é decorrente do momento magnético total não nulo destes radicais. 


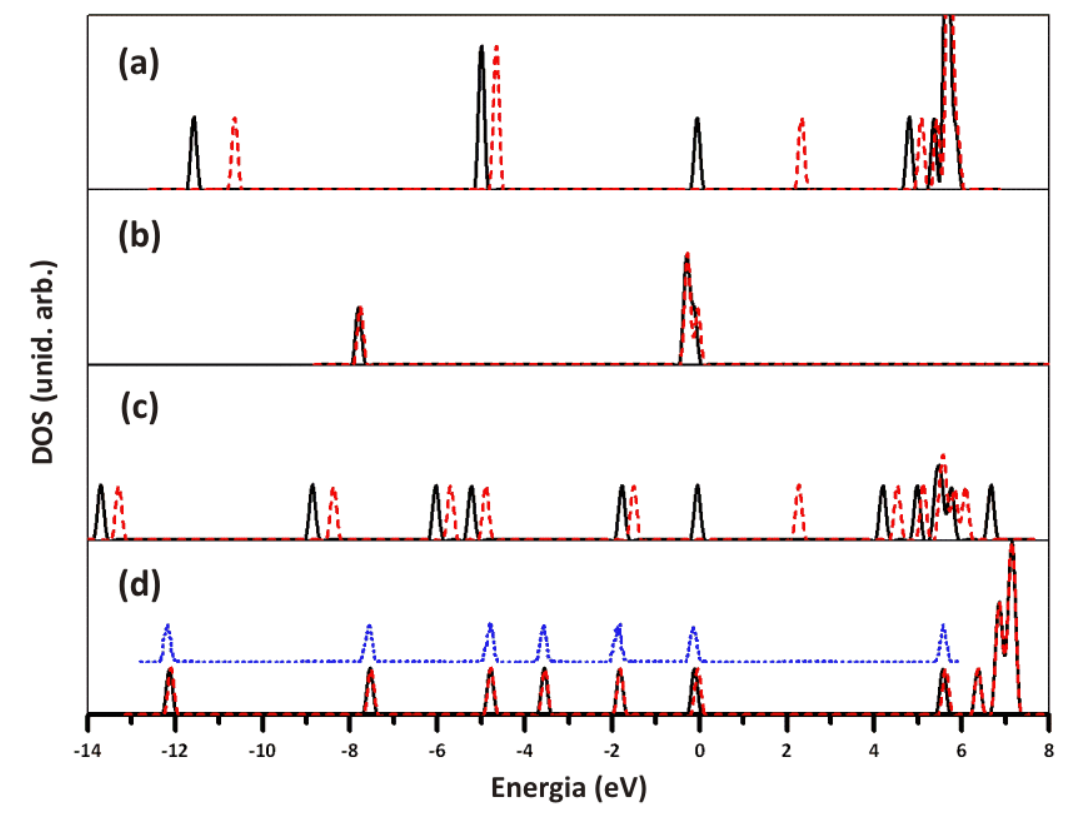

Fig. D.2: Densidade de estados (a) do radical metil $\left(\mathrm{CH}_{3}\right)$, (b) da molécula de metano $\left(\mathrm{CH}_{4}\right)$, (c) do radical vinil $\left(\mathrm{C}_{2} \mathrm{H}_{3}\right)$ e (d) da molécula de etileno $\left(\mathrm{C}_{2} \mathrm{H}_{4}\right)$. Nosso resultado da DOS do etileno concorda muito bem com outro calculo DFT-GGA [96] apresentado com a linha pontilhada em azul. As componentes de spin são representadas separadamente pelas linhas solida preta e a tracejada vermelha. 


\section{Apêndice E}

\section{Aproximação esférica}

Uma nanopartícula esférica no limite de muitos átomos de raio $R$ pode ser dividida em uma casca esférica na superfície de espessura $d$ e uma região interna de raio $R-d$. Assumindo que cada átomo na região superficial contribui com a energia por átomo da superfície e que cada átomo da região interna contribui com a energia por átomo do cristal, a energia total da nanopartícula pode ser separada aproximadamente como,

$$
E_{\text {tot }}=\varepsilon_{c} N_{c}+\varepsilon_{\text {sup }} N_{\text {sup }}
$$

onde $\varepsilon_{c}$ é a energia por átomos do cristal, $\varepsilon_{s u p}$ é a energia por átomo da superfície livre, $N_{c}$ o número de átomos na região interna assumida como cristalina e $N_{\text {sup }} \mathrm{O}$ número de átomos na região assumida como superficial.

No limite de muitos átomos a superfície da nanopartícula esférica de raio $R$ é uma casca esférica de espessura $d$ cujo volume é definido por

$$
V_{\text {sup }}=\frac{4 \pi}{3} R^{3}-\frac{4 \pi}{3}(R-d)^{3}=\frac{4 \pi}{3}\left(3 R^{2} d-3 R d^{2}+d^{3}\right),
$$

e o número de átomos na superfície por

$$
N_{\text {sup }}=\rho_{a} V_{\text {sup }}=\frac{4 \pi \rho_{a}}{3}\left(3 R^{2} d-3 R d^{2}+d^{3}\right)
$$


onde $\rho_{a}$ é a densidade de átomos do cristal. Para a região interna cristalina o volume é definido como

$$
V_{c}=\frac{4 \pi}{3}(R-d)^{3}=\frac{4 \pi}{3}\left(R^{3}-3 R^{2} d+3 R d^{2}-d^{3}\right),
$$

e, assim, o número de átomos nessa região pode ser expresso como,

$$
N_{c}=\rho_{a} V_{c}=\frac{4 \pi \rho_{a}}{3}\left(R^{3}-3 R^{2} d+3 R d^{2}-d^{3}\right) .
$$

Substituindo as equações E.3 e E.5 na equação E.1, a energia toma a seguinte forma,

$$
\begin{aligned}
E_{t o t} & =\varepsilon_{c} \frac{4 \pi \rho_{a}}{3}\left(R^{3}-3 R^{2} d+3 R d^{2}-d^{3}\right)+\varepsilon_{\text {sup }} \frac{4 \pi \rho_{a}}{3}\left(3 R^{2} d-3 R d^{2}+d^{3} \gamma \mathrm{E} .6\right) \\
& =\frac{4 \pi \rho_{a} R^{3}}{3}\left[\varepsilon_{c}+\frac{3 d \Delta \varepsilon}{R}-\frac{3 d^{2} \Delta \varepsilon}{R^{2}}+\frac{d^{3} \Delta \varepsilon}{R^{3}}\right]
\end{aligned}
$$

onde $\Delta \varepsilon=\varepsilon_{s u p}-\varepsilon_{c}$. A equação E.7 reescrita em função do número total de átomos $N$ toma a forma,

$$
E_{t o t}=N\left[\varepsilon_{c}+\frac{3 d \Delta \varepsilon}{N^{1 / 3}} \gamma^{1 / 3}-\frac{3 d^{2} \Delta \varepsilon}{N^{2 / 3}} \gamma^{2 / 3}+\frac{d^{3} \Delta \varepsilon}{N} \gamma\right]
$$

onde $N=\gamma R^{3}$ e $\gamma=\frac{4 \pi}{3} \rho_{a}$.

Desprezando os termos de ordem maior em $N$ e dividindo pelo total de átomos $(N)$, obtemos a energia por átomo da nanopartícula,

$$
\varepsilon_{a t}=\frac{E_{t o t}}{N}=\varepsilon_{c}+3 d \Delta \varepsilon \gamma^{1 / 3} \cdot N^{-1 / 3}
$$

que é uma expressão linear em função de $N^{-1 / 3}$,

$$
\varepsilon_{a t}=a+b \cdot N^{-1 / 3}
$$

onde o termo independente é definido pela energia do cristal $a=\varepsilon_{c}$, enquanto que o coeficiente angular $b$ é dependente da energia por átomos do cristal $\varepsilon_{c}$, da energia 
por átomo da superfície $\varepsilon_{\text {sup }}$, da espessura da superfície $d$ e da densidade atômica $\rho_{a}$, incorporadas no fator $\gamma$,

$$
b=3 d \Delta \varepsilon \gamma^{1 / 3}=3 d\left(\varepsilon_{\text {sup }}-\varepsilon_{c}\right) \gamma^{1 / 3} .
$$

Para o cristal de prata que possuí a estrutura cúbica de face centrada (FCC) com quatro átomos por célula unitária, a densidade atômica é dada por $\rho_{a}=4 / a_{0}^{3}$. Assim, a equação E.10 fica da forma,

$$
b=7,67663\left(\varepsilon_{\text {sup }}-\varepsilon_{c}\right) d / a_{0} .
$$

onde $a_{0}$ é o parâmetro de rede.

Substituindo os nossos resultados de $a_{0}=4,163 \AA$, $\varepsilon_{c}=2,727$ eV e $\varepsilon_{\text {sup }}=$ -2.595 eV e $d=5,572 \AA$ obtemos,

$$
\varepsilon_{a t}=-2,727+1,356 \cdot N^{-1 / 3}[e V]
$$

onde utilizamos para os valores de $\varepsilon_{s u p}$ e $d$ a média dos nossos resultados para as superfícies [111] e [001] $\left(\varepsilon_{111}=-2.619 \mathrm{eV}, \varepsilon_{001}=-2.575 \mathrm{eV}, d_{111}=5,949 \AA\right.$ e $d_{001}=5,196 \AA$ A). A espessura da superfície $d$ foi definida como a metade das espessuras das reconstruções utilizadas no cálculo das superfíces [110] e [111]. 


\section{Referências Bibliográficas}

[1] H Gleiter. Nanostructured materials: basic concepts and microstructure. Acta Materialia, 48(1):1, Jan 2000.

[2] Chungui Tian, Zhenhui Kang, Enbo Wang, Baodong Mao, Siheng Li, Zhongmin Su e Lin Xu. "One-step" controllable synthesis of $\mathrm{Ag}$ and $\mathrm{Ag}_{2} \mathrm{~S}$ nanocrystals on a large scale. Nanotechnology, 17(22):5681-5685, 2006.

[3] Jin-Song Hu, Han-Pu Liang, Li-Jun Wan, Chun-Li Bai e Yan-Guo Guo. Interface Assembly Synthesis of Inorganic Composite Hollow Spheres. The Journal of Physical Chemistry B, 108(28):9734-9738, julho 2004.

[4] Yugang Sun, Yadong Yin, Brian T. Mayers, Thurston Herricks e Younan Xia. Uniform Silver Nanowires Synthesis by Reducing $\mathrm{AgNO}_{3}$ with Ethylene Glycol in the Presence of Seeds and Poly (Vinyl Pyrrolidone). Chemistry of Materials, 14(11):4736-4745, 2002.

[5] M. Fleischmann, P.J. Hendra e A.J. McQuillan. Raman spectra of pyridine adsorbed at a silver electrode. Chemical Physics Letters, 26(2):163 - 166, 1974.

[6] David L. Jeanmaire e Richard P. Van Duyne. Surface raman spectroelectrochemistry: Part I. Heterocyclic, aromatic, and aliphatic amines adsorbed 
on the anodized silver electrode. Journal of Electroanalytical Chemistry, 84(1):1 - 20, 1977.

[7] M. Grant Albrecht e J. Alan Creighton. Anomalously intense Raman spectra of pyridine at a silver electrode. Journal of the American Chemical Society, 99(15):5215-5217, 1977.

[8] Shuming Nie e Steven R. Emory. Probing Single Molecules and Single Nanoparticles by Surface-Enhanced Raman Scattering. Science, 275(5303):1102-1106, 1997.

[9] William E. Doering e Shuming Nie. Single-Molecule and SingleNanoparticle SERS: Examining the Roles of Surface Active Sites and Chemical Enhancement. The Journal of Physical Chemistry B, 106(2):311317, janeiro 2002.

[10] Hongxing Xu, Erik J. Bjerneld, Mikael Käll e Lars Börjesson. Spectroscopy of Single Hemoglobin Molecules by Surface Enhanced Raman Scattering. Physical Review Letters, 83(21):4357-4360, Nov 1999.

[11] Martin Moskovits. Surface-enhanced spectroscopy. Reviews of Modern Physics, 57(3):783-826, Jul 1985.

[12] Ewen Smith e Geoffrey Dent. Modern Raman Spectroscopy: A Practical Approach. Wiley, 2005.

[13] Andre G Skirtach, Christophe Dejugnat, Dieter Braun, Andrei S Susha, Andrey L Rogach, Wolfgang J Parak, Helmuth Möhwald e Gleb B Sukhorukov. The role of metal nanoparticles in remote release of encapsulated materials. Nano letters, 5(7):1371-7, julho 2005. 
[14] Daeyeon Lee, Robert E Cohen e Michael F Rubner. Antibacterial properties of Ag nanoparticle loaded multilayers and formation of magnetically directed antibacterial microparticles. Langmuir : the ACS journal of surfaces and colloids, 21(21):9651-9, outubro 2005.

[15] Siddhartha Shrivastava, Tanmay Bera, Arnab Roy, Gajendra Singh, P Ramachandrarao e Debabrata Dash. Characterization of enhanced antibacterial effects of novel silver nanoparticles. Nanotechnology, 18(22):225103, 2007.

[16] Jose Luis Elechiguerra, Alejandra Camacho-Bragado, Justin L Burt, Jose R Morones, Xiaoxia Gao, Humberto H Lara e Miguel Jose Yacaman. Interaction of silver nanoparticles with HIV-1. Journal of nanobiotechno$\log y, 3: 6,2005$.

[17] Ximei Qian, Xiang-Hong Peng, Dominic O Ansari, Qiqin Yin-Goen, Georgia Z Chen, Dong M Shin, Lily Yang, Andrew N Young, May D Wang e Shuming Nie. In vivo tumor targeting and spectroscopic detection with surface-enhanced Raman nanoparticle tags. Nature biotechnology, 26(1):8390, 2008.

[18] Jeng-Han Wang e M C Lin. Reactions of trimethylindium on $\mathrm{TiO}_{2}$ nanoparticles: experimental and computational study. The journal of physical chemistry B, 109(44):20858-67, novembro 2005.

[19] Kwang-Hwi Cho, Jaebum Choo e Sang-Woo Joo. Surface-enhanced Raman scattering and density functional theory calculation of uracil on gold and silver nanoparticle surfaces. Spectrochimica Acta Part A: Molecular and Biomolecular Spectroscopy, 61(6):1141 - 1145, 2005. 
[20] Wanda Andreoni, Henrik Grönbeck e Alessandro Curioni. Density functional theory approach to thiols and disulfides on gold: $\mathrm{Au}(111)$ surface and clusters. International Journal of Quantum Chemistry, 80(4-5):598-608, 2000.

[21] YunWei Charles Cao, Rongchao Jin e Chad A. Mirkin. Nanoparticles with Raman Spectroscopic Fingerprints for DNA and RNA Detection. Science, 297(5586):1536-1540, 2002.

[22] Sukdeb Pal, Yu Kyung Tak e Joon Myong Song. Does the Antibacterial Activity of Silver Nanoparticles Depend on the Shape of the Nanoparticle? A Study of the Gram-Negative Bacterium Escherichia coli. Applied and Environmental Microbiology, 73(6):1712-1720, 2007.

[23] R. Xu, D. Wang, J. Zhang e Y. Li. Shape-dependent catalytic activity of silver nanoparticles for the oxidation of styrene. Chemistry, an Asian journal, 1(6):888-93, 2006.

[24] Clemens Burda, Xiaobo Chen, Radha Narayanan e Mostafa a El-Sayed. Chemistry and properties of nanocrystals of different shapes. Chemical reviews, 105(4):1025-102, 2005.

[25] Luis M Liz-Marzán. Nanometals: Formation and color. Materials Today, $7(2): 26-31,2004$.

[26] Paul Mulvaney. Surface Plasmon Spectroscopy of Nanosized Metal Particles. Langmuir, 12(3):788-800, 1996.

[27] Motoi Tobita e Yusuke Yasuda. Theoretical and Experimental Vibrational Characterizations of Amine-Coated Silver Nanoparticles. Society, pages 13851-13855, 2008. 
[28] V. Bertin, E. Agacino, R. López-Rendon e E. Poulain. The CO chemisorption on some active sites of Pd clusters: A DFT study. Journal of Molecular Structure: THEOCHEM, 769(1-3):243 - 248, 2006.

[29] P. Hohenberg e W. Kohn. Inhomogeneous Electron Gas. Physical Review, 136(3B):B864-B871, Nov 1964.

[30] W. Kohn e L. J. Sham. Self-Consistent Equations Including Exchange and Correlation Effects. Physical Review, 140(4A):A1133-A1138, Nov 1965.

[31] P. Jonsson. Computational Atomic Structure: An MCHF Approach. Taylor \& Francis, 1997.

[32] J. C. Slater. A Simplification of the Hartree-Fock Method. Physical Review, 81(3):385-390, Feb 1951.

[33] Elliott H. Lieb. Thomas-Fermi and related theories of atoms and molecules. Reviews of Modern Physics, 53(4):603-641, Oct 1981.

[34] D. M. Ceperley e B. J. Alder. Ground State of the Electron Gas by a Stochastic Method. Physical Review Letters, 45(7):566-569, Aug 1980.

[35] J. P. Perdew e Alex Zunger. Self-interaction correction to densityfunctional approximations for many-electron systems. Physical Review B, 23(10):5048-5079, May 1981.

[36] Yue Wang e John P. Perdew. Spin scaling of the electron-gas correlation energy in the high-density limit. Physical Review B, 43(11):8911-8916, Apr 1991.

[37] John P. Perdew e Yue Wang. Accurate and simple analytic representation of the electron-gas correlation energy. Physical Review B, 45(23):1324413249, Jun 1992. 
[38] John P. Perdew, J. A. Chevary, S. H. Vosko, Koblar A. Jackson, Mark R. Pederson, D. J. Singh e Carlos Fiolhais. Atoms, molecules, solids, and surfaces: Applications of the generalized gradient approximation for exchange and correlation. Physical Review B, 46(11):6671-6687, Sep 1992.

[39] Reiner M. Dreizler e Gross E.K.U. Density Functional Theory: An Approach to the Quantum Many-Body Problem . Springer-Verlag, 1990.

[40] Conyers Herring. A New Method for Calculating Wave Functions in Crystals. Physical Review, 57(12):1169-1177, Jun 1940.

[41] James C. Phillips e Leonard Kleinman. New Method for Calculating Wave Functions in Crystals and Molecules. Physical Review, 116(2):287-294, Oct 1959.

[42] M. L. Cohen e V. Heine. The fitting of pseudopotentials to experimental data and their subsequent application. Solid State Physics, 24:37, 1970.

[43] D. R. Hamann, M. Schlüter e C. Chiang. Norm-Conserving Pseudopotentials. Physical Review Letters, 43:1494, 1979.

[44] Leonard Kleinman e D. M. Bylander. Efficacious Form for Model Pseudopotentials. Physical Review Letters, 48(20):1425-1428, May 1982.

[45] David Vanderbilt. Optimally smooth norm-conserving pseudopotentials. Physical Review B, 32(12):8412-8415, Dec 1985.

[46] David Vanderbilt. Soft self-consistent pseudopotentials in a generalized eigenvalue formalism. Physical Review B, 41(11):7892-7895, Apr 1990.

[47] G. Kresse e D. Joubert. From ultrasoft pseudopotentials to the projector augmented-wave method. Physical Review B, 59(3):1758-1775, Jan 1999. 
[48] R. P. Feynman. Forces in Molecules. Physical Review, 56(4):340-343, Aug 1939.

[49] Kari Laasonen, Alfredo Pasquarello, Roberto Car, Changyol Lee e David Vanderbilt. Car-Parrinello molecular dynamics with Vanderbilt ultrasoft pseudopotentials. Physical Review B, 47(16):10142-10153, Apr 1993.

[50] G. Kresse e J. Furthmüller. Efficiency of ab-initio total energy calculations for metals and semiconductors using a plane-wave basis set. Computational Materials Science, 6:15, 1996.

[51] S. Goedecker e K. Maschke. Operator approach in the linearized augmentedplane-wave method: Efficient electronic-structure calculations including forces. Physical Review B, 45(4):1597-1604, Jan 1992.

[52] R. Car e M. Parrinello. Unified Approach for Molecular Dynamics and Density-Functional Theory. Physical Review Letters, 55(22):2471-2474, Nov 1985.

[53] Michael P. Teter, Michael C. Payne e Douglas C. Allan. Solution of Schrödinger's equation for large systems. Physical Review B, 40(18):1225512263, Dec 1989.

[54] G. Kresse e J. Furthmüller. Efficient iterative schemes for ab initio totalenergy calculations using a plane-wave basis set. Physical Review B, 54(16):11169-11186, Oct 1996.

[55] Richard P. Brent. Algorithms for Minimisation without Derivatives (Automatic Computation). Prentice Hall, 1972. 
[56] M. Preuss e F. Bechstedt. Vibrational spectra of ammonia, benzene, and benzene adsorbed on $\operatorname{Si}(001)$ by first principles calculations with periodic boundary conditions. Physical Review B, 73(15):155413, Apr 2006.

[57] Edgar Bright Wilson, J.C. Decius e Paul C. Cross. Molecular Vibrations: The Theory of Infrared and Raman Vibrational Spectra. Dover Publications, 1980.

[58] VASP Group. Vienna Ab-initio Simulation Package. http://cms.mpi.univie.ac.at/vasp/, abril de 2010.

[59] O Akhavan. Silver nanocube crystals on titanium nitride buffer layer. Journal of Physics D: Applied Physics, 42(10):105305 (6pp), 2009.

[60] T. P. Martin. Shells of atoms. Physics Reports, 273(4):199 - 241, 1996.

[61] Emil Roduner. Size matters: why nanomaterials are different. Chemical Society reviews, 35(7):583-92, 2006.

[62] L D Marks. Experimental studies of small particle structures. Reports on Progress in Physics, 57(6):603, 1994.

[63] J. J. Mock, M. Barbic, D. R. Smith, D. A. Schultz e S. Schultz. Shape effects in plasmon resonance of individual colloidal silver nanoparticles. The Journal of Chemical Physics, 116(15):6755-6759, 2002.

[64] Detlef Schooss, Martine N Blom, Joel H Parks, Bernd v Issendorff, Hellmut Haberland e Manfred M Kappes. The structures of $\mathrm{Ag}_{55}^{+}$and $\mathrm{Ag}_{55}^{-}$: trapped ion electron diffraction and density functional theory. Nano letters, 5(10):1972-7, 2005. 
[65] D. R. Jennison, P. A. Schultz e M. P. Sears. Ab initio calculations of Ru, $\mathrm{Pd}$, and Ag cluster structure with 55, 135, and 140 atoms. The Journal of Chemical Physics, 106(5):1856-1862, 1997.

[66] Martine N Blom, Detlef Schooss, Jason Stairs e Manfred M Kappes. Experimental structure determination of silver cluster ions $(\operatorname{Ag}(n)+, 19<$ or $=\mathrm{n}<$ or $=79)$. The Journal of Chemical Physics, 124(24):244308, 2006.

[67] Jonathan P. K. Doye e David J. Wales. Global minima for transition metal clusters described by Sutton-Chen potentials. New Journal of Chemistry, 22(7):733-744, 1998.

[68] Hannu Häkkinen, Michael Moseler, Oleg Kostko, Nina Morgner, Margarita Astruc Hoffmann e Bernd v. Issendorff. Symmetry and Electronic Structure of Noble-Metal Nanoparticles and the Role of Relativity. Physical Review Letters, 93(9):093401, Aug 2004.

[69] Romuald Poteau e Fernand Spiegelmann. Structural properties of sodium microclusters ( $\mathrm{n}=4-34)$ using a Monte Carlo growth method. The Journal of Chemical Physics, 98(8):6540-6557, 1993.

[70] Yugang Sun e Younan Xia. Shape-Controlled Synthesis of Gold and Silver Nanoparticles. Science, 298(5601):2176-2179, 2002.

[71] K. J. Koski, N. M. Kamp, R. K. Smith, M. Kunz, J. K. Knight e A. P. Alivisatos. Structural distortions in 5-10 nm silver nanoparticles under high pressure. Physical Review B, 78(16):165410, Oct 2008.

[72] Cai-Xia Kan, Jie-Jun Zhu e Xiao-Guang Zhu. Silver nanostructures with well-controlled shapes: synthesis, characterization and growth mechanisms. Journal of Physics D: Applied Physics, 41(15):155304 (9pp), 2008. 
[73] I Maliszewska, K Szewczyk e K Waszak. Biological synthesis of silver nanoparticles. Journal of Physics: Conference Series, 146(1):012025, 2009.

[74] Charles Kittel. Introduction to Solid State Physics. John Wiley and Sons, New York, 2004.

[75] R. Poteau, J.-L. Heully e F. Spiegelmann. Structure, stability, and vibrational properties of small silver cluster. Zeitschrift für Physik D Atoms, Molecules and Clusters, 40(1-4):479-482, maio 1997.

[76] M. N. Huda e A. K. Ray. Electronic structures and magic numbers of small silver clusters: A many-body perturbation-theoretic study. Physical Review A, 67(1):013201, Jan 2003.

[77] D. Reinhard, B. D. Hall, D. Ugarte e R. Monot. Size-independent fcc-toicosahedral structural transition in unsupported silver clusters: An electron diffraction study of clusters produced by inert-gas aggregation. Physical Review B, 55(12):7868-7881, Mar 1997.

[78] Yuannan Xie e John A. Blackman. Transferable tight-binding model for palladium and silver. Physical Review B, 64(19):195115, Oct 2001.

[79] T. L. Haslett, K. A. Bosnick e M. Moskovits. $\mathrm{Ag}_{5}$ is a planar trapezoidal molecule. The Journal of Chemical Physics, 108(9):3453-3457, 1998.

[80] K. A. Bosnick, T. L. Haslett, S. Fedrigo, M. Moskovits, W-T. Chan e R. Fournier. Tricapped tetrahedral $\mathrm{Ag}_{7}$ : A structural determination by resonance Raman spectroscopy and density functional theory. The Journal of Chemical Physics, 111(19):8867-8870, 1999. 
[81] H. Öström, H. Ogasawara, L.-Å . Näslund, K. Andersson, L. G. M. Pettersson e A. Nilsson. Geometric and electronic structure of methane adsorbed on a Pt surface. The Journal of Chemical Physics, 127(14):144702, 2007.

[82] K. Weiss, J. Weckesser e Ch. Wöll. An X-ray absorption study of saturated hydrocarbons physisorbed on metal surfaces. Journal of Molecular Structure: THEOCHEM, 458(1-2):143 - 150, 1998.

[83] A. Hauschild, R. Temirov, S. Soubatch, O. Bauer, A. Schöll, B. C. C. Cowie, T.-L. Lee, F. S. Tautz e M. Sokolowski. Normal-incidence Xray standing-wave determination of the adsorption geometry of PTCDA on $\operatorname{Ag}(111)$ : Comparison of the ordered room-temperature and disordered lowtemperature phases. Physical Review B, 81(12):125432, Mar 2010.

[84] T.E. Felter, W.H. Weinberg, P.A. Zhdan e G.K. Boreskov. An XPS and UPS investigation of the adsorption of ethylene on the (111) surface of silver. Surface Science Letters, 97(1):L313 - L319, 1980.

[85] J.C. Tang, J.F. Shen e Y.B. Chen. Structure determination of ethylene adsorbed on $\mathrm{Ag}(100)$ surface by multiple-scattering cluster method. Surface Science Letters, 244(3):L125 - L132, 1991.

[86] D. Coulman, J.L. Solomon, R.J. Madix e J. Stöhr. The orientation and electronic structure of 1,3-butadiene adsorbed and condensed on $\operatorname{Ag}(110)$ : a NEXAFS study. Surface Science, 257(1-3):97 - 102, 1991.

[87] P Yannoulis, K.-H Frank e E.-E Koch. Electronic structure and orientation of anthracene on $\operatorname{Ag}(111)$. Surface Science, 241(3):325 - 334, 1991.

[88] Marko Kralj, Petar Pervan, Milorad Milun, Predrag Lazić, Željko Crljen, Radovan Brako, Jörg Schneider, Axel Rosenhahn e Klaus Wandelt. 
Tetragonal silver films on V(100): Experimental and ab initio studies. Physical Review B, 68(19):195402, Nov 2003.

[89] S. K. Kwon, Z. Nabi, K. Kádas, L. Vitos, J. Kollár, B. Johansson e R. Ahuja. Surface energy and stress release by layer relaxation. Physical Review B, 72(23):235423, Dec 2005.

[90] V. Beutel, H.-G. Krämer, G. L. Bhale, M. Kuhn, K. Weyers e W. Demtröder. High-resolution isotope selective laser spectroscopy of $\mathrm{A}_{2}$ molecules. The Journal of Chemical Physics, 98(4):2699-2708, 1993.

[91] Michael D. Morse. Clusters of transition-metal atoms. Chemical Reviews, 86(6):1049-1109, dezembro 1986.

[92] H. Li, J. Quinn, Y. S. Li, D. Tian, F. Jona e P. M. Marcus. Multilayer relaxation of clean ag001. Phys. Rev. B, 43(9):7305-7307, Mar 1991.

[93] F Soria, J.L Sacedon, P.M Echenique e D Titterington. Leed study of the epitaxial growth of the thin film au(111)/ag(111) system. Surface Science, 68:448 - 456, 1977.

[94] Jian-Min Zhang, Yu Shu e Ke-Wei Xu. Multilayer relaxation of fcc metals (001) surface: A modified embedded atom method study. Solid State Communications, 137(8):441 - 445, 2006.

[95] M. Methfessel, D. Hennig e M. Scheffler. Trends of the surface relaxations, surface energies, and work functions of the $4 \mathrm{~d}$ transition metals. Phys. Rev. B, 46(8):4816-4829, Aug 1992.

[96] A. Kokalj, A. Dal Corso, S. de Gironcoli e S. Baroni. Adsorption of ethylene on the $\operatorname{Ag}(001)$ surface. Surface Science, 507-510:62 - 68, 2002. 
[97] David R. Lide (Editor). CRC Handbook of Chemistry and Physics, 90th Edition. CRC Press, 2009.

[98] R. C. Shiell, X. K. Hu, Q. J. Hu e J. W. Hepburn. A Determination of the Bond Dissociation Energy $\left(\mathrm{D}_{0}(\mathrm{H}-\mathrm{SH})\right)$ : Threshold Ion-Pair Production Spectroscopy (TIPPS) of a Triatomic Molecule. The Journal of Physical Chemistry A, 104(19):4339-4342, 2000.

[99] S. H. S. Wilson, J. D. Howe e M. N. R. Ashfold. On the near ultraviolet photodissociation of hydrogen sulphide. Molecular Physics, 88(3):841 - 858, 1996.

[100] Lynda R. Peebles e Paul Marshall. High-accuracy coupled-cluster computations of bond dissociation energies in $\mathrm{SH}, \mathrm{H}_{2} \mathrm{~S}$, and $\mathrm{H}_{2} \mathrm{O}$. The Journal of Chemical Physics, 117(7):3132-3138, 2002. 